\title{
Smartphone Sensors for Health Monitoring and Diagnosis
}

\author{
Sumit Majumder ${ }^{1}\left(\mathbb{D}\right.$ and M. Jamal Deen ${ }^{1,2, *(\mathbb{C})}$ \\ 1 Department of Electrical and Computer Engineering, McMaster University, Hamilton, ON L8S 4L8, Canada; \\ majums3@mcmaster.ca \\ 2 School of Biomedical Engineering, McMaster University, Hamilton, ON L8S 4L8, Canada \\ * Correspondence: jamal@mail.ece.mcmaster.ca; Tel.: +1-905-525-9140 (ext. 27137)
}

Received: 29 March 2019; Accepted: 30 April 2019; Published: 9 May 2019

\begin{abstract}
Over the past few decades, we have witnessed a dramatic rise in life expectancy owing to significant advances in medical science and technology, medicine as well as increased awareness about nutrition, education, and environmental and personal hygiene. Consequently, the elderly population in many countries are expected to rise rapidly in the coming years. A rapidly rising elderly demographics is expected to adversely affect the socioeconomic systems of many nations in terms of costs associated with their healthcare and wellbeing. In addition, diseases related to the cardiovascular system, eye, respiratory system, skin and mental health are widespread globally. However, most of these diseases can be avoided and/or properly managed through continuous monitoring. In order to enable continuous health monitoring as well as to serve growing healthcare needs; affordable, non-invasive and easy-to-use healthcare solutions are critical. The ever-increasing penetration of smartphones, coupled with embedded sensors and modern communication technologies, make it an attractive technology for enabling continuous and remote monitoring of an individual's health and wellbeing with negligible additional costs. In this paper, we present a comprehensive review of the state-of-the-art research and developments in smartphone-sensor based healthcare technologies. A discussion on regulatory policies for medical devices and their implications in smartphone-based healthcare systems is presented. Finally, some future research perspectives and concerns regarding smartphone-based healthcare systems are described.
\end{abstract}

Keywords: smartphone; remote healthcare; mHealth; telehealth; medical device; regulation; smartphone sensor

\section{Introduction}

Life expectancy in many countries has increased drastically over the last several decades. This large increase can be attributed primarily to the remarkable advances in healthcare and medical technologies, and the growing consciousness about health, nutrition, sanitation, and education [1-4]. However, this increased life expectancy, combined with the globally decreasing birthrate is expected to result in a large aging population in the near future. In fact, the elderly population over the age of 65 years is expected to outnumber the children under the age of 14 years by 2050 [3]. Furthermore, approximately $15 \%$ of the world's population have some forms of disability, and 110-190 million adults suffer from major functional difficulties [5]. Disability of any form in a person limits mobility and independence, thus preventing or delaying them from receiving necessary healthcare support on time. In addition, a significant number of people around the globe suffer from chronic diseases and medical conditions such as cardiovascular diseases, lung diseases, different forms of cancer, diabetes and diabetes-related complications. It is reported that six of ten American adults ( $>18$ years) suffer from at least one chronic disease, with four of ten having multiple chronic conditions [6]. Further, chronic diseases account for 
$\sim 65-70 \%$ of total mortality among the ten leading causes of death [7]. In fact, heart disease and cancer together account for $48 \%$ of all deaths, thus becoming the leading cause of mortality $[7,8]$.

In addition, the unregulated blood sugar i.e. diabetes is likely to be the seventh leading cause of death by 2030 [9]. Diabetes increases the risk of long-term complications such as kidney failure, limb amputations, and diabetic retinopathy (DR). Diabetic retinopathy is an eye disease that results from the damage of retinal blood vessels due to the prolonged presence of excessive glucose in the blood. It may lead to blindness if not treated in time. In fact, DR was estimated to account for 5 million blindness globally in 2002 [10]. Other prevalent eye-related diseases include cataract, glaucoma, and age-related macular degeneration (AMD) that together with DR caused $65 \%$ of all blindness globally in 2010, with cataract alone accounting for 51\% [11]. Furthermore, poor air quality in many large cities threatens city-dwellers with diseases like asthma and lung diseases. Globally, an estimated 235 million people are currently suffering from asthma, which caused 383,000 deaths in 2015 [12]. Therefore, the demand for healthcare services is understandably rising more rapidly than ever before.

An important issue related to providing adequate healthcare services is the continuously increasing cost of pharmaceuticals, modern medical diagnostic procedures and in-facility care services, which together renders the existing healthcare services unaffordable. To give one example, in the 2017 budget of the Province of Ontario in Canada, an additional $\$ 11.5$ billion was allocated for the next three years in healthcare sectors [13]. Further, the total health spending per Canadian was expected to be $\$ 6839$ in 2018, representing more than 11\% of Canada's GDP and these numbers are similar to most other OECD (Organization for Economic Co-operation and Development) countries [14]. Therefore, present-day healthcare services are likely to cause a substantial socioeconomic burden on many nations, particularly the developing and least developed ones [15-19]. Furthermore, a large fraction of the elderly relies on other persons such as family members, friends and volunteers, or an expensive formal care services such as caregivers and elderly care centers for their daily living and healthcare needs [20-22]. Therefore, enabling superior healthcare and monitoring services at an affordable price is urgently needed, particularly for persons having limited access to healthcare facilities or to those living under constrained or fixed budget conditions. However, through long-term monitoring of key physiological parameters and activities of the elderly in a continuous fashion, many of the medical complications can be avoided or managed properly [22-25]. Long term monitoring of health enables early diagnoses of developing diseases. However, current practice requires frequent visits to or long term stays at expensive healthcare facilities. In addition, a shortage of skilled healthcare personnel, and limited financial capability, coupled with increasing healthcare costs [26] contribute to the bottleneck in realizing long-term health monitoring. Smartphone-based healthcare systems, on the other hand, can potentially enable a cost-effective alternative for long-term health monitoring and may allow the healthcare personnel to monitor and assess their patients remotely without interfering with their daily activities [22,27].

The enormous advances in energy efficient and high-speed computing and communication technologies have revolutionized the global telecom industry. Furthermore, the significant progress in display, sensor and battery technologies together have paved the way for modern mobile devices such as smartphones and tablets, enabling seamless internet connectivity, entertainment, and health and fitness monitoring on the go along with conventional voice and text communication. Smartphones have grown in popularity over the past decade and by 2021, the global penetration of smartphones is expected to exceed 3.8 billion [28]. Modern day smartphones come with a number of embedded sensors such as a high-resolution complementary metal-oxide semiconductor (CMOS) image sensor, global positioning system (GPS) sensor, accelerometer, gyroscope, magnetometer, ambient light sensor and microphone. These sensors can be used to measure several health parameters such as heart rate (HR), HR variability (HRV), respiratory rate (RR), and health conditions such as skin diseases and eye diseases, thus turning the communication device into a continuous and long-term health monitoring system. Table 1 presents the health parameters and conditions that can be monitored using current embedded sensors of the smartphone. The data that are measured by the sensors can be analyzed 
and displayed on the phone and/or transmitted to a distant healthcare facility or healthcare personnel for further investigation over the wireless mobile communication platform such as 3G, high speed packet access (HSPA), and long-term evolution (LTE). These existing platforms offer high-speed and seamless internet connectivity even on the go, thereby allowing people to remain connected with their healthcare providers [7,22].

Table 1. Smartphone sensors used for health monitoring.

\begin{tabular}{|cc|}
\hline Monitored Health Issues & Typically Used Smartphone Sensors \\
\hline $\begin{array}{c}\text { Cardiovascular activity e.g., heart rate } \\
\text { (HR) and HR variability (HRV) } \\
\text { Eye health }\end{array}$ & Image sensor (camera), microphone \\
\hline $\begin{array}{c}\text { Respiratory and lung health } \\
\text { Skin health }\end{array}$ & Image sensor (camera) \\
Daily activity and fall & Image sensor (camera), microphone \\
Sleep & Image sensor camera) \\
Ear health & Motion sensors (accelerometer, gyroscope, proximity sensor), Global \\
positioning system (GPS)
\end{tabular}

In this article, we present a detailed review of the current state of research and development in the health monitoring systems based-on embedded sensors in smartphones. In Section 2, we discuss the evolution of smartphones. Some important recent works on different health monitoring systems are presented in Section 3, which is followed by a discussion (Section 4) on the regulatory policies associated with smartphone-based medical devices. Finally, the paper is concluded in Section 5 with a discussion on future research perspectives and some key challenges in realizing smartphone-based medical devices.

\section{Evolution of Smartphone}

In 1992, IBM announced a ground-breaking device named Simon Personal Communicator that brought together the functionalities of a cellular phone and a Personal Digital Assistant (PDA) [29-31], thus unveiling a whole new concept of so-called 'smartphone' in the cellular phone industry. Simon featured a $4.5^{\prime \prime} \times 1.4^{\prime \prime}$ monochrome LCD touchscreen and came with a stylus and a charging base station. Along with conventional voice communication, the device was also capable of communicating emails, faxes, and pages—some features that were later attributed to smartphones. Simon featured a notes collection to write in, an address book, calendar, world clock and an appointment scheduler, and was also flexible to third-party applications [29-31]. While it was a giant leap into the market by IBM, it, however, was expensive, costing the customer $\$ 899$ with a service contract. Being much ahead of its time and with such a high price tag, Simon failed to attract customers. Even though the tech giant sold approximately 50,000 units in 6 months [32], it opted out of making a second-generation Simon.

In 1996, Nokia revealed a clamshell phone, Nokia 9000 Communicator, which opened to a full QWERTY keyboard and physical navigation buttons flanking a monochrome LCD screen nearly as big as the device itself. It featured Web browsing capability on top of most of the features that IBM's Simon offered. However, Ericsson first coined the term 'Smart-phone' for its Ericsson GS 88. The GS 88, also known as 'Penelope', was strikingly similar to the Nokia 9000. However, it was never released to the public, arguably because of its weight and poor battery quality [31]. Later in 2000, Ericsson first officially used the term 'Smartphone' for the Ericsson R380, which was much cheaper, smaller and lighter than the Nokia 9000. Ericsson R380 was the first device to use the mobile-specific Symbian operating system (OS) and only second to IBM's Simon to have a touchscreen in a phone. R380 was one of the first few smartphones that used the wireless application protocol (WAP) for faster and smoother web browsing.

In 2002, Handspring and RIM released their first smartphones Treo-180 and Blackberry 5810 (5820 for Europe) in the market, respectively [29-31]. The Treo-180 brought the functionality of a phone, an 
email messaging device and a PDA together, and enabled the users to check the calendar while talking on the phone and to dial directly from the contact list. The Blackberry 5810 featured enterprise e-mail and instant messaging services, text messaging, and a WAP browser. However, this device lacked an integrated microphone, for which the user had to attach a headset to make or receive calls. Both the BlackBerry 5810 and the Treo-180 featured a large monochrome screen and a QWERTY keyboard like a PDA. However, unlike the BlackBerry 5810, the Treo-180 came in a clamshell format with a visible antenna and a hinged lid over the phone that flipped up to serve as the earpiece for phone conversations. Then RIM released Blackberry 6210, otherwise known as the 'BlackBerry Quark' in the following year, featuring a built-in microphone and speaker [30,31].

In 2000, both Samsung and Sharp introduced a camera phone in their respective local markets. In South Korea, Samsung released SCH-V200 that featured a 1.5" TFT-LCD display and a 0.35-megapixel video graphics array (VGA) camera that could capture up to 20 images. A few months later, in Japan, Sharp released the J-SH04 in Japan with a 256-color display and a built-in 0.11-megapixel CMOS camera. Although the camera resolution of J-SH04 was much less than that of the SCH-V200, it featured a phone-integrated camera in the true sense for the first time and allowed for transferring of images directly from it, whereas the SCH-V200 brought two separate devices in one enclosure and therefore needed to transfer the pictures to a computer for sharing. However, none of the camera phones supported web browsing and email communication until Sanyo launched the first smartphone with a built-in camera in 2002. The Sanyo SCP-5300 came in a clamshell format and featured dual color displays, WAP browser, and an integrated 0.3-megapixel camera with short-range LED light sensor pro flash. It also had brightness and white balance control, self-timer, digital zoom, and several filter effects such as sepia, black-and-white, and negative colors.

Fast forward to a decade later, modern smartphones featured a number of sensors such as high-resolution and high-speed CMOS image sensor, GPS sensor, accelerometer, gyroscope, magnetometer, ambient light sensor, microphone, and fingerprint sensor (Figure 1). In addition, the processing and data storage capability of current smartphones has improved significantly. Figure 2 shows the built-in sensors that most present-day smartphones possess.

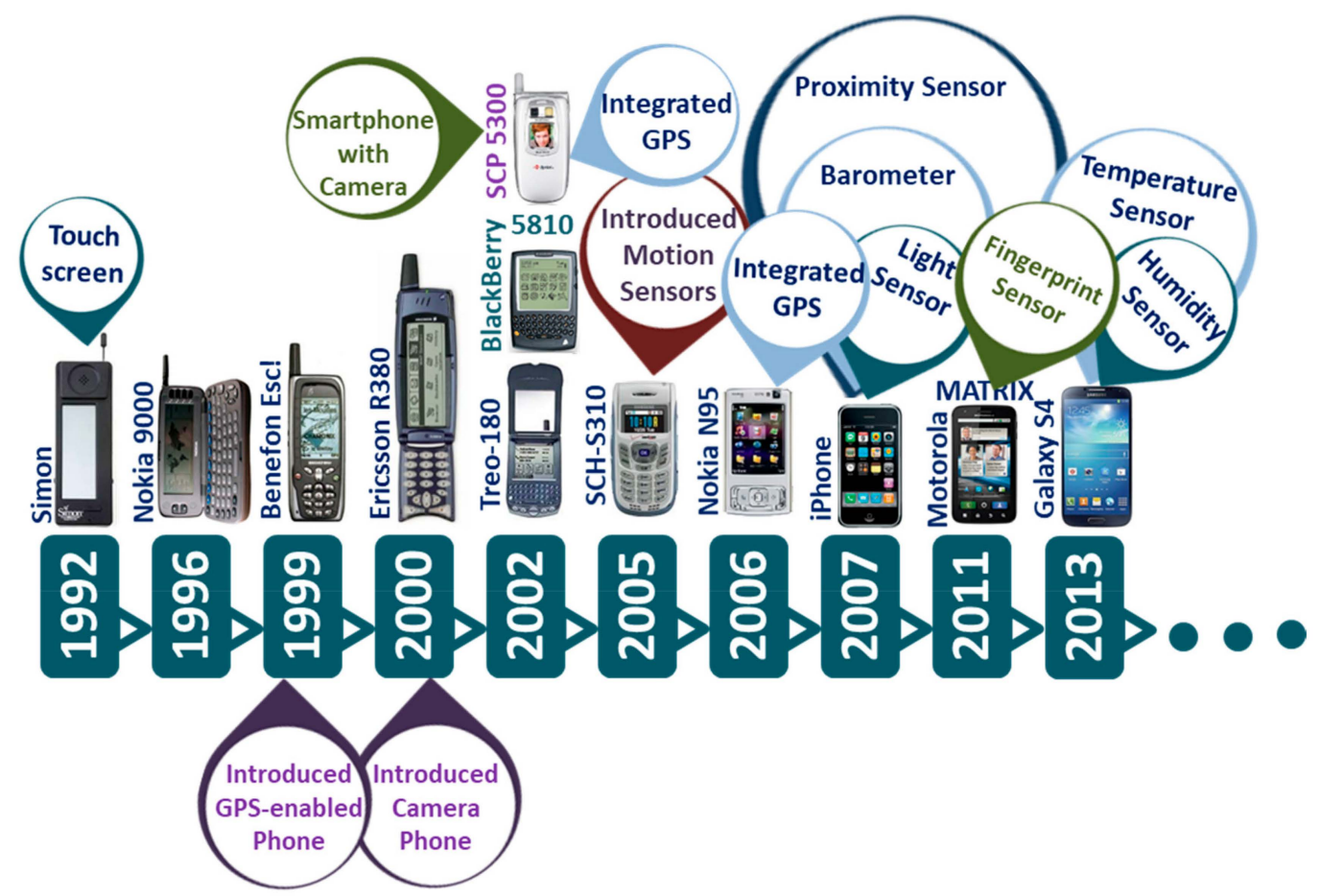

Figure 1. Evolution of smartphones and smartphone-embedded sensors over time. 


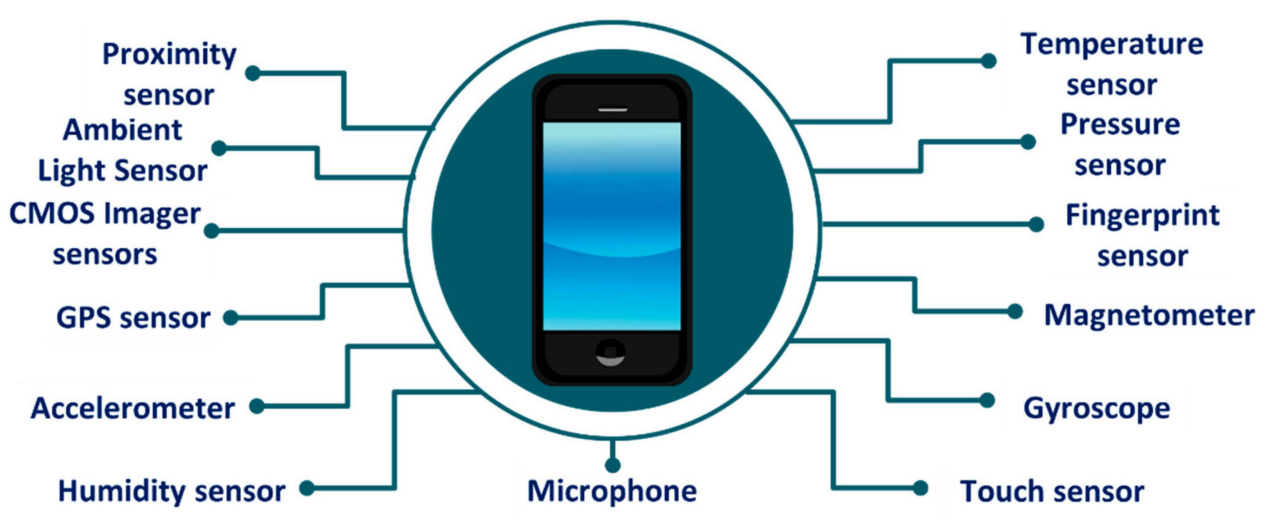

Figure 2. Built-in sensors in a typical present-day smartphone.

\section{Smartphone Sensors for Health Monitoring}

As discussed earlier, the modern-day smartphones are fitted with a number of sensors. These sensors allow for active and/or passive sensing of several health parameters and health conditions. The data thus measured by the smartphone-sensors, sometimes coupled with information related to device usage such as call logs, app usage and short message service (SMS) patterns can provide valuable information of an individual's physical and mental health over a long period of time. In this way, the smartphone can potentially be turned into a viable and cost-effective device for continuous health monitoring. In the following sections (Sections 3.1-3.7), we discuss how the smartphone can be used for heart, eye, skin, mental health and activity monitoring, respectively.

\subsection{Cardiovascular Health Monitoring}

Heart rate (HR) or pulse rate is one of the four 'vital signs' that is routinely monitored by physicians to diagnose heart-related diseases such as different types of arrhythmias [22,33]. HR and HR variability (HRV) are typically extracted from the Electrocardiogram (ECG) (Figure 3a). However, these systems, particularly the conventional 12-lead ECG systems are expensive, restrict user's movement and require trained medical professionals to operate in clinical settings. HR and HRV can also be measured using portable and hand-held single-lead ECG devices [22,34]. Furthermore, with the advancement of wearable sensor technologies, HR and HRV can now be obtained using commercial fitness trackers such as Fitbit ${ }^{\circledR}$ (San Francisco, CA, USA), Jawbone ${ }^{\circledR}$ (San Francisco, CA, USA), Striiv ${ }^{\circledR}$ (Redwood City, CA, USA), and Garmin ${ }^{\circledR}$, (Olathe, KS, USA) [22].

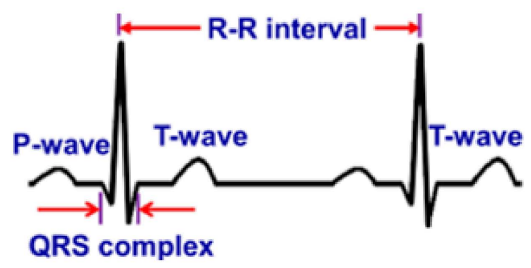

(a)

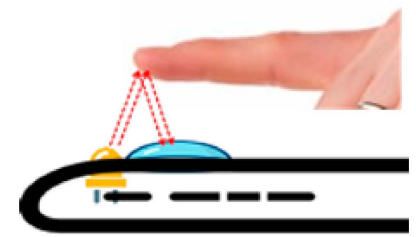

(b)

Figure 3. Measuring heart rate (a) from a typical trace of a single lead Electrocardiogram (ECG) signal, and (b) using a smartphone camera.

However, these portable and wearable systems require additional accessories, which can be avoided by exploiting the embedded sensors such as a camera and microphone in the smartphone for monitoring HR and HRV. Using smartphone camera sensors, it is possible to estimate HR and HRV from the photoplethysmogram (PPG) signal derived from the video of the bare skin such as of the fingertip (Figure $3 b$ ) or the face. The light absorption characteristics of hemoglobin in blood differ from the surrounding body tissues such as flesh and bone. PPG estimates the volumetric changes in blood by detecting the fluctuation of transmissivity and/or reflectivity of light with arterial pulsation 
through the tissue (Figure 4) [22,35]. Although near-infrared (NIR), red light sources are used in most commercial systems [22,35], some researchers [36-40] exploited the smartphone embedded white flashlight to illuminate the tissue to measure the PPG.

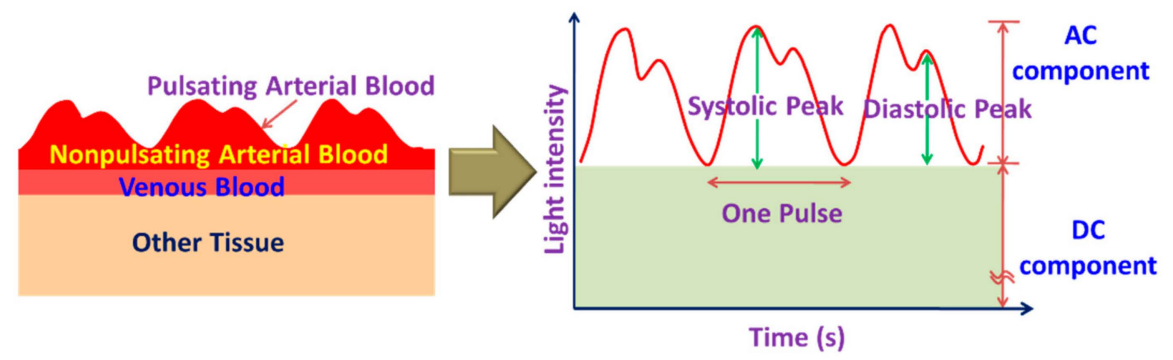

Figure 4. Photoplethysmograph (PPG) signal obtained from the pulsatile flow of blood volume.

Most published smartphone-based HR and HRV monitoring applications [36-40] follow a similar approach where these parameters are extracted from the PPG signal either by measuring pulse-to-pulse time difference in time-domain [39] or by finding the dominant frequency in the frequency domain [36,38]. In Reference [39], the HR and HRV were estimated from the PPG signal obtained from the fingertip using the flashlight and the camera of a smartphone. The green channel of the video data was used to derive the pulse signal after a low-frequency band-pass filtering. Instead of using a conventional peak/valley detection method, the authors detected the steepest slope of each pulse wave and evaluated the correlation of the PPG signal with a pulse wave pattern to determine the cardiac cycles. The calculated HR and HRV were highly correlated to that measured from a commercial ECG monitor, although the degree of improvement in the measurement accuracy with the proposed algorithm over the conventional method was not reported. In addition, the authors did not evaluate the performance of the proposed algorithm when there were any bodily movements. A previously reported [41,42] motion detection technique was employed in Reference [36] to identify and discard the corrupt video data that is highly affected by motion artifacts. The PPG signal was derived from the video of the index fingertip recorded using all three channels (red, blue and green) of a smartphone camera. They calculated a threshold based on the difference of the maximum and the minimum intensity and summed up the pixel values with intensity greater than the threshold for each frame, from which the PPG signal was obtained. The periodic change in the blood volume flow during the cardiac cycles was reflected in the PPG signal acquired through the red channel in comparison to the other two channels. The pulse rate was finally extracted by performing simple Fast Fourier Transform (FFT) analysis on the PPG obtained through the red channel, achieving an average accuracy of as high as $98 \%$ with a maximum error of three beats per minute (bpm) with respect to the actual pulse. However, the algorithm cannot correct motion artifact in the video. Rather, it relies on restarting the video recording when the movement exceeds a predefined level.

In Reference [38], both the front- and rear-cameras of a smartphone were used to simultaneously monitor the heart rate (HR) and respiration rate (RR). The HR was obtained as usual from the PPG signal of the fingertip placed on top of the rear-facing camera. The front camera was used to estimate the RR by detecting the movement of the chest and the abdomen. The HR and RR were obtained by identifying the dominant frequency of the images in frequency-domain (Welch's power spectral density). The authors reported achieving a high (95\%) agreement in the measured HR compared to that obtained using the standard ECG from 11 healthy subjects with a variation ranging from -5.6 to 5.5 beats-per-minute. The RR estimated from the chest and the abdominal walls resulted in average median errors of $1.4 \%$ and $1.6 \%$, respectively. In order to achieve a wide dynamic range of 6-60 breaths per minute, an automatic region-of-interest (ROI) selection protocol was used. With this protocol, a signal either from the abdomen or the chest based on the absolute value of mean autocorrelation was selected. However, this approach of monitoring RR restricts the movement of the body during video recording to avoid motion artifacts (MA). MA can be eliminated or reduced by incorporating MA 
estimation algorithms [41-43] in the system. In addition, extra caution is necessary while estimating RR in presence of colorful and patterned cloths, which can affect the fidelity of video recordings, thereby affecting the estimation accuracy of the RR.

All HR monitoring systems discussed above are contract-based, which require the user to keep the fingertip in close contact with the smartphone camera lens using sufficient strength. Any alteration of the finger position and illumination condition may result in an erroneous estimate of HR [44]. Contactless monitoring systems, on the other hand, estimate HR from the PPG signal derived from the video of the face. Such a non-contact cardiac pulse monitoring application named FaceBeat was presented in Reference [45]. The application was based on an algorithm similar to the first-of-its-kind video-based HR monitoring system proposed in Reference [46], which had exploited the webcam of a laptop for video recording. FaceBeat extracts cardiac pulse and measures HR from the video of a user's face recorded using the front camera of the smartphone. The photodetector array of the camera sensor detects the variation in the reflected light from a specific region of interest (ROI) in the face with the change of blood volume in the facial blood vessels. The authors exploited the green channel data of the recorded video, which as reported in References $[40,44,47,48]$, is most suitable for evaluating $\mathrm{HR}$, particularly in the presence of motion artifacts. The authors used independent component analysis (ICA) to remove noise and motion artifacts from the video data of the ROI and performed the frequency domain analysis on the both the raw and decomposed signals to extract HR and HRV. The HR thus measured showed a maximum average error of $1.5 \%$ with respect to the reference ECG signal obtained from a commercial ECG monitor. However, the complex computation process required for the application increase the processor load and computation time, thereby increasing the power consumption and reducing the battery life.

Unlike the conventional approach, which estimates HR from the fluctuation of reflected light through specific color channels ( $R, G, B)$, researchers in Reference [49] proposed a method that estimates both HR and RR by detecting the variation in the hue of the reflected light from the face. A $20 \mathrm{~s}$ video of the subject's face was recorded. However, only the forehead region of the face was analyzed in the frequency domain to determine the dominant frequencies in the time-varying changes of the average Hue. The authors reported achieving highly accurate HR and RR measurements showing a higher correlation to the measurements with standard instruments than the green channel PPG. Nevertheless, this approach may not work if the forehead skin is covered with any object such as hair, headband or cap, or has scar tissue on it. Although face-based contactless monitoring of HR offers a more convenient alternative to the contact-based systems, its performance can vary with the variation in illumination, skin color, facial hair, scar and movement of the face. Table 2 presents some smartphone-sensor based cardiovascular monitoring systems presented in the literature. 
Table 2. Smartphone-sensors for cardiovascular health monitoring.

\begin{tabular}{|c|c|c|c|c|c|c|c|c|c|c|c|}
\hline Ref. & Year & $\begin{array}{c}\text { Measured } \\
\text { Signs }\end{array}$ & Type & $\begin{array}{c}\begin{array}{c}\text { Smartphone } \\
\text { Model }\end{array} \\
\end{array}$ & Sensor Used & $\begin{array}{c}\text { Video } \\
\text { Resolution }\end{array}$ & $\begin{array}{c}\text { Frame Rate } \\
\text { (fps) }\end{array}$ & $\begin{array}{r}\text { Video } \\
\text { Length }\end{array}$ & Method & $\begin{array}{c}\text { Performance wrt } \\
\text { Standard Monitors }\end{array}$ & $\begin{array}{c}\text { \# of } \\
\text { Subjects }\end{array}$ \\
\hline [37] & 2018 & HR, HRV & $\begin{array}{l}\text { Contact-based } \\
\text { (index finger) }\end{array}$ & $\begin{array}{c}\text { iPhone 6, } \\
\text { Apple Inc., } \\
\text { Cupertino CA }\end{array}$ & Front camera & $1280 \times 720$ & 240 & $5 \mathrm{~min}$ & $\begin{array}{l}\bullet \text { Reflection of light from the } \\
\text { finger is measured. }\end{array}$ & $\begin{array}{l}\text { Pearson Correlation } \\
\text { coefficient (PC) for } \\
\text { most parameters } \\
\text { between PPG and } \\
\text { ECG: }>0.99\end{array}$ & $\begin{array}{l}50(11 \mathrm{~F}, \\
39 \mathrm{M})\end{array}$ \\
\hline [39] & 2016 & HR, HRV & $\begin{array}{l}\text { Contact-based } \\
\text { (index finger) }\end{array}$ & $\begin{array}{l}\text { iPhone 4S, } \\
\text { Apple Inc., } \\
\text { Cupertino CA }\end{array}$ & Rear camera & & 30 & $5 \mathrm{~min}$ & $\begin{array}{l}\text { - Combination of the steepest } \\
\text { slope detection of pulse wave } \\
\text { derived from the green channel of } \\
\text { the reflected light and its } \\
\text { correlation to an optimized pulse } \\
\text { wave pattern. }\end{array}$ & $\begin{array}{l}\text { PC: }>0.99 \text { (HR), } \geq 0.90 \\
\text { (HRV) }\end{array}$ & $\begin{array}{l}68(28 \mathrm{~F}, \\
40 \mathrm{M})\end{array}$ \\
\hline [38] & 2016 & $\mathrm{HR}, \mathrm{RR}$ & $\begin{array}{l}\text { Contact-based } \\
\text { (HR) and } \\
\text { contactless } \\
\text { (RR) }\end{array}$ & $\begin{array}{c}\text { HTC One M8, } \\
\text { HTC } \\
\text { Corporation, } \\
\text { New Taipei } \\
\text { City, Taiwan }\end{array}$ & $\begin{array}{l}\text { Front (for } \\
\text { RR) and rear } \\
\text { (for HR) } \\
\text { camera }\end{array}$ & $\begin{array}{l}\text { RR: } 320 \times 240 \\
\text { (ROI: } 49 \times 90 \\
\text { abdomen) } \\
\text { HR: } 176 \times 144 \\
\text { (ROI: } 176 \times 72)\end{array}$ & $\begin{array}{c}30 \\
\text { (down-sampled } \\
\text { to } 20(\mathrm{RR}), \\
25(\mathrm{HR}))\end{array}$ & - & $\begin{array}{l}\text { - Frequency domain analysis of } \\
\text { the noncontact video recordings } \\
\text { of chest and abdominal motion. }\end{array}$ & $\begin{array}{l}\text { Average of median } \\
\text { errors for RR: } \\
1.43 \%-1.62 \% \text { between } \\
6 \text { and } 60 \text { breaths per } \\
\text { minute }\end{array}$ & $\begin{array}{c}11 \\
(2 \mathrm{~F}, 9 \mathrm{M})\end{array}$ \\
\hline [45] & 2012 & $\mathrm{HR}$ & $\begin{array}{l}\text { Contactless } \\
\text { (face) }\end{array}$ & $\begin{array}{c}\text { iPhone 4, } \\
\text { Apple Inc., } \\
\text { Cupertino CA }\end{array}$ & Front camera & $640 \times 480$ & 30 & $20 \mathrm{~s}$ & $\begin{array}{l}\text { - Analysis of the raw video signal } \\
\text { (green channel) and } \\
\text { ICA-decomposed signals of the } \\
\text { face in the frequency domain. }\end{array}$ & $\begin{array}{l}\text { Error rate: } 1.1 \% \text { (raw } \\
\text { signal), } 1.5 \% \\
\text { (ICA-decomposed } \\
\text { signals) }\end{array}$ & $\begin{array}{c}10 \\
(2 \mathrm{~F}, 8 \mathrm{M})\end{array}$ \\
\hline [49] & 2018 & $\mathrm{HR}, \mathrm{RR}$ & $\begin{array}{c}\text { Contactless } \\
\text { (face) }\end{array}$ & $\begin{array}{l}\text { LG G2, LG } \\
\text { Electronics Inc., } \\
\text { Korea }\end{array}$ & Rear camera & - & $\begin{array}{c}30 \\
\text { (down-sampled } \\
\text { to 10) }\end{array}$ & $20 \mathrm{~s}$ & $\begin{array}{l}\text { - Frequency domain analysis of } \\
\text { the color variations in the } \\
\text { reflected light (hue) from the face. }\end{array}$ & $\begin{array}{l}\text { PC: } 0.9201 \text { (HR) and } \\
0.6575 \text { (RR) }\end{array}$ & $\begin{array}{l}25(10 \mathrm{~F}, \\
15 \mathrm{M})\end{array}$ \\
\hline [36] & 2016 & $\mathrm{HR}$ & $\begin{array}{l}\text { Contact-based } \\
\text { (index finger) }\end{array}$ & - & Rear camera & $1920 \times 1080$ & - & - & $\begin{array}{l}\text { - Frame-difference based motion d } \\
\text { data quality. } \\
\text { - Uses all } 3 \text { channels (R, G, B) for F } \\
\text { - Blood volume flow was } \\
\text { observed clearly in the Red } \\
\text { channel. }\end{array}$ & $\begin{array}{l}\text { etection for improving } \\
\text { PG extraction. } \\
\text { Average accuracy: } \\
98 \%\end{array}$ & 20 \\
\hline [50] & 2015 & $\begin{array}{l}\text { Pulse, HR, } \\
\text { HRV }\end{array}$ & $\begin{array}{l}\text { Contact-based } \\
\text { (index finger) }\end{array}$ & $\begin{array}{c}\text { Motorola Moto } \\
\text { X, Motorola, } \\
\text { Libertyville, IL } \\
\text { and Samsung S } \\
5\end{array}$ & Rear camera & $640 \times 480$ & 30 & $100 \mathrm{~s}$ & $\begin{array}{l}\text { - Extracts PPG by averaging the } \\
\text { Green channel data of the video. } \\
\text { - HR is calculated by detecting } \\
\text { the consecutive PPG peaks. }\end{array}$ & $\begin{array}{l}\text { PC of pulse and R-R } \\
\text { interval from two } \\
\text { phone models }>0.95\end{array}$ & 11 \\
\hline
\end{tabular}


Table 2. Cont

\begin{tabular}{|c|c|c|c|c|c|c|c|c|c|c|c|}
\hline Ref. & Year & $\begin{array}{c}\text { Measured } \\
\text { Signs }\end{array}$ & Type & $\begin{array}{c}\text { Smartphone } \\
\text { Model }\end{array}$ & Sensor Used & $\begin{array}{c}\text { Video } \\
\text { Resolution }\end{array}$ & $\begin{array}{c}\text { Frame Rate } \\
\text { (fps) }\end{array}$ & $\begin{array}{l}\text { Video } \\
\text { Length }\end{array}$ & Method & $\begin{array}{l}\text { Performance wrt } \\
\text { Standard Monitors }\end{array}$ & $\begin{array}{c}\text { \# of } \\
\text { Subjects }\end{array}$ \\
\hline [40] & 2014 & HR, NPV & $\begin{array}{l}\text { Contact-based } \\
\text { (index finger) }\end{array}$ & $\begin{array}{c}\text { iPhone 4S, } \\
\text { Apple Inc., } \\
\text { Cupertino CA }\end{array}$ & Rear camera & $\begin{array}{c}\text { ROI: } \\
192 \times 144\end{array}$ & 30 & $20 \mathrm{~s}$ & $\begin{array}{l}\text { - HR and NPV were measured in } \\
\text { the presence of a controlled } \\
\text { motion }(6 \mathrm{~Hz}) \text { of the left hand. } \\
\text { - Evaluated the effect of motion } \\
\text { artifact (MA) on the PPG in all } \\
\text { three color }(\mathrm{R}, \mathrm{G}, \mathrm{B}) \text { channels. }\end{array}$ & $\begin{array}{l}\text { Higher SNR for B and } \\
\text { G channel PPG in } \\
\text { presence of } 6 \mathrm{~Hz} \text { MA. } \\
\text { PC: HR>0.996 (R, B, } \\
\text { G), NPV }=0.79(\mathrm{G})\end{array}$ & $12(\mathrm{M})$ \\
\hline [51] & 2014 & HR, HRV & $\begin{array}{l}\text { Contact-based } \\
\text { (index finger) }\end{array}$ & $\begin{array}{c}\text { Sony Xperia S, } \\
\text { Sony } \\
\text { Corporation, } \\
\text { Tokyo, Japan. }\end{array}$ & Rear camera & - & - & $60 \mathrm{~s}$ & $\begin{array}{l}\text { - HR was estimated by detecting } \\
\text { the consecutive PPG peaks and } \\
\text { also the dominant frequency. } \\
\text { - Combines several parameters } \\
\text { (HR, HRV, Shannon entropy) to } \\
\text { detect Atrial fibrillation (AF). }\end{array}$ & $\begin{array}{l}\text { HR error rate: } 4.8 \% \\
\text { AF detection: } 97 \% \\
\text { specificity, } 75 \% \\
\text { sensitivity }\end{array}$ & \\
\hline [52] & 2012 & HR, HRV & $\begin{array}{l}\text { Contact-based } \\
\text { (index finger) }\end{array}$ & $\begin{array}{l}\text { iPhone } 4 \mathrm{~s} \text { and } \\
\text { Motorola } \\
\text { Droid, } \\
\text { Motorola, } \\
\text { Libertyville, IL }\end{array}$ & Rear camera & $\begin{array}{c}\text { ROI: } \\
50 \times 50\end{array}$ & $\begin{array}{l}30 \text { (iPhone), } \\
20 \text { (Droid) }\end{array}$ & $\begin{array}{l}2,5 \text { min } \\
\text { (iPhone, } \\
\text { Droid) }\end{array}$ & $\begin{array}{l}\text { - Several ECG parameters were } \\
\text { extracted with two different } \\
\text { models of smartphone both in } \\
\text { supine and tilt position and } \\
\text { performed comparative analysis } \\
\text { with the data obtained from a } \\
\text { standard five lead ECG. }\end{array}$ & $\begin{array}{l}\text { PC: 1.0 (HR), PC for } \\
\text { Other ECG } \\
\text { parameters: } 0.72-1 \\
\text { (Droid), 0.8-1 (iPhone) }\end{array}$ & $\begin{array}{c}9 \\
\text { (iPhone) } \\
13 \\
\text { (Droid) }\end{array}$ \\
\hline [44] & 2012 & $\mathrm{HR}$ & $\begin{array}{l}\text { Contact-based } \\
\text { (index finger) }\end{array}$ & $\begin{array}{l}\text { HTC HD2 and } \\
\text { Samsung } \\
\text { Galaxy S }\end{array}$ & Rear camera & $\begin{array}{c}\text { ROI: } \\
288 \times 352 \\
(\text { HTC) } 480 \times \\
720 \text { (Samsung) }\end{array}$ & $\begin{array}{c}25 \\
\text { (HTC) } \\
30 \text { (Samsung) }\end{array}$ & $6 \mathrm{~s}$ & $\begin{array}{l}\bullet \text { HR is calculated by detecting } \\
\text { the consecutive PPG peaks. }\end{array}$ & Error: \pm 2 bpm & 10 \\
\hline [53] & 2012 & $\mathrm{HR}$ & $\begin{array}{l}\text { Contact-based } \\
\text { (index finger) }\end{array}$ & $\begin{array}{c}\text { Motorola } \\
\text { Droid, } \\
\text { Motorola, } \\
\text { Libertyville, IL }\end{array}$ & Rear camera & $\begin{array}{c}\text { ROI: } \\
176 \times 144\end{array}$ & 20 & $5 \mathrm{~min}$ & $\begin{array}{l}\bullet \text { HR from the PPG signals was } \\
\text { obtained at sitting, reading and } \\
\text { video gaming by using an } \\
\text { Android-based software. }\end{array}$ & $\begin{array}{l}\mathrm{PC}: \geq 0.99 \\
\text { Error: } \pm 2.1 \mathrm{bpm}\end{array}$ & $\begin{array}{c}14(11 \mathrm{~F}, 3 \\
\mathrm{M})\end{array}$ \\
\hline
\end{tabular}




\subsection{Pulmonary Health Monitoring}

Air pollution across the globe has increased significantly in the last decade [54] resulting in billions of people being at increased risk for chronic pulmonary diseases such as cough, asthma, chronic obstructive pulmonary disease (COPD) and lung cancer. In addition, smoking tobacco is one of the key risk factors for lung cancer and other pulmonary diseases [55]. In fact, lung cancer is the most common form of cancers and caused $\sim 19 \%$ of all cancer-related deaths in 2018 [55]. Therefore, early detection of these lung diseases and continuous monitoring of pulmonary health are paramount for timely and effective medical intervention. Many researchers [56-62] used the microphone of a smartphone to detect the sound of a cough and breathing and analyzed the recorded audio signals in efforts to develop a cost-effective and portable tool for faster assessment of pulmonary health.

The smartphone can be used for lung rehabilitation exercise. In Reference [56], an interactive game was developed where the users play to dodge obstacles through inhalation and exhalation. The game, 'Flappy Breath' was designed for smartphones and either used its built-in microphone or a Bluetooth-enabled stretchable chest belt to detect breathing. When played using the microphone, the game detects the frequency and strength of the input sound, calculates the average volume of airflow, and also calibrates itself to identify the frequencies corresponding to silence, inhalation and exhalation. However, interferences from other nearby sources can corrupt the sound of breathing and may even make the game unresponsive to breathing. In contrast, the game does not require any initial calibration when played using the chest belt. It also allows the users to keep their hands free, but it incurs an additional cost to the user. The app can also store a person's breathing patterns and information related to their airflow over a long period of time that can be useful in the long-term monitoring of lung health.

A cough detection algorithm, proposed in Reference [57], was used to analyze the audio signal recorded by the smartphone's microphone to detect the cough event. There, the authors first obtained the spectrogram from the time-varying audio signal, and the cough sound was found to generate higher energy over a wide frequency range compared to other sounds such as throat clearing, speech, and noise. Based on the distinct pattern, the spectrogram of the cough sound from several training sequences was isolated, normalized and analyzed using the principal component analysis (PCA). A subset of the key principal components was then used to reconstruct the cough signal with high fidelity and finally, to classify the cough events. The authors reported achieving a sensitivity of $92 \%$ and a false positive rate of $0.5 \%$ in recognizing cough events using a random forest classifier. However, the phone was placed around the user's neck or in the shirt pocket to improve the audio quality of the recorded sound, which may not be comfortable or always feasible for regular use. Therefore, further research is needed to implement the algorithm in a mobile platform for a complete phone-based cough detection system. A similar phone-based system for identifying and monitoring nasal symptoms such as blowing the nose, sneezing and runny nose was proposed in Reference [58]. This system also tracks the location information using the GPS data in the case of a nose related event, thereby allowing it to keep a record of contextual information related to the event for future reference.

Some researchers [58-62] used the microphone of the smartphones to realize a low-cost spirometer in a mobile platform. Spirometers are widely used in clinical settings to quantify the flow and volume of air inspired and expired by the lungs during breathing. In standard spirometry, a volume-time (VT) curve (Figure 5a) and a flow-volume (FV) curve (Figure 5b) are obtained from forced expiratory flow. These curves are used to extract some clinically important parameters such as forced vital capacity (FVC), forced expiratory volume in $1 \mathrm{~s}$ (FEV1), peak expiratory flow (PEF), and the ratio FEV1 to FVC (FEV1/FVC), which are routinely used clinically to determine the degree of airflow obstruction in patients with pulmonary disorders such as asthma, COPD and cystic fibrosis. However, clinical spirometers are expensive and cost several thousands of dollars. Therefore, a smartphone-based spirometer can be a viable low-cost alternative to these expensive spirometers, particularly for the people in remote areas and in underdeveloped countries. 


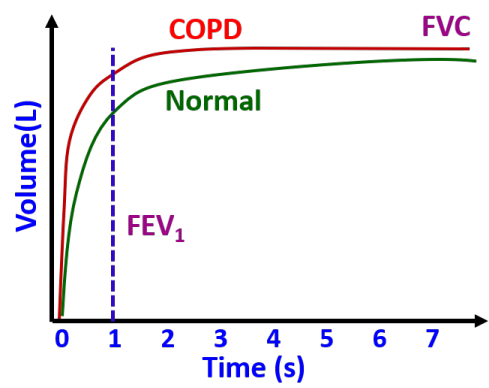

(a)

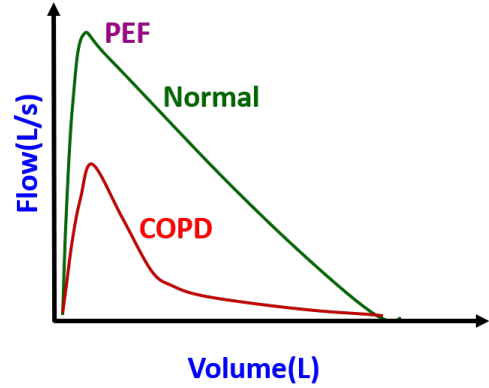

$(\mathbf{b})$

Figure 5. Typical spirometric flow curves (a) volume-time curve, and (b) flow-volume curve.

A smartphone-based spirometer, 'SpiroSmart', was proposed in Reference [58] using the built-in microphone to record the sound of forced exhalation and send the audio data to a remote server for analysis and parameter extraction. In the server, an algorithm to estimate the flow rate from the audio signal of forced exhalation was implemented. There, the authors first compensated for the loss of air pressure as the sound travels a distance from the mouthpiece to the microphone. Then, they estimated the air pressure at the opening of the mouth, which was converted to flow rate. This signal was further processed to extract a set of features from a window of $15 \mathrm{~ms}$ to approximate the flow rate over time. Finally, the spirometric parameters were estimated from the flow rate features following a bagged decision tree and mean square error-based regression techniques, and k-means clustering. In addition, the FV curve was estimated by regression using a combination of conditional random field (CRF) and a bagged decision tree. The authors reported achieving a median error of $\sim 8 \%$ for the four spirometric parameters in reference to the measurements from a clinical spirometer. In a later work, the same research group proposed a call-in based system in References [60,61], where instead of recording the sound on the phone, users can directly call-in to record the audio of forced exhalation in a remote server. The system, named 'SpiroCall', runs a similar algorithm in the server as 'SpiroSmart' and estimated the spirometric parameters from the audio data. The transmission of exhalation sound over voice channels was found to have a negligible effect on the bandwidth and resolution of the signal as well as on the accuracy of the system, thus making the system suitable for remote monitoring of lung health.

In the smartphone-based spirometer proposed in Reference [62], the authors attached a commercial mouthpiece with the smartphone using a custom-made 3D-printed adapter fabricated with polylactic acid (PLA) material. Following a down-sampling and subsequent filtering of the original audio signal, the authors performed a time-frequency analysis on the recorded signal using variable frequency complex demodulation (VFCDM). From VFCDM, they derived two curves-maximum power of each sample against accumulated maximum power and accumulated maximum power against time-which showed a similar pattern to the typical FV curve and VT curve, respectively. Finally, FVC, FEV1, and PEF were extracted from these curves. Although the individual parameters showed poor correlation with the reference, the FEV1/FVC or the Tiffeneau-Pinelli index, which is a key metric in diagnosing chronic obstructive pulmonary disease (COPD), was found to be highly correlated $(r=0.8)$ to the reference measurements with a root mean squared error (RMSE) of $\sim 5.5 \%$ and $\sim 14.5 \%$ in healthy persons and COPD patients, respectively.

In References [63,64], a smartphone application, 'LungScreen' was developed to realize a personalized tool for lung cancer risk assessment. The application assesses the risk of lung cancer based on the user's response to an interactive questionnaire that includes duration of tobacco use, occupational environment and family history of lung cancer. Based on this information, it instantly classifies the users into three risk groups-low, moderate and high. Using the location information from the GPS sensor of the smartphone, the users at high risk of lung cancer are referred and navigated to their nearest screening centers for further investigation. Although the app can be useful for initial and fast screening of lung cancer, the sensitivity and specificity of the app were not reported [63]. In 
addition, in Reference [64], 32 participants were found positive in a low-dose computed tomography (LDCT) screening among the 158 participants (Baranya County, Hungary) who were identified by the app being at high risk of non-small-cell lung carcinoma (NSCLC), the false negative rate (FNR) of the app was not reported.

\subsection{Ophthalmic Health Monitoring}

Diabetic Retinopathy (DR) is one of the common complications of diabetes, which if diagnosed late and left untreated, can lead to blindness. Currently, the seven-field stereoscopic-dilated fundus photographs are considered as the 'gold standard' for diagnosing DR by the Early Treatment of Diabetic Retinopathy Study (ETDRS) group [65,66]. However, this protocol requires an expensive imaging system, specially-skilled photography personnel, and specialized processing and storage of films. Single-field digital fundus photography (Figure 6), although not as comprehensive as the seven-field stereoscopic-dilated fundus photography, can still serve as a screening tool for DR before a detailed ophthalmic evaluation and management [67]. Single-field digital fundus imaging is less expensive and more convenient in comparison to the standard seven-field stereoscopic ETDRS photography. However, this system is still costly with a price of the complete imaging system ranging from several thousand to ten thousand dollars [68], thus limiting its large-scale adoption for diagnosing DR and other eyes-related diseases, especially in developing and under-developed countries. However, the ever-increasing popularity and rapid technological advances of smartphone cameras, coupled with modern-day cloud-based image processing, storage and management services have paved the way for low-cost and efficient remote screening and diagnosis of ophthalmic diseases. This smartphone-based imaging technology can potentially be useful in inpatient consultations and emergency room visits [69].

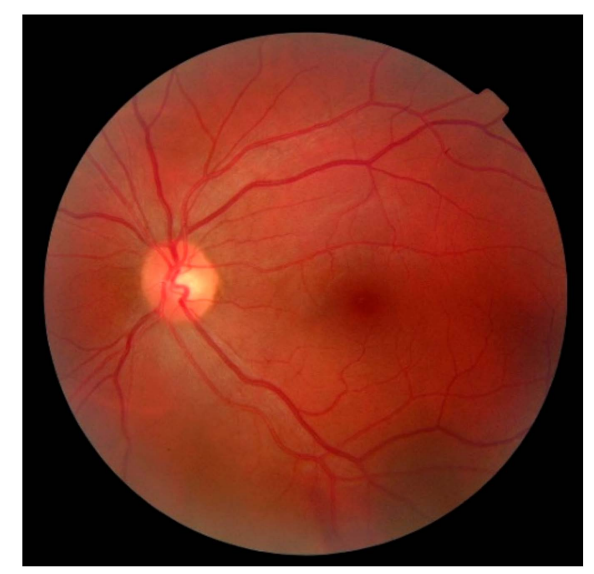

Figure 6. Image of the retinal fundus of a healthy eye; Source: https://pixabay.com/en/eye-fundusclose-1636542/.

At present, there are some smartphone applications available to perform simple ophthalmic tests, although their reliability and performance are often not guaranteed. In order to diagnose Diabetic Macular Edema (DME), Diabetic Retinopathy (DR), and most types of age-related macular degeneration (AMD), a good quality fundus image with an adequate field-of-view is critical. A resolution of at least 50 pixels $/{ }^{\circ}$ along with an imager larger than $1024 \times 768$ pixels are required [70], and most modern-day smartphone-cameras meet this requirement. The idea of using the smartphone camera for retinal fundus imaging was first presented in Reference [69]. In this work, the image of the retinal fundus was captured with a smartphone camera through a 20 Diopter (D) lens, and a pen torch was used for illumination. Although the first of its kind, the system was not user-friendly and cannot ensure good image quality since multiple tasks such as holding the pen torchlight, the smartphone and the lens altogether while directing the light, focusing the camera, and finally pressing the touchscreen for capturing the image, must be performed. An alternative method is proposed in Reference [71], for capturing good quality fundus image. Unlike Reference [69], this system exploited the embedded 
flashlight of the smartphone as a light source for the camera. The user can use one hand to control the smartphone for focusing, magnifying and recording the video image while directing the light to the patient's retina by holding a 20D or 28D ophthalmic lens with the other. The still image of the retinal fundus was then obtained from the video sequence. In Reference [72], the authors demonstrated capturing fundus images from human and rabbit eyes using a similar approach as [71]. They exploited an inexpensive application (Filmic Pro, Cinegenix LLC, Seattle, WA, USA; http://fimicpro.com/) to control the illumination, focus, and light exposure while recording the video image. Although all systems reported capturing a fundus image, no validation or comparison in reference to the standard systems was reported. Furthermore, these techniques require the use of both hands, thus leaving no room for eye indentation. In addition, the potential for peripheral retinal imaging was not explored.

In Reference [73], a 3D printed lightweight attachment was designed for smartphones to capture high-quality fundus images. Unlike the systems reported in References [69,71,72], the attachment can hold an ophthalmic lens at a recommended but an adjustable distance from the lens of the smartphone camera and can use either the phone's built-in flash or external light source for illumination. A similar attachment for smartphones and an external LED light source were used in Reference [68] for near visual acuity testing and fundus imaging, thus enabling remote screening of DR patients. A similar fixture was also presented in Reference [74] which has slots to accommodate a smartphone and hold a $20 \mathrm{D}$ lens, thus allowing the physicians to use the system in one hand and keep the other hand free for indentation. Along with central fundus images, both systems [73,74] enables capturing high-quality images of the peripheral retina such as ora serrata and pars plana. Thus, they can be useful in screening for peripheral lesions as well, although the researchers in Reference [73] did not explore this possibility.

In Reference [75], a 3D printed plastic attachment $\left(14 \times 15.25 \times 9 \mathrm{~cm}^{3}\right)$ designed for the smartphones to enable high-quality wide-field imaging of retinal fundus was developed. The attachment houses three white LEDs for illumination, optical components including one 54D lens, one $20 \mathrm{~mm}$ focal length achromatic lens for light collection, two polarizers and a beam splitter, and a phone holder to ensure proper alignment between the camera sensor and the imaging optics. The smartphone can adjust the illumination level to the retina by regulating a battery powered on/off dimming circuit that independently controls each LED. The variability in axial length and the refractive error in the subject's eyes were corrected by exploiting the auto-focus mechanism of the smartphone. The Ocular CellScope, as they named the complete imaging system, cost only $\$ 883$ and was reportedly capable of capturing a wide field-of-view $\left(\sim 55^{\circ}\right)$ in a single fundus image with a dilated pupil, thus making it a promising low-cost alternative to most commercial retinal fundus imaging systems.

Similar to the Ocular CellScope, a much smaller $\left(47 \times 18 \times 10 \mathrm{~mm}^{3}\right)$ and less expensive $(\$ 400)$ magnetic attachment called D-Eye was reported in References [76] and [77]. The device houses similar optical components except for the light source, for which D-Eye exploits the smartphone's embedded flashlight. The cross-polarization technique significantly reduced the corneal Purkinje reflections, thus making it possible to easily visualize the optic disc and screen patients, particularly for glaucoma even with undilated pupils. The authors reported achieving a field of view of $\sim 20^{\circ}$ for each fundus image with a significant agreement with dilated retinal bio-microscopy which is conventionally used for grading the severity level of diabetic retinopathy. Furthermore, the retinal fundus imaging of babies was convenient due to their spontaneous attraction to the non-disturbing light emitted by the device. In addition, the device allows the examiner to work at an ergonomically convenient distance $(>\sim 1 \mathrm{~cm})$ while using the smartphone's screen to focus the light on the patient's retinal fundus. A stitching algorithm can be used to create a composite image, thus increasing the field-of-view of the retinal fundus. Figure 7 shows the typical arrangement of the optical components for fundus imaging with a smartphone. 




Figure 7. Typical arrangement of the optical components for fundus imaging with a smartphone.

A portable eye examination kit (PEEK) was presented in References [78,79] that exploited the camera of a smartphone to realize a portable ophthalmic imaging system. The system can perform an automatic cataract test by acquiring the image of an eye with a smartphone camera and comparing it to a set of preloaded images of cataract affected eyes with different intensity. However, additional external hardware is required to make PEEK suitable for fundus imaging. The additional hardware primarily comprises a red LED to illuminate the blood vessels and hemorrhages, a blue LED to observe corneal abrasions and ulcers after staining the eye with fluorescein, and a lens to magnify the image. The image of the retinal fundus is then displayed on the screen of the smartphone for diagnostic purpose. The system was successfully used to identify visual impairment in children $[80,81]$ and to monitor the effect of prolonged exposure to extreme environments such as the long frigid darkness of Antarctica during the winter on the health of the explorers' eyes [82].

\subsection{Skin Health Monitoring}

Skin cancer is one of the most common of all human cancers that is caused by the abnormal growth of skin tissue. Experts have identified three major types of skin cancer basal cell carcinoma (BCC), squamous cell carcinoma (SCC), and melanoma, the malignant form of the latter being the most dangerous one among the three. Melanoma is primarily caused by over-exposer to harmful ultra-violet rays of the sun that hinders melanin synthesis by damaging the genetic material of the melanin-producing melanocyte cells of the skin and thus putting people at high risk of skin cancer. Malignant melanoma tends to spread to other parts of the body and may turn fatal if not diagnosed and treated early. According to the America Cancer Society, 91,270 new cases of skin melanoma were estimated to be diagnosed in the US in 2018, out of which 9320 deaths were estimated [83]. Skin cancer is characterized by the development of precancerous lesions with varying shape, size, color and texture. Apart from skin cancer, there are other types of skin diseases such as psoriasis, eczema, and moles that require medical attention, thus causing loss of productivity and increase in medical expenditures. In fact, one in four Americans underwent treatment for at least one skin disease in 2013, costing \$11 billion in lost productivity and $\$ 75$ billion for treatment and associated costs [84]. Therefore, a low-cost solution for early detection of skin disease would be of immense use. Smartphones, being widely popular at present, can offer a viable solution for early diagnosis of skin diseases, most particularly for remote screening and long-term monitoring of skin lesions. Figure 8 shows some common medical conditions associated with the skin.

To evaluate the efficacy of smartphone-based imaging in assessing the evolution of skin lesions, a cross-sectional study of skin disease was conducted in Reference [85]. Photographs were taken and sent by the patients themselves reportedly assisted the physicians to strengthen, modify and confirm the diagnosis in $76.5 \%$ of the patients, thus significantly influencing the diagnosis and treatment of skin 
diseases. Furthermore, in comparison to the conventional paper-based referral system, it was observed that smartphone-based Teledermoscopy (TDS) referral schemes can significantly reduce the waiting time for skin-cancer patients [86]. In addition, the quality of most images captured by the smartphones was good enough to reliably improve the triage decisions, thus potentially making the management of patients with skin cancer faster and more efficient as compared to the traditional paper-based referrals.



(a)

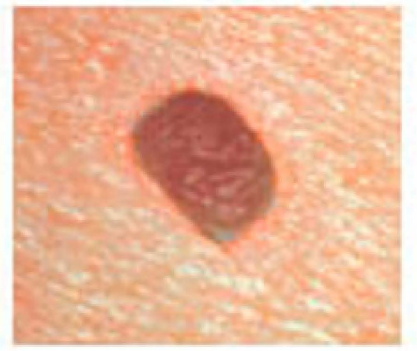

(c)

Benign

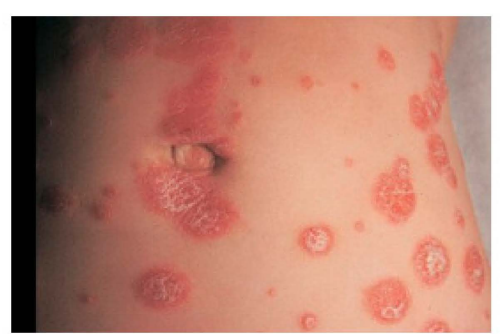

(b)

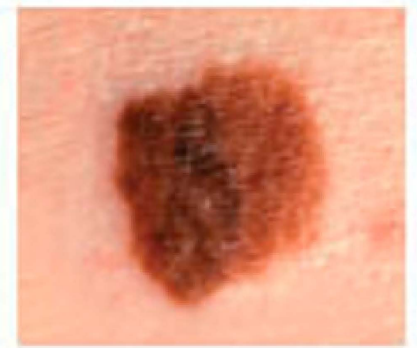

Malignant

Figure 8. Several types of skin diseases (a) Eczema, (b) Psoriasis and (c) two forms of Melanoma.

Most existing portable solutions for skin disease detection rely on conventional image processing techniques along with conventional monochrome or RGB color imaging $[87,88]$. However, owing to its poor spatial and spectral resolution, conventional imaging approaches may not be suitable for resolving heterogeneous skin lesions $[89,90]$ and can potentially lead to diagnostic inaccuracies. The spectral imaging techniques, on the other hand, exploits the spectral reflectance characteristics of affected sites on the skin $[91,92]$ to resolve heterogeneous lesions and was reported to be useful in differentiating skin diseases, such as early-stage melanoma from dysplastic nevi and melanocytic nevi [93], and various acne lesion types [94]. A ring-shaped light source for the smartphone camera to study the feasibility of using smartphones for skin chromophore mapping was presented in Reference [95]. The ring comprises one white LED and three LEDs with different emission spectrum (red, green and blue) as well as two orthogonally oriented polarizers. The polarizers reduce the specular-reflected light from the skin, thus allowing the camera sensor to detect light scattered only from the skin [96]. The white light enables identifying the skin malformation, while the distribution of skin chromophores is estimated from the reflected or scattered RGB lights. Thee different smartphones were tested both in vitro and in vivo to estimate the Hemoglobin index (HI) and the Melanin index (MI). Both HI and MI reportedly increased in the in-vitro test with the concentration of absorbents in the phantoms. In vivo tests further showed the Hemangiomas and the Nevi having higher HI and MI, respectively compared to the healthy skin. Although the results achieved from all the smartphones were promising, they lacked consistency to some extent, which was attributed to the built-in automatic camera settings such as white balance, and ISO of some smartphones, and the difference in spectral sensitivities of the cameras.

A smartphone-based miniaturized $\left(92 \times 89 \times 51 \mathrm{~mm}^{3}\right)$ multi-spectral imaging (MSI ) system, which is somewhat similar in principle to the approach in Reference [95] was implemented in Reference [90] to facilitate portable and low-cost means of skin disease diagnosis. Instead of using four different LEDs as in Reference [95], the system exploits the smartphone's flashlight, nine narrow-band band-pass 
filters, and a motorized filter wheel to periodically obtain light of different wavelengths, which along with a plano-concave lens, a mirror, a 10× magnifying lens, and two linear polarizers are housed in a compact enclosure. An Android application (SpectroVision) was developed to control a custom interface circuit, perform multispectral imaging and analyze skin lesions. By controlling the motorized filter remotely via Bluetooth, the application captures nine images at different wavelengths ranging from $440 \mathrm{~nm}$ to $690 \mathrm{~nm}$ and one white-light image. The captured images are sent to a skin diagnosis/management platform over WiFi or LTE, where further processing of the images such as gray-scale conversion, shading correction, calibration and normalization is performed. A quantitative analysis of the nevus regions using the system was performed. In addition, quantifying acne lesions using ratio-metric spectral imaging and analysis was reported, thus demonstrating the potential of the system in diagnosing and managing skin lesions.

In order to capture the cellular details of human skin with a smartphone, a low-cost and first-of-its-kind confocal microscope was developed and used in Reference [97]. A two-dimensional confocal image of the skin was obtained by using a slit aperture and a diffraction grating, thus avoiding any additional beam scanning devices. The diffraction grating spread the focused illumination line on different locations on the tissue with different wavelengths. The authors reported observing characteristic cellular structures of human skin, including spinous and basal keratinocytes and papillary dermis with a lateral and axial resolution of $2 \mu \mathrm{m}$ and $5 \mu \mathrm{m}$, respectively. However, in comparison to commercial systems, the designed system has a shallow imaging depth, which can be attributed to the use of slit aperture and a shorter wavelength $(595 \mathrm{~nm})$ light source of the smartphone device. In addition, the low illumination efficiency limits the imaging speed to only $4.3 \mathrm{fps}$. A light source of longer wavelength and enhanced coupling with the illumination slit [98] may improve the imaging depth and speed. Nevertheless, the small dimension $\left(16 \times 18 \times 19 \mathrm{~cm}^{3}\right)$ and low cost $(\$ 4200)$ of such a high-resolution imaging system may enable the system to be used in rural areas with limited resources for standard histopathologic analysis.

A smartphone-based system named DERMA/care was proposed in Reference [99] to assist in the screening of melanoma. An inexpensive and small dimension $(6 \mathrm{~cm} \times 4 \mathrm{~cm} \times 2 \mathrm{~cm})$ off-the-shelf microscope was mounted on the camera of the smartphone for capturing high-resolution images of the skin. In addition, a mobile application that can extract some characteristic features from the image of the affected skin was developed. The application was used to extract textural features such as entropy, contrast and variance, and geometric features such as area, perimeter and diameter. The features were then fed to a support vector machine (SVM) classifier to enable automatic classification of skin lesions. In another work, a multi-layer perceptron (MLP) was employed on a smartphone to analyze skin images captured by its camera, thus enabling skin cancer detection [100]. A similar application was proposed in Reference [101], which upon capturing the image of the skin, can alert the users about a potential sunburn and/or the severity of melanoma. There a novel method to compute the time-to-skin-burn by utilizing the information of burn frequency level and UV index level was introduced. Additionally, for dermoscopic image analysis, a system for the smartphones that incorporates algorithms for image acquisition, hair detection and exclusion, lesion segmentation, feature extraction, and classification was developed. After excluding the hair and identifying the ROI, a comprehensive set of features were extracted to feed to a two-level classifier. The authors reported achieving high accuracy $(>95 \%)$ in classifying among benign, atypical, and melanoma images.

\subsection{Mental Health Assessment}

As mentioned earlier, present-day smartphones have a number of embedded sensors such as accelerometer, GPS, light sensor and microphone. The data from these embedded sensors can be collected passively with the smartphone, which coupled with the user's phone usage information such as call history, SMS pattern and application usage may potentially be used to digitally phenotype an individual's behavior and assess one's mental health. For example, an individual's stress level or emotional state can be deduced from their voice while talking over the phone and recording the 
conversation with the smartphone's microphone [102-104]. In addition, the accelerometer can provide information about physical activity and movement during sleep. The GPS can provide information about the location and thus the context and variety of activity. Therefore, the smartphone enables a less intrusive and more precise alternative to the traditional self-reporting approach, and it may be very useful in assessing the mental wellbeing of an individual.

Many researchers used the smartphone data to assess or predict an individual's general mental health such as social anxiety [105], mood [106,107] or daily stress level [108]. The GPS location data of 16 university students were analyzed in Reference [105], and it was reported that there was a significant negative correlation between time spent at religious locations and social anxiety. The accelerometer data along with device activity, call history and SMS patterns were analyzed in References [106] and [107] to predict mood. A prediction model based on the Markov-chain Monte Carlo method was developed in Reference [107] and it achieved an accuracy of 70\% in mood prediction. In Reference [106], personalized linear regression was used to predict mood from the smartphone data. In Reference [108], by extracting device usage information and data from smartphone sensors (accelerometer, GPS, light sensor, microphone), an attempt was made to determine the factors associated with daily stress levels and mental health status [108]. There, researchers found a correlation between sleep duration and mobility with the daily stress levels. They also found speech duration, geospatial activity, sleep duration and kinesthetic activity to be associated with mental health status.

Some works in the literature also exploited the sensor data and usage information of the smartphone to assess specific mental health conditions such as depression [109-114], bipolar disorder [115-119], schizophrenia [119-122] and autism [123]. A significant correlation between some features of the GPS location information and depression symptom was observed in Reference [111]. For example, in Reference [114], the authors analyzed the data from the smartphone's GPS, accelerometer, light sensor and microphone as well as call history, application usage, and SMS patterns of 48 university students. They observed that the students' depression was significantly but negatively correlated with sleep and conversation frequency and duration. Some researchers $[109,110,112,113]$ attempted to predict depression from the smartphone sensor data. In Reference [109], they predicted depression based on the accelerometer, GPS and light sensor data from the smartphone. Both the support vector machine (SVM) and random forest classifier were used in Reference [113] to predict depression from the GPS and accelerometer data, as well as from the calendar, call history, device activity and SMS patterns. However, the prediction accuracy in References [109] and [113] was only slightly better than the chance. In Reference [110], only the GPS data was used to predict depression and with the SVM classifier, moderate sensitivity and specificity of prediction were achieved. In Reference [112], both the GPS data and the device activity information were exploited to predict depressive symptoms. Using a logistic regression classifier for prediction, the authors achieved a prediction accuracy of $86 \%$.

Some significant correlations between the activity levels and bipolar states were observed in some individual patients, where the physical activity level was measured with the smartphone's accelerometer [115]. In Reference [119], the authors used data from the Bluetooth, GPS sensor and battery consumption information of the smartphone to track an individual's social interactions and activities. There, they found that the data from these sensors are significantly correlated with their depressive and manic symptoms. In References [116,117], the accelerometer and GPS data of the smartphone were used to detect the mental state and state change of persons with bipolar disorder. They reported detecting state change with $96 \%$ precision and $94 \%$ recall and achieved an accuracy of $80 \%$ in state recognition [116]. Using additional information from the microphone and call logs, the precision and recall increased to $97 \%$; thus improving the reliability of the system. However, the state recognition accuracy was somewhat reduced, which was attributed to the noisy ground-truth and inconsistencies in the daily behavioral patterns of the participants [117]. In Reference [118], the accelerometer and light sensor data of the smartphone, the call history and SMS patterns were exploited in a generalized and a personalized model to predict the state among persons with bipolar disorder. A precision and recall of $85 \%$ and $86 \%$, respectively was achieved in state prediction. 
In Reference [120], a study on the feasibility and acceptance of passive sensing by smartphone sensors among the people with schizophrenia was conducted. Persons with schizophrenia were mostly found open to sensing with smartphones and two-thirds expressed interest in receiving feedback, but a third expressed concern about privacy. The GPS location information was exploited to recognize outdoor activities among people with schizophrenia and thereby to infer social functioning [121]. In Reference [122], the authors proposed a system called CrossCheck that used data from the GPS, accelerometer, light sensor and microphone as well as call history, application usage, and SMS patterns to predict the change in mental health among patients with schizophrenia. There, they collected data from 21 patients and observed statistically significant associations between the patients' mental health status and features corresponding to sleep, mobility, conversations and smartphone usage. The authors used random forest regression to predict the mental health indicators in the patients with schizophrenia and reported achieving a mean error of $7.6 \%$ with respect to the scores derived from the participants' responses to a questionnaire.

Recently, Apple Inc.'s ResearchKit initiative launched a mobile application called "Autism and Beyond" [123]. This application captures images of the users' facial expressions in response to standardized stimuli by the iPhone's front-facing camera and analyzes these images using algorithms designed for emotion recognition. This application can potentially identify individuals who are at risk of autism and other developmental disorders. A large-scale trial is currently underway to assess the validity and utility of this approach.

\subsection{Activity and Sleep Monitoring Systems}

Daily physical activities such as walking, running and climbing stairs involve several joints and muscles of the body and require proper coordination between the nervous system and the musculoskeletal system. Therefore, any abnormalities in the functioning of these biological systems may potentially affect the natural patterns of these activities. For example, persons at the early onset of Parkinson's disease tend to exhibit small and shuffled steps, and occasionally experience difficulties to start, stop and take turns while walking [22,124]. Additionally, due to gradual deterioration of motor control with age, older adults are at high risk of fall and mobility disability. In fact, an estimated 10\% (2.7 million) of Canadians, aged 15 years and over, suffered from mobility-related disabilities in 2017 [125]. Furthermore, falls in the older adults may cause hip and bone fractures, joint injuries, and traumatic brain injury, which not only require longer recovery time but also restrict physical movement thereby affecting an individual's daily activities. In addition, fall-related fractures reportedly have a strong correlation with mortality [124]. Moreover, nearly one-third (30\%) of Canadian adults between 18 and 79 years of age were estimated to be at intermediate or high risk for sleep apnea [126], which is often associated with high blood pressure, heart failure, diabetes, stroke, attention deficit/hyperactivity disorder, and increased automobile accidents $[127,128]$. Therefore, quantitative assessment of gait, knee joints and daily activities including sleep are critical in early diagnosing musculoskeletal or cognitive diseases, sleep disorders, fall and balance assessment, as well as in the post-injury rehabilitation period.

Most existing activity monitoring systems rely on a network of cameras fixed at key locations in a home [22,129]. Although such systems can provide comprehensive information about complex gait activities, they are expensive and generally have a limited field-of-view. In recent years, there has been a growing interest in using smartphone embedded motion sensors such as accelerometers, gyroscopes, and magnetometers as well as location sensors such as the GPS sensor for real-time monitoring of human gait and activities of daily living (ADL) [130-157]. These sensors measure the linear and angular movement of the body, and the location of the user, which can be used to quantify and classify human gait events and activities in real time. A general architecture of smartphone-based activity monitoring is presented in Figure 9. 




Figure 9. General architecture of a smartphone-based activity monitoring system.

At the heart of an activity monitoring and recognition system is the classification or recognition algorithm. However, signal processing techniques and extraction of appropriate features also play critical roles in realizing a computationally efficient and reliable system. Signal processing techniques may include filtering, data normalization and/or data windowing or segmentation. Subsequently, a good number of key features from the statistical, temporal, spatial and frequency domains are extracted to feed into the classification model. Table 3 presents a list of typical features that are extracted from the motion signals. Finally, an appropriate classification model such as support vector machine (SVM) $[137,138,155,158,159]$, naive Bayes (NB) $[136,149,155,156]$, k-means clustering [138,149], logistic regression [134,155,156], k-nearest neighbor (KNN) [133,136,155,156,158], neural network (NN) $[140,141,143,151,152]$ or a combination of models $[134,140,141,148,150]$ are employed for activity recognition.

Table 3. Typical features extracted from motion signals [22].

\begin{tabular}{cccc}
\hline Spatial Domain & Temporal Domain & Frequency Domain & Statistical Domain \\
\hline Step length & Double support time & Spectral power & Correlation \\
Stride length & Stance time & Peak frequency & Mean \\
Step width & Swing time & Maximum spectral amplitude & standard deviation \\
RMS acceleration & Step time & & Covariance \\
Walking speed & Stride time & & energy \\
Signal vector magnitude (SMV) & Cadence (steps/min) & & Kurtosis \\
\hline
\end{tabular}

The Manhattan distance metric was used in Reference [130] to compare the accelerometer data of an average gait cycle from a test sample to three template cycles corresponding to three different walking speeds. The authors attempted both statistical and machine learning approaches and the highest accuracy $(\sim 99 \%)$ in classifying three different walking speeds was achieved with the support vector machine (SVM). An important limitation of this approach is that it relies on the local peak and valley detection to identify the gait cycles, but their consistency varies with walking speed and/or style. A two-stage continuous hidden Markov model (CHMM) was proposed in Reference [131] for recognition of human activities. Some subsets of optimal features were first produced by employing the random forest importance measures. The static and dynamic activities were then distinguished by applying the first-level CHMM, which was followed by a second-level CHMM for achieving a finer classification of the activities with an accuracy of $~ 92 \%$. In Reference [132], a fuzzy min-max (FMM) neural network based incremental classification approach was used to learn activities, which includes walking, ascending and descending stairs, sitting, standing, and laying. The authors then applied a classification and regression tree (CART) algorithm to predict these activities and reported achieving a recognition accuracy of $\sim 96.5 \%$. A voting scheme was adopted in Reference [134] to combine the classification results from an ensemble of classifiers such as a J48 decision tree, logistic regression (LR) and multilayer perceptron (MLP). These authors reported identifying four activities such as walking, jogging, sitting and standing with an accuracy of more than $97 \%$. However, the proposed approach performed poorly in distinguishing between activities like ascending and descending stairs, where the recognition accuracy reduced to $\sim 85 \%$ and $\sim 73 \%$, respectively. In Reference [135], four smartphones were attached to the waist, back, leg, and wrist and captured motion data from the accelerometer 
and gyroscope for activity measurement; humidity, temperature, and barometric pressure sensors for sensing environmental parameters; and Bluetooth beacons for location estimation. A modified conditional random field (CRF) algorithm was implemented on each unit to classify the activities individually using a set of suitable features extracted from the preprocessed sensor data. The decisions from each unit were then assessed based on their relevance to the body positions to finally determine the activities. The authors reported identifying 19 daily activities including cooking, cleaning utensils and using bathroom sink and refrigerator with more than $80 \%$ accuracy.

An orientation independent activity recognition system based on smartphone embedded inertial sensors was reported in Reference [137]. The raw sensor data were processed by signal processing techniques including coordinate transformation and principal component analysis. A set of statistical features were extracted from the processed sensor signals, which is then fed to several classification algorithms such as ANN, KNN and SVM to identify the same six activities (walking, ascending and descending stairs, sitting, standing, and laying) investigated in References [131-133]. The authors also presented an online-independent SVM (OISVM) for incremental learning that can deal with the inherent differences among the measured signals resulted from the variability associated with the device placement and the participants. There they reported identifying the activities with an accuracy of $\sim 89 \%$ using OISVM. In order to deal with the high computational costs associated with the machine learning techniques for activity recognition, a hardware-friendly support vector machine (HF-SVM) based on fixed-point arithmetic was proposed in Reference [138]. There the authors reported achieving a recognition accuracy of $89 \%$, which is comparable to the performance of the conventional SVM.

Some researchers [139-143,150-152] exploited more advanced techniques such as deep neural networks for activity recognition. Unlike conventional machine learning approaches, these techniques do not employ separate feature extraction and feature selection schemes. Rather, they automatically learn the features and perform activity recognition simultaneously. In References [140,141], a deep convolutional neural network (Convnet) was formed by stacking several convolutional and pooling layers to extract key features from the raw sensor data. The Convnet, being coupled with multilayer perceptron (MLP) can classify six activities as [131-133] with an accuracy of $\sim 95 \%$. By incorporating additional features extracted from the temporal fast Fourier transform (tFFT) of the raw data, the performance of the Convnet was found to improve by $~ 1 \%$. The authors in Reference [142] implemented an activity recognition system using a bidirectional long short-term memory (BLSTM)-based incremental learning approach that exploits both the vertical and horizontal components of the preprocessed sensor data to obtain a two-dimensional feature. Several such BLSTM classifiers were then combined to form a multicolumn BLSTM (MBLSTM). The authors compared the performance of MBLSTM with that of several classifiers such as SVM, KNN and BLSTM, and achieved the lowest error rate $(\sim 15 \%)$ in recognizing seven activities that include jumping, running, normal and quick walking, step walking, ascending and descending stairs. In Reference [150], a smartphone-based activity recognition system was developed using a deep belief network (DBN). There the authors first extracted a set of five hundred and sixty-one features from the motion signals following a signal processing step that includes signal filtering and data windowing. A kernel principal component analysis (KPCA) was then employed on these features and only the first one hundred principal components were fed into the DBN while training the model for activity recognition. The authors reported achieving an accuracy of $\sim 96 \%$ in recognizing 12 activities that include standing, sitting, lying down, walking, ascending and descending stairs, stand-to-sit, sit-to-stand, sit-to-lie, lie-to-sit, stand-to-lie, and lie-to-stand. However, unlike most deep learning-based system, the approach in Reference [150] requires a stand-alone feature extraction step, thus increasing the computational load. In general, the key issues associated with the deep learning-based approaches are their high computational cost, making them unsuitable for real-time applications, especially for devices with limited high-end processing capabilities.

Some researchers exploited smartphones for fall detection [144,145,157-162] and posture monitoring [146,147]. In Reference [144], the angle between the longitudinal axis of the device and the gravitational vector was continuously monitored using the smartphone embedded motion 
sensor. When this angle drops below a pre-determined threshold of $40^{\circ}$, the system recognizes the event as a fall. The proposed system, when worn on the waist, was able to distinguish a fall from a normal body motion, i.e., lying, sitting, static standing and horizontal/vertical activities with high accuracy. However, the system requires the phone to remain attached to the waist for fall detection, which may not be comfortable or always feasible for users. A similar fall detection system was implemented in Reference [145] where the smartphone was kept in the shirt pocket with its front side facing the body in order to maintain consistency in the orientation of the sensors. The system monitors the changes in the acceleration along the three directions and detects a fall if the change happens faster than an experimentally established minimum time spent on performing normal activities of daily living. However, no quantitative information regarding the accuracy of the system was provided in both References [144,145]. In Reference [159], the authors proposed an SVM-based fall detection algorithm. They used smartphone's built-in accelerometer to record user's motion data by placing the phone in the front pocket of the shirt. The participants performed some activities of daily living (ADL), and also some simulated fall events. The authors reported distinguishing fall events from non-fall activities with high sensitivity ( $97 \%$ ) and specificity (95\%). A detailed review of smartphone-based fall detection systems was presented in References [161,162].

In Reference [146], the authors reported a smartphone-based posture monitoring application named Smart Pose. The accelerometer data and facial images were captured simultaneously while holding the smartphone and facing towards it. The pitch and roll orientation of the device, and thereby the cumulative average of tilt angle (CATA) of the user's neck is estimated, assuming the device's orientation correlates to and represents the position of the user's neck. A bad posture is determined when CATA exceeds an acceptable range of $80^{\circ}$ to $100^{\circ}$. The authors compared the performance of their proposed system with a commercial three-dimensional posture analysis system and reported achieving similar performance with the Smart Pose. An application named iBalance-ABF was proposed in Reference [147] to assess the balance of the body and to provide audio feedback to the user accordingly. The smartphone embedded accelerometer, gyroscope and magnetometer were used to determine the tilt of the mediolateral trunk. When the tilt angle of the trunk exceeds an adjustable but predetermined threshold, the system sends audio feedback to the user over the earphone. The smartphone, mounted on a belt, however, needs to be attached to the back at the level of the L 5 vertebra, which requires assistance. Nevertheless, iBalance-ABF can be useful, particularly for older adults to improve their posture and balance.

Applications based-on smartphone-sensors that facilitate monitoring of knee joints [162,163], sleeping patterns [164-166] and sleep disorders [167] were reported. Table 4 summarizes several recent smartphone-sensor based activity and sleep monitoring systems. In addition, it should be noted that there are published research results that used external inertial measurement units (IMUs) for activity recognition [7,22,142]. For example, the authors in Reference [143] combined the convolutional neural network (CNN) and LSTM to form a deep convolutional LSTM (DeepConvLSTM) and used this approach for activity recognition. The $\mathrm{CNN}$ can determine the key features from the signal automatically, while the LSTM translates the temporal patterns of the signals into features. The authors reported recognizing a complex set of daily activities with high precision (F1 score $>0.93$ ). Smartphone embedded motion sensors such as accelerometers, gyroscopes and magnetometers can replace these external IMUs and achieve similar performance. However, in order to recognize a complex set of activities, as it was reported in Reference [143], it requires several sets of IMUs/smartphones to be attached at different parts of the body, which is not cost-effective and may not be practical. 
Table 4. Smartphone-sensor based activity monitoring systems.

\begin{tabular}{|c|c|c|c|c|c|c|c|}
\hline Ref. & Proposition & Phone & Sensors & Experiment Protocol & $\mathbf{n}$ & Method & Performance/Comment \\
\hline [130] & $\begin{array}{l}\text { Human activity and } \\
\text { gait recognition }\end{array}$ & $\begin{array}{l}\text { Samsung } \\
\text { Nexus S }\end{array}$ & $a, \omega$ & $\begin{array}{l}\text { - Subjects walked } \sim 30 \mathrm{~m} \text { for each of three different walking } \\
\text { speeds } \\
\text { - Smartphone in the trouser pocket } \\
\text { - Sampling rate: } 150 \text { sample/s }\end{array}$ & 25 & $\begin{array}{l}\text { - Each gait cycle was detected } \\
\text { and normalized in length. } \\
\text { - Several distance metrics } \\
\text { between the test and template } \\
\text { cycle were calculated as features. } \\
\text { - Statistical analysis and machine } \\
\text { learning used for recognition. }\end{array}$ & $\begin{array}{l}\text { - Gait recognition accuracy } \\
89.3 \% \text { with dynamic time } \\
\text { warping (DTW) distance } \\
\text { metric. } \\
\text { - Activity recognition } \\
\text { accuracy }>99 \% \text {. }\end{array}$ \\
\hline [131] & $\begin{array}{l}\text { Human activity } \\
\text { recognition }\end{array}$ & $\begin{array}{l}\text { Samsung } \\
\text { Galaxy S II }\end{array}$ & $a, \omega$ & $\begin{array}{l}\text { - University of California Irvine (UCI) Human activity } \\
\text { recognition (HAR) dataset } \\
\text { - Subjects performed an activity twice, with the phone (1) } \\
\text { mounted on the belt at the left side (2) placed according to the } \\
\text { user's preference. }\end{array}$ & 30 & $\begin{array}{l}\text { - Feature selection using random } \\
\text { forests variable importance } \\
\text { measures. } \\
\text { - Two-stage continuous HMM for } \\
\text { activity recognition. } \\
\text { - First and 2nd level for coarse } \\
\text { classification and fine } \\
\text { classification, respectively. }\end{array}$ & $\begin{array}{l}\text { - Activity (walking, } \\
\text { ascending and descending } \\
\text { stairs, sitting, standing, and } \\
\text { laying) recognition accuracy } \\
91.76 \% \text {. }\end{array}$ \\
\hline [132] & $\begin{array}{l}\text { Human activity } \\
\text { recognition }\end{array}$ & $\begin{array}{l}\text { Samsung } \\
\text { Galaxy S II }\end{array}$ & $a, \omega$ & $\begin{array}{l}\text { - UCI HAR dataset } \\
\text { - Activities are: walking, ascending and descending stairs, } \\
\text { sitting, standing, and laying }\end{array}$ & 30 & $\begin{array}{l}\text { - A hybrid model based on the } \\
\text { fuzzy min-max (FMM) neural } \\
\text { network and the classification } \\
\text { and regression tree (CART). }\end{array}$ & $\begin{array}{l}\text { - Activity (walking, } \\
\text { ascending and descending } \\
\text { stairs, sitting, standing, and } \\
\text { laying) recognition accuracy } \\
96.52 \% \text {. }\end{array}$ \\
\hline [133] & $\begin{array}{l}\text { Evaluation of } \\
\text { hyperbox (HB) NN } \\
\text { for classifying } \\
\text { activities }\end{array}$ & $\begin{array}{l}\text { Samsung } \\
\text { Galaxy S II }\end{array}$ & $a, \omega$ & $\begin{array}{l}\text { - UCI HAR dataset } \\
\text { - Five subsets of varying sizes ( } 5 \%, 10 \%, 20 \%, 50 \% \text { and } 100 \% \text { of } \\
\text { the dataset) were created for training purpose }\end{array}$ & 30 & $\begin{array}{l}\text { - One HB is assigned for all } \\
\text { attributes of a class and has one } \\
\text { or more associated neurons for } \\
\text { class distribution. } \\
\text { - Points falling into (1) only one } \\
\text { HB are immediately classified (2) } \\
\text { overlapping regions of HBs use } \\
\text { the neural outputs for prediction. }\end{array}$ & $\begin{array}{l}\text { - Performance was } \\
\text { comparable to SVM, decision } \\
\text { tree, KNN and MLP classifier. } \\
\text { - Activity (walking, } \\
\text { ascending and descending } \\
\text { stairs, sitting, standing, and } \\
\text { laying) recognition accuracy } \\
75 \%-87.4 \%\end{array}$ \\
\hline [134] & $\begin{array}{l}\text { Human activity } \\
\text { recognition }\end{array}$ & $\begin{array}{l}\text { Nexus One, } \\
\text { HTC Hero, } \\
\text { Motorola } \\
\text { Backflip }\end{array}$ & $a$ & $\begin{array}{l}\text {-Wireless sensor data mining (WISDM) dataset from } \\
\text { http://www.cis.fordham.edu/wisdm/dataset.php } \\
\text { - Sampling rate: } 20 \text { samples/s }\end{array}$ & 36 & $\begin{array}{l}\text { - Extracted } 43 \text { features from the } \\
\text { mean and standard deviation of } \\
\text { acceleration, mean absolute } \\
\text { difference, mean resultant } \\
\text { acceleration, time between peaks } \\
\text { and binned distribution. } \\
\text { - A Voting scheme to combine the } \\
\text { results from the J48 decision tree, } \\
\text { logistic regression and MLP. }\end{array}$ & $\begin{array}{l}- \text { Accuracy }>\sim 97 \% \text { (walking, } \\
\text { jogging, sitting and standing), } \\
\sim 86 \% \text { (ascending stairs), and } \\
\sim 73 \% \text { (descending stairs) }\end{array}$ \\
\hline [156] & $\begin{array}{l}\text { Human activity } \\
\text { recognition }\end{array}$ & iPod Touch & $a, \omega$ & $\begin{array}{l}\text { - Measured activities: sitting, walking, jogging, and ascending } \\
\text { and descending stairs at different paces }\end{array}$ & 16 & $\begin{array}{l}\text { - Evaluated different } \\
\text { classification models (decision } \\
\text { tree, multilayer perception, Naive } \\
\text { Bayes, logistic regression, KNN } \\
\text { and meta-algorithms such as } \\
\text { boosting and bagging) in terms of } \\
\text { recognition accuracy. }\end{array}$ & $\begin{array}{l}\text { - Accuracy for sitting, } \\
\text { walking, and jogging at } \\
\text { different paces: } 90.1 \%-94.1 \% \\
\text { - Accuracy for ascending and } \\
\text { descending stairs: } \\
52.3 \%-79.4 \%\end{array}$ \\
\hline
\end{tabular}


Table 4. Cont

\begin{tabular}{|c|c|c|c|c|c|c|c|}
\hline Ref. & Proposition & Phone & Sensors & Experiment Protocol & $\mathbf{n}$ & Method & Performance/Comment \\
\hline [135] & $\begin{array}{l}\text { Complex activity } \\
\text { recognition system }\end{array}$ & $\begin{array}{l}\text { Samsung } \\
\text { Galaxy S IV }\end{array}$ & $\begin{array}{l}a, \mathrm{\omega}, \mathrm{P}, \mathrm{T}, \mathrm{H} \\
\text { (and } \\
\text { Gimbal } \\
\text { beacons) }\end{array}$ & $\begin{array}{l}\text { - Four smartphones worn on the waist lower back, thigh, and } \\
\text { wrist. } \\
\text { - Participants performed } 19 \text { activities in } 45 \text { minutes according } \\
\text { to their own order of choice and repetition. }\end{array}$ & & $\begin{array}{l}\text { - Conditional random field (CRF) } \\
\text { based classification was } \\
\text { performed on each device } \\
\text { separately. } \\
\text { - Final recognition was based on th } \\
\text { device to that particular activity. } \\
\text { - } 19 \text { activities are: walk and run ind } \\
\text { and eat, use - bathroom sink and ref } \\
\text { to/from outdoor, ascending and desc } \\
\text { bed, floor, and, sofa, sit on the bed, }\end{array}$ & $\begin{array}{l}\text { - Activity recognition } \\
\text { accuracy }>80 \% \\
\text { e result from the most relevant } \\
\text { loors, clean utensil, cook, sit } \\
\text { rigerator, move from/to indoor } \\
\text { ending stairs, stand, lie on the - } \\
\text { floor, sofa, and, toilet. }\end{array}$ \\
\hline [136] & $\begin{array}{l}\text { A feature selection } \\
\text { approach for faster } \\
\text { recognition }\end{array}$ & $\begin{array}{l}\text { Samsung } \\
\text { Galaxy S II }\end{array}$ & $a, \omega$ & $\begin{array}{l}\text { - UCI HAR dataset } \\
\text { - Activities are: walking, ascending and descending stairs, } \\
\text { sitting, standing, and laying. }\end{array}$ & 30 & $\begin{array}{l}\text { - Data segmentation by sliding } \\
\text { window and extraction of time } \\
\text { and frequency domain features } \\
\text { - A hybrid of the filter and the } \\
\text { wrapper (FW) methods for } \\
\text { feature selection } \\
\text { - Performance verified by naïve } \\
\text { Bayes and KNN. }\end{array}$ & $\begin{array}{l}\text { - Activity recognition } \\
\text { Accuracy, precision and } \\
\text { F1-score to } 87.8 \%, 88.0 \% \text { and } \\
87.7 \% \text { (with } a, \omega \text { data) } \\
\text { - Significant reduction in } \\
\text { recognition time. }\end{array}$ \\
\hline [137] & $\begin{array}{l}\text { Algorithm for } \\
\text { Human activity } \\
\text { recognition }\end{array}$ & $\begin{array}{l}\text { Google } \\
\text { NEXUS } 4\end{array}$ & $a, \omega$ & $\begin{array}{l}\text { - Subjects performed each activity twice for } 30 \mathrm{~s} \text { each, keeping } \\
\text { the device at five different orientations. }\end{array}$ & 5 & $\begin{array}{l}\text { - Employed coordinate } \\
\text { transformation and principal } \\
\text { component analysis (CT-PCA) on } \\
\text { the data to eliminate the effect of } \\
\text { orientation variation. } \\
\text { - Used several classification } \\
\text { models for evaluation. }\end{array}$ & $\begin{array}{l}\text { - Activity (static, walking, } \\
\text { running, going upstairs, and } \\
\text { going downstairs) recognition } \\
\text { accuracy } 88.74 \% \text { with } \\
\text { online-independent SVM } \\
\text { (OISVM) }\end{array}$ \\
\hline [138] & $\begin{array}{l}\text { A hardware friendly } \\
\text { SVM for HAR }\end{array}$ & $\begin{array}{l}\text { Samsung } \\
\text { Galaxy S II }\end{array}$ & $a, \omega$ & $\begin{array}{l}\text { - UCI HAR dataset } \\
\text { - Activities are: walking, ascending and descending stairs, } \\
\text { sitting, standing, and laying. }\end{array}$ & 30 & $\begin{array}{l}\text { - Standard support vector } \\
\text { machine (SVM) with fixed-point } \\
\text { arithmetic for computational cost } \\
\text { reduction. }\end{array}$ & $\begin{array}{l}\text { Activity recognition accuracy } \\
\text { 89\% (similar to standard } \\
\text { SVM) }\end{array}$ \\
\hline [139] & $\begin{array}{l}\text { Unsupervised } \\
\text { learning for activity } \\
\text { recognition }\end{array}$ & $\begin{array}{l}\text { Samsung } \\
\text { Galaxy Nexus }\end{array}$ & $a, \omega$ & $\begin{array}{l}\text { - Smartphone was kept in a pants pocket for measurements } \\
\text { - } n=5 \text { activities: walking, running, sitting, standing, and lying } \\
\text { down } \\
\text { - Each activity was performed for } 10 \mathrm{~min} \text {. }\end{array}$ & - & $\begin{array}{l}\text { - Experiment 1: known } n \text {. } \\
\text { k-means, Gaussian mixer model, } \\
\text { and average-linkage hierarchical } \\
\text { agglomerative clustering (HIER) } \\
\text { were used for recognition. } \\
\text { - Experiment 2: unknown } n \text {. } \\
\text { Density-based spatial clustering } \\
\text { of applications with noise } \\
\text { (DBSCAN) along with three other } \\
\text { models used for classification. } \\
\text { - DBSCAN requires setting two par } \\
\text { for other models, } n \text { was chosen base } \\
\text { ski-Harabasz index (CH). }\end{array}$ & $\begin{array}{l}\text { - GMM achieved } 100 \% \\
\text { recognition accuracy when } n \\
\text { is known } \\
\text { - HIER and DBSCAN } \\
\text { achieved over } 90 \% \\
\text { recognition accuracy when } n \\
\text { is unknown. } \\
\text { ameters (eps and minPts) and } \\
\text { d on local maxima of the Calin' }\end{array}$ \\
\hline
\end{tabular}


Table 4. Cont.

\begin{tabular}{|c|c|c|c|c|c|c|c|}
\hline Ref. & Proposition & Phone & Sensors & Experiment Protocol & $\mathbf{n}$ & Method & Performance/Comment \\
\hline \multirow[t]{2}{*}{$\begin{array}{l}{[140,} \\
141]\end{array}$} & \multirow[t]{2}{*}{$\begin{array}{l}\text { DNN for Human } \\
\text { activity recognition }\end{array}$} & \multirow[t]{2}{*}{$\begin{array}{l}\text { Samsung } \\
\text { Galaxy S II }\end{array}$} & \multirow[t]{2}{*}{$a, \omega$} & \multirow[t]{2}{*}{$\begin{array}{l}\text { - UCI HAR dataset } \\
\text { - Activities are: walking, ascending and descending stairs, } \\
\text { sitting, standing, and laying. }\end{array}$} & \multirow[t]{2}{*}{30} & \multicolumn{2}{|c|}{$\begin{array}{l}\text { - DNN was formed by stacking several convolutional and pooling } \\
\text { layers to extract discriminative features. }\end{array}$} \\
\hline & & & & & & \multicolumn{2}{|c|}{$\begin{array}{l}\text { - Number of layers, number of feature maps, pooling and } \\
\text { convolutional filter size were adjusted to maximize test-accuracy } \\
\text { by 'softmax' classifier. } \\
\begin{array}{ll}\text { - Multilayer perceptron for final } & \text { - Accuracy: } 94.79 \%-95.75 \% \\
\text { recognition. } & \end{array}\end{array}$} \\
\hline [148] & $\begin{array}{l}\text { Human activity } \\
\text { recognition }\end{array}$ & $\begin{array}{l}\text { Samsung } \\
\text { Galaxy S II and } \\
\text { Huawei P20 } \\
\quad \text { Pro }\end{array}$ & $a, \omega$ & $\begin{array}{l}\text { - Smartphone was attached to the waist. } \\
\text { - Sampling frequency }=50 \mathrm{~Hz} \\
\text { - 10,299 samples with Samsung Galaxy SII and } 4752 \text { samples } \\
\text { with Huawei P20 }\end{array}$ & 30 & $\begin{array}{l}\text { - An Ensemble Extreme learning } \\
\text { machine with Gaussian random } \\
\text { projection (GRP). } \\
\text { - GRP was used for the } \\
\text { initialization of input weights of } \\
\text { base ELMs. }\end{array}$ & $\begin{array}{l}\text { Activity (sitting, standing, } \\
\text { laying, walking, walking } \\
\text { upstairs and downstairs) } \\
\text { recognition accuracies: } \\
97.35 \% \text { (Samsung), } 98.88 \% \\
\text { (Huawei) }\end{array}$ \\
\hline \multirow[t]{3}{*}{ [154] } & \multirow[t]{3}{*}{$\begin{array}{l}\text { Human activity } \\
\text { recognition }\end{array}$} & \multirow{2}{*}{\multicolumn{2}{|c|}{$\begin{array}{l}\text { Samsung Galaxy Note I, } \\
\text { Motorola Droid, }\end{array}$}} & \multirow[t]{3}{*}{$\begin{array}{l}\text { - Collected } 2 \text { weeks of GPS data continuously } \\
\text { - Subjects prepared a journal of real-time information about } \\
\text { their everyday activities. }\end{array}$} & \multirow[t]{3}{*}{3} & $\begin{array}{l}\text { - A fuzzy logic -based approach } \\
\text { for classification. }\end{array}$ & Classification accuracy: $\sim 96 \%$ \\
\hline & & & & & & $\begin{array}{l}\text { - Location uncertainty improved } \mathrm{b} \\
\text { different activities at a single locat }\end{array}$ & $\begin{array}{l}\text { calculating the probabilities of } \\
\text { on. }\end{array}$ \\
\hline & & Nokia N900 & GPS & & & $\begin{array}{l}\text { - Recognized activities by a segm } \\
\text { adjusting for location uncertaintie }\end{array}$ & th aggregation method while \\
\hline [149] & $\begin{array}{l}\text { Human activity } \\
\text { recognition }\end{array}$ & $\begin{array}{l}\text { Samsung } \\
\text { Galaxy S } 4\end{array}$ & $a, \omega$ & $\begin{array}{l}\text { - Free walk at a natural pace and run in a straight path, } \\
\text { maintain a standing position and minimize additional bodily } \\
\text { movement ( } 25 \mathrm{~s} \text { each). }\end{array}$ & 1 & $\begin{array}{l}\text { - Feature set consisted of linear } \\
\text { acceleration, normal acceleration } \\
\text { and angular velocity. } \\
\text { - Naive Bayes and k-means } \\
\text { clustering for classification }\end{array}$ & Classification accuracy: 85\% \\
\hline \multirow[t]{2}{*}{ [150] } & \multirow[t]{2}{*}{$\begin{array}{l}\text { Human activity } \\
\text { recognition }\end{array}$} & & \multirow[t]{2}{*}{$a, w$} & \multirow[t]{2}{*}{$\begin{array}{l}\text { - A database of } 12 \text { activities (standing, sitting, lying down, } \\
\text { walking, ascending and descending stairs, stand-to/from-sit, }\end{array}$} & \multirow[t]{2}{*}{ - } & \multicolumn{2}{|c|}{$\begin{array}{l}\text { - Extracted features were processed by a kernel principal } \\
\text { component analysis (KPCA) and linear discriminant analysis } \\
\text { (LDA). }\end{array}$} \\
\hline & & & & & & $\begin{array}{l}\text { - Deep belief network (DBN) for } \\
\text { classification. }\end{array}$ & $\begin{array}{l}\text { Mean recognition rate: } 89.61 \% \\
\text { and } \\
\text { overall accuracy: } 95.85 \%\end{array}$ \\
\hline
\end{tabular}


Table 4. Cont

\begin{tabular}{|c|c|c|c|c|c|c|c|}
\hline Ref. & Proposition & Phone & Sensors & Experiment Protocol & $\mathbf{n}$ & Method & Performance/Comment \\
\hline [151] & $\begin{array}{l}\text { Human activity } \\
\text { recognition }\end{array}$ & Huawei Mate 9 & $a, \omega$ & $\begin{array}{l}\text { - Activities were logged approximately } 5-8 \text { hours a day for } 4 \\
\text { months }\end{array}$ & 1 & $\begin{array}{l}\text { - A six-layer independently } \\
\text { recurrent neural network } \\
\text { (IndRNN) processed data of } \\
\text { different lengths and captured the } \\
\text { temporal patterns at different } \\
\text { time intervals. }\end{array}$ & Classification accuracy: $\sim 96 \%$ \\
\hline [152] & $\begin{array}{l}\text { Human activity } \\
\text { recognition }\end{array}$ & $\begin{array}{l}\text { Samsung } \\
\text { Galaxy S II }\end{array}$ & $\begin{array}{l}a, \omega, \phi, \\
\text { and P }\end{array}$ & $\begin{array}{l}\text { - UCI HAR dataset } \\
\text { - Activities are: walking, ascending and descending stairs, } \\
\text { sitting, standing, and laying }\end{array}$ & 30 & $\begin{array}{l}\text { - DNN-based subassembly } \\
\text { divides sensor data into various } \\
\text { motion states. The transformation } \\
\text { subassembly derives the intrinsic } \\
\text { correlation between the sensor } \\
\text { data and personal health. }\end{array}$ & $\begin{array}{l}\text { - Accuracy: } 95.9 \% \text { with } \\
\text { unsupervised feature } \\
\text { extraction } \\
\text { • } 96.5 \% \text { with manual feature } \\
\text { extraction }\end{array}$ \\
\hline [153] & $\begin{array}{l}\text { Walk@Work(W@W)-App } \\
\text { for HAR }\end{array}$ & $p$ & $a, \omega$ & $\begin{array}{l}\text { - } 1 \mathrm{~h} \text { laboratory protocol and two continuous hours of } \\
\text { occupational free-living activities }\end{array}$ & $17(10 \mathrm{~F} 7 \mathrm{M})$ & $\begin{array}{l}\text { - Calculated agreement, } \\
\text { intra-class correlation coefficients } \\
\text { (ICC) and mean differences of } \\
\text { sitting time against the } \\
\text { inclinometer ActivPAL3TM, and } \\
\text { step counts against the SW200 } \\
\text { Yamax Digi-Walker pedometer } \\
\text { for performance comparison. }\end{array}$ & $\begin{array}{l}\text { - ICC: } 0.85 \text { for self-paced } \\
\text { walking, } 0.80 \text { for active } \\
\text { working tasks. } \\
\text { - ICC (free-living): } 0.99,0.92 \\
\text { with a difference of } 0.5 \mathrm{~min} \\
\text { and } 18 \text { steps for sitting time } \\
\text { and stepping, respectively. }\end{array}$ \\
\hline [155] & $\begin{array}{l}\text { Human activity } \\
\text { recognition }\end{array}$ & $\begin{array}{l}\text { Samsung } \\
\text { Galaxy S II }\end{array}$ & $a, \omega, \phi$ & $\begin{array}{l}\text { - Four smartphones attached to four body position: right } \\
\text { pocket, belt, right arm, and right wrist } \\
\text { • Measured activities: walking, running, sitting, standing, } \\
\text { walking upstairs and downstairs }\end{array}$ & 4 & $\begin{array}{l}\text { - Data from three types of sensors } \\
\text { were evaluated in terms of } \\
\text { recognition accuracy using seven } \\
\text { classifiers (naïve Bayes, SVM, } \\
\text { neural networks, logistic } \\
\text { regression, KNN, rule-based } \\
\text { classifiers and decision trees). }\end{array}$ & $\begin{array}{l}\text { - Best performance was } \\
\text { achieved using both } \\
\text { gyroscope and accelerometer } \\
\text { data together. } \\
\text { - Magnetometer data played } \\
\text { little role. }\end{array}$ \\
\hline [147] & $\begin{array}{l}\text { Balance analysis and } \\
\text { Audio Bio-Feedback } \\
\text { (ABF) system }\end{array}$ & iPhone 4 & $\begin{array}{l}a, \omega, \phi, \\
\text { mic }\end{array}$ & $\begin{array}{l}\text { - Smartphone was mounted on a belt. } \\
\text { - Subjects wore the belt on the posterior low back at the level of } \\
\text { the L5 vertebra and a pair of earphones, placed arms close to } \\
\text { the trunk, stood barefoot, with their eyes closed. }\end{array}$ & $\begin{array}{l}20(11 \mathrm{~F} \text { and } \\
9 \mathrm{M})\end{array}$ & \multirow{2}{*}{\multicolumn{2}{|c|}{$\begin{array}{l}\text { - Tilt angles and heading were } \\
\text { calculated from accelerometer } \\
\text { and gyroscope, respectively as } \\
\text { well as from the magnetometer. } \\
\text { - Kalman filter was used to correctly estimate the rotation angles } \\
\text { from the difference between the two previous estimates. } \\
\text { - Audio feedback sent through the mic when trunk orientation is } \\
\text { above a threshold. } \\
\text { tions, and } 2 \text { experimental conditions with and without ABF. } \\
\text { r } 30 \mathrm{~s} \text {. }\end{array}$}} \\
\hline & & & & $\begin{array}{l}\text { ubjects kept sway minimum in parallel feet }(10 \mathrm{~cm} \text { apart), } \\
\text { ach experimental condition was performed in random ord }\end{array}$ & & & \\
\hline
\end{tabular}


Table 4. Cont

\begin{tabular}{|c|c|c|c|c|c|c|c|}
\hline Ref. & Proposition & Phone & Sensors & Experiment Protocol & $\mathbf{n}$ & Method & Performance/Comment \\
\hline [144] & $\begin{array}{l}\text { Fall detection and } \\
\text { notification system }\end{array}$ & $\begin{array}{l}\text { Lenovo } \\
\text { Le-phone }\end{array}$ & $a$ & - Smartphone mounted on the waist & - & \multicolumn{2}{|c|}{$\begin{array}{l}\text { - Extracted signal magnitude area (SMA), signal magnitude vector } \\
\text { (SMV) and tilt angle from the median filtered accelerometer data. } \\
\text { • Fall detection with a decision } \\
\text { tree-based algorithm. } \\
\begin{array}{l}\text { - In case of a fall, a multimedia } \quad \text { Performance comparison } \\
\text { messaging service (MMS) was } \\
\text { sent with time and location info. }\end{array}\end{array}$} \\
\hline [145] & Fall detection & $\begin{array}{l}\text { Samsung } \\
\text { Galaxy S III }\end{array}$ & $a$ & - Collected acceleration data & & $\begin{array}{l}\text { - Detected a fall if the } \\
\text { acceleration along a direction } \\
\text { changed at a faster rate than that } \\
\text { in normal daily activities. }\end{array}$ & $\begin{array}{l}\text { - Performance comparison } \\
\text { not reported. }\end{array}$ \\
\hline [157] & $\begin{array}{l}\text { Fall detection, } \\
\text { tracking and } \\
\text { notification system }\end{array}$ & - & $a$ & $\begin{array}{l}\text { - Evaluated the tracking error range at two outdoors and one } \\
\text { indoor fall location. } \\
\text { - Tests conducted near a school and a subway station at three } \\
\text { periods of the day: 7:00-12:00, 12:00-18:00, and 18:00-24:00 to } \\
\text { evaluate the accuracy of tracking with mobile obstacles. }\end{array}$ & 10 & $\begin{array}{l}\text { - Calculated accelerometer SMV. } \\
\text { - Rapid change in the SMV to a } \\
\text { large value indicated a fall. } \\
\text { - In case of a fall detected, the } \\
\text { GPS location of the smartphone is } \\
\text { communicated. } \\
\text { - The real-time location tracking } \\
\text { system used Google's 3D } \\
\text { mapping services. }\end{array}$ & $\begin{array}{l}\text { - Overall accuracy of the } \\
\text { location tracking system: }<9 \\
\text { m. } \\
\text { - Larger error range observed } \\
\text { between 12:00 and 18:00. } \\
\text { - High density of Wi-Fi } \\
\text { installations improves } \\
\text { location accuracy. }\end{array}$ \\
\hline [158] & $\begin{array}{l}\text { Fall detection and } \\
\text { daily activity } \\
\text { recognition }\end{array}$ & $\begin{array}{l}\text { Sony C6002 } \\
\text { Xperia Z, } \\
\text { Apple iPhone } \\
\quad 4 \mathrm{~s}\end{array}$ & $a, \omega, \phi$ & $\begin{array}{l}\text { - Subjects kept phones in the right, left and front-pockets and } \\
\text { fall onto a } 15 \mathrm{~cm} \text { thick cushion. } \\
\text { - Activities: four types of fall (forward, backward, toward the } \\
\text { left and right) and ADL. }\end{array}$ & 8 & $\begin{array}{l}\text { - Activities were classified using } \\
\text { supervised machine learning } \\
\text { (SVM, Decision tree, KNN and } \\
\text { discriminant analysis) algorithms. } \\
\text { - A fall is detected when SMV } \\
\text { goes above a threshold value } \\
\left(24.2 \mathrm{~ms}^{-2}\right) \text {. }\end{array}$ & $\begin{array}{l}\text { - ADL (sitting, standing, } \\
\text { walking, laying, walking } \\
\text { upstairs and walking } \\
\text { downstairs) recognition } \\
\text { accuracy } 99 \% \text { with the SVM. }\end{array}$ \\
\hline [159] & $\begin{array}{l}\text { Fall detection } \\
\text { algorithm }\end{array}$ & Sony Z3 & $a$ & $\begin{array}{l}\text { - Smartphone was placed in the front pocket } \\
\text { - Subjects performed six activities of daily living and six fall } \\
\text { activities }\end{array}$ & $\begin{array}{l}10(7 \mathrm{M} \text { and } \\
3 \mathrm{~F}\end{array}$ & $\begin{array}{l}- \text { Six features (SMV, sum vector exc } \\
\text { and min value of acceleration in gr } \\
\text { the absolute derivation of accelerat } \\
\text { and gravity vector changing angle) } \\
\text { accelerometer data. } \\
\text { - SVM was used to classify fall } \\
\text { and non-fall events. }\end{array}$ & $\begin{array}{l}\text { luding gravity magnitude, max } \\
\text { avity vector direction, mean of } \\
\text { ion in gravity vector direction, } \\
\text { were derived from the } \\
\text { - } 96.67 \% \text { sensitivity, } 95 \% \\
\text { specificity }\end{array}$ \\
\hline [160] & $\begin{array}{l}\text { Fall detection based } \\
\text { on high-level fuzzy } \\
\text { petri net (HLFPN) }\end{array}$ & HTC Desire S & $a$ & $\begin{array}{l}\text { - Smartphone was placed in the thigh pocket } \\
\text { - Activities: Falls (forward, backward, vertical, and sideways) } \\
\text { and ADLs (walking, jogging, jumping, sitting, and squatting). }\end{array}$ & $\begin{array}{l}12(7 \mathrm{~F} \text { and } \\
5 \mathrm{M})\end{array}$ & $\begin{array}{l}\text { - Calculated accelerometer SMV } \\
\text { and frequency of occurrences } \\
\text { from the accelerometer data. } \\
\text { - Fuzzy degree was generated by su } \\
\text { into the membership function form } \\
\text { - Final classification with HLFPN. }\end{array}$ & $\begin{array}{l}\text { - Fall detection accuracy } 90 \% \\
\text { with HLFPN } \\
\text { ubstituting the calculated values } \\
\text { ulated by the experiment. }\end{array}$ \\
\hline [163] & Knee Joint ROM & iPhone 6 & $a$ & $\begin{array}{l}\text { - Dynamic knee extension ROM was measured three times } \\
\text { with an interval of } 5 \text { min. } \\
\text { - Phone was attached to the tibia } \\
\text { - An isokinetic dynamometer used to generate and measure } \\
\text { the knee motion for validation. }\end{array}$ & $21(\mathrm{M})$ & $\begin{array}{l}\text { - A MATLAB program } \\
\text { automatically detected the } \\
\text { min/max values of knee extension } \\
\text { angles from the accelerometer } \\
\text { data. } \\
\text { - The difference between the min } \\
\text { and max values was calculated as } \\
\text { the dynamic knee extension } \\
\text { ROM. }\end{array}$ & $\begin{array}{l}- \text { Highly correlated }\left(r_{s}=\right. \\
0.899) \text { and low error }\left(\sim 0.62^{\circ}\right) \\
\text { wrt the commercial system } \\
\text { (Biodex System } 4 \text { Pro) } \\
\text { - Limits of agreement: }-9.1 \text { to } \\
8.8 \text { deg. } \\
- \text { ICCE between two methods } \\
>0.862\end{array}$ \\
\hline
\end{tabular}


Table 4. Cont

\begin{tabular}{|c|c|c|c|c|c|c|c|}
\hline Ref. & Proposition & Phone & Sensors & Experiment Protocol & $\mathbf{n}$ & Method & Performance/Comment \\
\hline [164] & $\begin{array}{l}\text { Assessment of } \\
\text { smartphone } \\
\text { apps for } \\
\text { measuring }\end{array}$ & - & $\begin{array}{l}\text { Camera, } \\
\text { inclinometer } \\
(a, \omega, \phi)\end{array}$ & $\begin{array}{l}\text { - Five measurements of knee range of motion } \\
\text { from each subject by a commercial system, two } \\
\text { apps - Goniometer Pro and Dr. Goniometer } \\
\text { - Goniometer Pro (by 5fuf5) and Dr. Goniometer } \\
\text { (by CDM S.R.L.) were based on smartphone } \\
\text { inclinometer and camera, respectively. }\end{array}$ & $\begin{array}{c}10 \\
(5 \mathrm{~F} \text { and } \\
5 \mathrm{M})\end{array}$ & $\begin{array}{l}\text { - Goniometer Pro: attached to the } \\
\text { anterior of the thigh proximal to the } \\
\text { skin incision, and on the anterior of } \\
\text { the distal tibia distal to the skin } \\
\text { incision and knee flexion angle }\left(\theta_{F x}\right) \\
\text { was derived by adding the two } \\
\text { measured angles. } \\
\text { - Dr. Goniometer: calculated } \theta_{F x} \text { by tal } \\
\text { the operated knee with markers virtua } \\
\text { trochanter, the knee joint and the ankl }\end{array}$ & $\begin{array}{l}\text { - } \theta_{F x} \text { by Dr. Goniometer was } \\
\text { clinically identical to } \theta_{F x} \text { from the } \\
\text { commercial system, with a mean } \\
\text { difference of }<1^{\circ} \text { and } 1 / 50 \\
\text { difference }>3^{\circ} \\
\text { ing pictures from the lateral side of } \\
\text { ly placed at the level of the greater } \\
\text { joint. }\end{array}$ \\
\hline [165] & $\begin{array}{l}\text { An app Toss } \\
\text { 'N' } \\
\text { Turn (TNT) for } \\
\text { sleep quality } \\
\text { monitoring }\end{array}$ & $\begin{array}{c}\text { Any Android } \\
\text { phone (version } \\
4.0+\text { ) }\end{array}$ & $\begin{array}{l}a, \text { Mic, light } \\
\text { sensor, screen } \\
\text { proximity } \\
\text { sensor }\end{array}$ & $\begin{array}{l}\text { - Subjects installed TNT in the phones and kept } \\
\text { it in the bedroom while sleeping and entered a } \\
\text { daily sleep diary every morning. } \\
\text { - TNT stores sensor data, data about running } \\
\text { processes, battery and display screen state in a } \\
\text { protected database on the phone. }\end{array}$ & $\begin{array}{l}27 \\
(19 \mathrm{~F} \text { and } \\
8 \mathrm{M})\end{array}$ & $\begin{array}{l}\text { - The time-series sensor data were } \\
\text { divided into a series of } \\
\text { non-overlapped } 10 \text { min windows for } \\
\text { data analysis and feature extraction. } \\
\text { - Extracted } 32,122 \text { and } 198 \text { features } \\
\text { associated with sleep detection, daily } \\
\text { sleep quality inference, and global } \\
\text { sleep quality inference, respectively. }\end{array}$ & $\begin{array}{l}\text { - Classification accuracy: } 93.06 \% \\
\text { (Sleep state), } 83.97 \% \text { (daily sleep } \\
\text { quality), } 81.48 \% \text { (overall sleep } \\
\text { quality) }\end{array}$ \\
\hline [166] & $\begin{array}{l}\text { Best effort } \\
\text { sleep (BES) } \\
\text { model for } \\
\text { sleep duration } \\
\text { monitoring }\end{array}$ & & $\begin{array}{l}\text { Light sensor } \\
\text { and Mic } \\
\text { (+ Phone } \\
\text { usage) }\end{array}$ & $\begin{array}{l}\text { - BES tracked six phone usage features (total } \\
\text { duration of phone-lock, phone-off, phone } \\
\text { charging, phone in darkness, phone in a } \\
\text { stationary state and phone in a silent } \\
\text { environment) on a daily basis for one week. }\end{array}$ & 8 & $\begin{array}{l}\text { - Model assumption: Sleep duration } \\
\text { is a weighted linear combination of } \\
\text { six features. } \\
\text { - Weights are estimated using a } \\
\text { non-negative least-squares } \\
\text { regression. }\end{array}$ & $\begin{array}{l}\text { - Sleep duration estimation error } \\
\text { range: } \pm 42 \mathrm{~min} \\
\text { - Estimated duration is close to } \\
\text { commercial wearable systems. }\end{array}$ \\
\hline [167] & $\begin{array}{l}\text { Sleep } \\
\text { monitoring } \\
\text { system }\end{array}$ & iPhone & $a$ & $\begin{array}{l}\text { - Subjects recorded data for at least four } \\
\text { consecutive nights using both the ActiGraph, } \\
\text { attached to the non-dominant wrist and the } \\
\text { smartphone, placed close to the pillow. }\end{array}$ & $\begin{array}{l}13 \\
(4 \mathrm{~F} \text { and } \\
9 \mathrm{M})\end{array}$ & $\begin{array}{l}\text { - Four sleep measures (sleep onset } \\
\text { latency (SOL), total sleep time (TST), } \\
\text { wake after sleep onset (WASO), and } \\
\text { sleep efficiency (SE\%)) are extracted } \\
\text { from both systems. }\end{array}$ & $\begin{array}{l}\text { - Satisfactory agreement with the } \\
\text { ActiGraph for all sleep } \\
\text { parameters except for the SOL. }\end{array}$ \\
\hline [127] & $\begin{array}{l}\text { Contactless } \\
\text { Sleep Apnea } \\
\text { Detection }\end{array}$ & $\begin{array}{l}\text { Samsung } \\
\text { Galaxy S4 }\end{array}$ & $\begin{array}{l}\text { Phone speaker } \\
\text { and } \\
\text { micro-phone }\end{array}$ & $\begin{array}{l}\text { - The speaker transmits } 18-20 \mathrm{kHz} \text { sound waves } \\
\text { and the microphone senses the reflections. } \\
\text { - Total of } 296 \text { hours of measurements } \\
\text { - Polysomnography (simultaneously done EEG, } \\
\text { EMG, airflow, SpO2, electrooculogram) was } \\
\text { conducted for performance comparison. }\end{array}$ & $\begin{array}{l}37 \\
(17 \mathrm{~F} \text { and } \\
20 \mathrm{M})\end{array}$ & $\begin{array}{l}\text { - Employed FMCW (frequency } \\
\text { modulated continuous wave) } \\
\text { transmissions to isolate reflections } \\
\text { arriving at different times. } \\
\text { - Mapped the human body-specific } \\
\text { arrival times of the reflected signals } \\
\text { to carrier frequency shift, allowing } \\
\text { for extracting the amplitude changes } \\
\text { due to breathing. } \\
\text { - Reflection patterns of } \\
\text { non-breathing movements are } \\
\text { different than breathing movements. }\end{array}$ & $\begin{array}{l}\text { - Highly correlated (correlation } \\
\text { coefficient of } 0.9957,0.9860, \text { and } \\
0.9533 \text { for central apnea, } \\
\text { obstructive apnea and hypopnea, } \\
\text { respectively) with the ground } \\
\text { truth } \\
\text { - Average error (rate of apnea and } \\
\text { hypopnea events) < } 1.9 \text { events } / \mathrm{h} \text {. }\end{array}$ \\
\hline
\end{tabular}




\subsection{Hearing Impairment Monitoring Systems}

According to the World Health Organization (WHO), 6.1\% of the world's population including one-third of the adults aged 65 or above suffer from different levels of hearing loss [168]. Moreover, the number of people with disabling hearing impairment is estimated to grow rapidly over the coming years, reaching 630 million by 2030 and over 900 million in 2050 [168]. Hearing impairment at mild to moderate level may cause people to lose $50 \%-70 \%$ of speech in the noisy environment [169-171] and can degrade a person's quality of life, if not corrected [171,172]. Generally, a hearing test is performed by the pure-tone audiometry (PTA) to determine the hearing threshold levels of an individual based on the patients' feedbacks to pure tones stimuli. Therefore, PTA is usually recommended for patients over five years of age i.e., old enough to follow the test procedures [173]. In addition, PTA requires trained personnel, special infrastructure and arrangements to keep the ambient noise levels low during the test and regular maintenance of the systems to ensure high precision and accuracy in the test results $[174,175]$. Consequently, hearing care services are expensive and so are scarce, particularly in developing and lesser-developed countries. Fortunately, smartphone-based hearing assessments applications can provide a low-cost and faster alternative to conventional hearing screening procedures.

In Reference [176], a smartphone application for hearing loss screening called uHear was evaluated in twenty-six subjects aged $84.4 \pm 6.7$ years. The result was compared with respect to that obtained from a standard portable audiometer as well as from the participants' feedback obtained through a questionnaire. For most frequencies, the pure tone thresholds for the uHear application were found to be higher than the audiometric thresholds $(40 \mathrm{~dB})$, which was attributed by the authors to the poor quality of the earbuds, causing leakage of audio signals and penetration of ambient noise to the ear canal. However, $92 \%$ of the test results from the application were found to be in agreement with that obtained from the audiometer, resulting in a screening sensitivity and specificity of $100 \%$ and $60 \%$, respectively. Another such application, HearScreen ${ }^{\mathrm{TM}}$ was investigated in References $[177,178]$ for assessing hearing loss. In Reference [177], the HearScreen ${ }^{\mathrm{TM}}$ application was operated by community health workers (CHW) to perform community-based screening of hearing loss through home visits over a period of 12 weeks. The referral rates by HearScreen ${ }^{\mathrm{TM}}$ were reported to be $12 \%$ and $6.5 \%$ for children (2-15 years) and adults (16-85 years), respectively. Although the authors in Reference [177] reported receiving positive feedbacks from the CHWs about the application in terms of its usability, screening time, and community need, the sensitivity and specificity of the application were not verified. However, the performance of HearScreen ${ }^{\mathrm{TM}}$ was investigated in Reference [178] with respect to a clinical audiometer. There, they investigated HearScreen ${ }^{\mathrm{TM}}$ application to screen for hearing loss among 1,236 participants and validated the test results with clinical pure-tone audiometry. With HearScreen ${ }^{\mathrm{TM}}$, the authors reported achieving high sensitivity $(81.7 \%)$ and specificity $(83.1 \%)$ in screening for hearing loss at an average screening time of around one minute.

A smartphone-based audiometer was presented in Reference [179] that used custom designed hearing aids as the audio source. There, they implemented a program on the smartphone that controlled the hearing aids over a low-power wireless communication medium to generate audio stimuli. The generated audio signals showed a little variation of less than $0.5 \mathrm{~dB}$ hearing level (HL) at all six frequencies $(1 \mathrm{kHz}, 2 \mathrm{kHz}, 4 \mathrm{kHz}, 8 \mathrm{kHz}, 500 \mathrm{~Hz}$ and then $250 \mathrm{~Hz}$ ) compared to the expected values. The system was further tested on twenty subjects with different degrees of hearing loss in a sound-proof environment and verified with respect to a conventional audiometer. While assessing hearing-loss severity at different levels, the proposed system demonstrated little difference $(<6 \mathrm{~dB}$ $\mathrm{HL}$ on average) in the hearing thresholds with respect to the conventional audiometer. Owing to the systems significantly reduced (50\%) screening time, high portability and low cost in comparison to the conventional audiometers, the system can, therefore, be very useful and effective for hearing loss screening at point-of-care diagnostics in rural and urban areas.

A detailed review of some ear and hearing assessment applications was presented in Reference [180]. Only a small subset of all these applications was reported to have been investigated by peer-reviewed studies and the reported performance of these applications in terms of screening 
accuracy, referral rates, sensitivity and specificity varied across the studies. Nevertheless, even though a smartphone based system may not determine the degree of hearing loss as accurately as a conventional audiometer, it may be useful and effective for faster initial screening for hearing loss at home or at primary healthcare centers in the rural and urban areas of developing and least-developed countries.

To assist hearing-impaired people, hearing aids are generally prescribed by the physicians. Hearing aids amplify the audio signals entering the ears, thus improving the audibility of the sound. Smartphone-based hearing aids can allow the users to control the volume and frequency-gain response as per their comfort level, thereby making them a viable alternative to conventional hearing aids. In Reference [181], the feasibility of smartphone applications based hearing aids was studied on a group of people aged between 50 and 90 years with mild-to-moderately severe hearing loss, who had been using hearing aids for less than 3 months. The participants used a conventional hearing aid and two smartphone apps, EARs and microphone, each for 2-3 weeks. While using the smartphone apps they attached an inline microphone to the shirt and in-ear headphones to the phone. From the electroacoustic measurements and speech-in-noise test, the authors observed similar performance among all three devices. However, the authors attributed the differences in the placement of microphones in the hearing aid compared to the smartphone apps for similar speech-in-noise performance. In addition, the participants overall showed greater satisfaction with smartphone applications compared to the hearing aids.

A smartphone-based hearing assistive system was presented in Reference [182] to assist people with mild-to-moderate hearing loss. The application (SmartHear), picks up the speaker's voice by the smartphone's microphone, converts the analog signal to pulse-code-modulated (PCM) digital signals. The PCM signals are then transmitted over the Bluetooth medium to a receiver, which converts the digital signal back to the analog domain and sends the analog signal to the ear through headphones. The authors reported achieving an average improvement in speech intelligibility by 0.2 on a scale of $0-1$ at four different noise levels and across four different audiograms for mild-to-moderate hearing loss. However, unlike the traditional hearing aids, the smartphone's microphone in the proposed architecture resides near the speaker's vicinity, which may not be always feasible for practical use.

\section{Regulatory Policies}

As smartphone-based health monitoring systems and applications are increasing rapidly and becoming more pervasive in society, there is a growing concern about the safety issues and associated potential dangers $[183,184]$. Concerns also remain among many researchers about whether and/or how a regulatory policy would be adopted and enforced by the government bodies such as the US Food and Drug Administration (FDA), and Medicines and Healthcare Products Regulatory Agency (MHRA) in the United Kingdom (UK) $[185,186]$.

Many experts [187-195] have raised questions about the accuracy and reliability of smartphone-based health monitoring applications/systems, the vast majority of which reportedly lacked enough involvement of medical professionals during the design and evaluation phases. For example, in Reference [189], the authors studied and tested a dermatology app called 'Skin Scan', which was found to recognize only $10.8 \%$ images correctly as high-risk melanomas against 93 clinical images from the National Cancer Institute and Fitzpatrick's Dermatology in General Medicine. Furthermore, in January 2017, a team of researchers [196] conducted a search for suitable apps in the iTunes App Store and Google Play that can assist people to deal with anxiety disorders and selected 52 apps for study. They found that $63.5 \%$ (33 out of 52) of the apps were reported as having no information about the intervention approach. In addition, no information related to the manufacturers' professional credentials were available for more than two-thirds (35 out of 52) of the applications. Only two out of the 52 anxiety apps were found to be thoroughly tested by the psychiatrists [196]. Therefore, cautious use of many of these applications was advised in References $[190,192]$ due to their diagnostic inaccuracies and unreliability. Some of them are reported to be unsafe to use $[188,193,194]$ and even may cause life-threating consequences [195]. Hence, adoption and enforcement of some regulatory 
policies were recommended by the experts $[187,191]$ to ensure accountability, data-privacy, information security and patient welfare in terms of safety and diagnostic effectiveness.

Following the FDA's release of a draft guideline for regulating mobile medical apps in 2011, key experts in this industry expressed their expectations regarding the policies for medical apps [197]. These experts urged the FDA to draw a clear demarcation line between the medical apps and the fitness or wellness app, as well as between diagnosing apps and monitoring apps. They recommended for defining the risk-level threshold of regulatory significance for medical apps. They also suggested defining the boundaries of FDA regulations for apps serving as device accessories and making a guideline to deal with the modular applications. In February 2015, the FDA released the latest version of the guidelines defining the categories of smartphone-based healthcare applications that must require regulatory oversight [198]. According to the guideline, FDA will regulate only those medical applications that can turn a smartphone into a medical device such as ophthalmoscopes and dermatoscopes using external and/or internal sensors and devices. Regulatory oversight will also be applied to those applications that can be used as an accessory to the FDA-approved medical devices such as a smartphone-based ECG monitor. In short, regulatory oversight from the FDA is required if any application that can possibly affect the 'performance or functionality' of the FDA-regulated medical devices, and thus may pose a risk to patient safety. However, some mobile applications, although being a medical device by the definition, enjoy "enforcement discretion" as they pose a low risk to patients [198]. Regardless, all high-risk class III devices and about $75 \%$ of medium-risk Class II devices require clinical trials and/or other evidence to demonstrate their safety and compliance with the intended operation [184]. However, if a device demonstrates substantially similar performance to an already approved and legally marketed device (predicate device), it may enjoy an exemption from new clinical trials upon proper evidence that shows the device has same intended use and technological characteristics as the predicate device [199]. In the case when the new device has different technological characteristics in terms of device safety and effectiveness-first, it must not raise any new concerns, and second, it must meet the minimum standards of the predicate device [199]. Nevertheless, there remain serious concerns about safety assurances in the process of device approval based on predicate devices. Therefore, both the Institute of Medicine [200] and the U.S. Congress [201] understandably urged to curtail this approach of device approval. So far, the FDA has approved several healthcare applications developed for the mobile platform [202]. The diagnostic radiology app 'Mobile MIM' is the first such application ever available in iTunes stores [203]. This app allows a healthcare professional to view, assess and securely share images with patients, peers or partner institutions, thus reducing diagnosis and treatment delay. KardiaMobile (AliveCor, Inc.) is another FDA approved device that comes with an application, which can turn a smartphone into a portable single-lead electrocardiogram (ECG) machine [204]. Other FDA approved healthcare apps for smartphones include the iExaminer ${ }^{\mathrm{TM}}$ (Welch Allyn, Inc.) adapter for PanOptic ${ }^{\mathrm{TM}}$ Ophthalmoscope [205], BlueStar ${ }^{\circledR}$ (WellDoc, Inc.) for type 2 diabetes management [206], and ResolutionMD ${ }^{\circledR}$ (PureWeb Inc., Calgary, Canada) for viewing and assessing diagnostic images [207].

In Europe, according to the EU Medical Device Directive MDD 93/42/EEC [208], published on 14 June 1993 and amended in the Directive 2007/47/EC [209], any stand-alone or combination of 'instrument, apparatus, appliance, software, material or other article' intended for healthcare purposes including diagnosis, monitoring, prevention and treatment will be considered be as 'medical device'. Therefore, most smartphone-based healthcare applications including those that monitor and assess cardiovascular health, eye and skin health through imaging, and lung health, will fall under the umbrella of 'medical device' and thus require Conformité Européenne (CE) certification for marketing the product within the European Economic Area (EEA). The CE certification or 'CE marking' ensures the product's conformity with the health, safety, and environmental protection standards set by the EU's harmonization legislation [210]. For example, an Irish app ONCOassist ${ }^{\mathrm{TM}}$ [211] was designed as a decision support tool for professional oncologists at the point-of-care and incorporated prognostic tools, drug interaction checker, survival rate predictors for diseases such as breast cancer, colon cancer, 
and lung cancer. In addition, this app also incorporated some algorithms to determine, for example, liver cirrhosis severity, level of consciousness, the prognostic score for patients with advanced Hodgkin lymphoma and appropriate dosage of chemotherapy agents based on patient's body surface area (BSA) and thereby, was considered as a medical device. ONCOassist ${ }^{\mathrm{TM}}$ received the CE certification in 2013 and displays the CE mark on its welcome screen.

A new medical device regulation (MDR) [212] (EU) 2017/745 was published in the Official Journal of the European Union repealing the MDD 93/42/EEC on 5 May 2017. The new MDR brings previously unregulated non-medical and cosmetic devices under the umbrella of 'medical device', with many of them being reclassified as medium to high risk (such as class IIa, Ilb and III) devices. The other key changes in the MDR over the MDD includes inclusion of medical purpose devices and active implantable medical devices (AIMD), requirements for the manufacturers to update clinical data, technical documentation, and labeling; and generate and provide detailed clinical data to validate safety and performance claims and enforce unique device identification (UDI) for tracking. A wider range of smartphone-based commercial healthcare apps will now be defined as the 'medical devices' according to the MDR that require the manufacturers, and app development companies to revisit their safety and quality control processes to ensure compliance with the new MDR, that is scheduled to be enforced on May 26, 2020. Although these changes are meant to ensure a much safer, transparent and sustainable regulatory framework for the consumer, changeover on such a scale in a limited timeframe is a mammoth task for manufacturers and regulatory bodies to achieve. Furthermore, the scheduled parting of the United Kingdom (UK) from the EU-popularly termed as 'Brexit' —is causing more confusion for the manufactures to this already highly challenging task. It was unclear whether the UK would comply with EU regulations [213]. However, the UK Government, on 4 July 2017, vowed to work closely with the EU in terms of medicines regulation to ensure public health and safety even after leaving the EU [214]. In a recent statement, the UK's Department of Health and Social Care declared that it will comply with the key elements of the MDR and recognize all medical devices approved for the EU market and CE-marked after leaving the EU, in the case a no Brexit deal is reached [215].

Currently, the Medicines and Healthcare Products Regulatory Agency (MHRA) of the UK complies with the existing Medical Device Directive (MDD) and defines any healthcare app or software as a 'medical device' based on the functionality or service it provides to the users and the associated risks in terms of patient's safety [216]. According to the MHRA, an app/software is most likely to be considered as a 'medical device' if it is designed to perform some calculations or run some algorithms on the raw data to detect, diagnose and prevent disease, or to monitor the course of a disease or injury. Apps that are intended for archiving records without modification, providing existing information, and making general recommendations for an expert's advice, can safely be excluded from 'medical devices' category. However, if the decision-support apps perform some calculations or interpret or interpolate the data and do not allow the clinicians to review the raw data, then such apps/software are highly likely to fall into the 'medical device' category. Apps that perform simple and straightforward calculations to track physical fitness such as heart rate, step-count or BMI (body mass index) are not considered as 'medical devices'. However, apps/software that perform complex calculations, for example, to determine medicine doses can potentially fall into the high-risk class III 'medical device' category [217-219]. The MHRA recommends the users to use a CE marked medical purpose app to ensure user safety.

In order to receive a 'CE mark' for the medical purpose apps-a 'medical device' by the MDD 93/42/EEC - the manufacturers need to identify the class of the device based on the perceived risk associated with it and select the corresponding conformity assessment procedure. The conformity assessment procedure ensures tighter control to be applied to the device in case the perceived risks associated with it is higher. Next, the manufacturer prepares a document that generally includes the technical details about the design and manufacturing process of the device as well as the intended operation of the product to demonstrate the product's compliance with the MDD 93/42/EEC. For a low-risk i.e., class I device, the manufacturer can self-declare the device's compliance with the Directive. 
For class IIa devices, manufacturers must also declare the device's compliance with the corresponding regulatory requirements of the Directive. Additionally, class IIa devices as well as class IIb and class III devices must require a notified body (NB) to carry out a detailed conformity assessment and receive a 'Declaration of Conformity' certificate from the NB to submit as an evidence of the app/software's being compliant with the MDD 93/42/EEC [208].

However, it was argued in a report to the U.S. Congress of the Global Legal Research Center that the 'CE mark' on a medical device does not necessarily ensure the quality of the device in terms of its performance and clinical effectiveness, rather it merely shows its compliance with the EU legislation [220]. Medical devices in the EU are approved based on the safety and performance standards, and demonstration of the devices' clinical efficacy is not required by the MDD [184]. However, the new MDR, which is scheduled to be in force in 2020 has put more emphasis on clinical trials and evidence [212]. On the other hand, the US Food and Drug Administration (FDA) requires the devices to ensure not only the safety and performance but also their clinical efficacy [221]. Furthermore, only one organization, the FDA, governs the entire process of device approval in the US. While this ensures better surveillance on the regulatory processes, however, often it turns out to be an expensive, rigid and lengthy process for manufacturers [222]. In contrast, in the EU, the manufacturers can flexibly appoint one of the many EU approved private, for-profit 'notified bodies' to assess and approve the devices in terms of regulatory standards, thus expediting the process for obtaining a 'CE' mark, but this may be, at a potential risk of compromised safety [223,224]. In addition, some 'high-risk medical devices developed, for instance, by an academic institution, can likely be distributed through/among the associated entities for non-commercial use without a CE mark, whereas in the US, prior FDA-approval is an absolute necessity before distribution [225]. However, the approval process of medical devices based on the predicate device and without rigorous new clinical evidence can deter the manufactures to carry out expensive and time-consuming clinical trials, which not only raise concerns in terms of device safety and efficacy but also may lessen the scope of device improvement and innovation [225].

While the US and the EU represent $40 \%$ of the global markets for medical devices [226], other markets such as Canada, Australia, and Japan have their own regulatory bodies to enforce regulatory policies for medical devices. Health Canada, for example, categorizes the medical devices into four classes from Class I to Class IV based on the risks associated with the devices [227]. Prior to marketing a medical device in Canada, the manufactures or the distributors must apply for and receive the Canadian Medical Device License (MDL) for class II, III, and IV devices and the Medical Device Establishment License (MDEL) for class I devices [227]. However, the information required to file an application for Health Canada approval is approximately the same as that required in the US and EU [228]. On the other hand, Australia's Therapeutic Goods Administration (TGA) relies mostly on the EU regulations and CE mark certification from the European NBs before granting approval to market medical devices there [229]. Recently, Australia's TGA decided to begin recognizing registrations and certifications from additional foreign medical device regulators including US FDA, Health Canada, the Japanese Pharmaceutical and Medical Devices Agency (PMDA) [230].

In 2014, the International Medical Device Regulators Forum (IMDRF) launched the Medical Device Single Audit Program (MDSAP) pilot to develop an efficient and standardized global directive to auditing and monitoring medical devices [231]. The regulatory bodies participating in this program include TGA of Australia, Agência Nacional de Vigilância Sanitária (ANVISA) of Brazil, Health Canada, the U.S. FDA, and the Ministry of Health and Labor and Welfare (MHLW) of Japan, while the EU participated as an observer [231]. TGA has recently decided to recognize registrations and certifications from MDSAP auditing organizations [230]. Starting in January 2019, Health Canada also planned to discard the Canadian Medical Device Conformity Assessment System (CMDCAS) and replace it with the MDSAP certification. In fact, Health Canada urged the MDL holders to submit evidence for MDSAP transition from CMDCAS and/or MDSAP certificates by the 31st December 2018 [232]. 


\section{Conclusions and Research Challenges}

In this paper, we have presented a state-of-the-art survey on health and activity monitoring systems that exploit the embedded sensors in smartphones for measuring physiological parameters and tracking health conditions. The ubiquity of smartphones has grown enormously in the past decade. In addition, the significant advances in sensor technologies in terms of size, cost, energy requirements and sensitivity has enabled the integration of a number of sensors into present-day smartphones. The embedded sensors in smartphones such as the image sensor, microphone, ambient light sensor and motion sensors coupled with modern high-speed data transfer technologies may assist people to lead an independent and active life while ensuring non-invasive monitoring of their health and physical well-being in a regular fashion without adding much to their personal expenses.

Monitoring the health of the heart, eye, respiratory systems and skin, as well as the activities of daily living (ADL) and mental conditions in a continual fashion, can provide detailed information about an individual's overall health and wellbeing over a prolonged period of time. The smartphone and its embedded sensors coupled with present-day information and communications technologies have opened a new window of opportunity for cost-effective remote healthcare services. The raw medical data thus obtained by the smartphone sensors can be sent over the internet to a remote healthcare facility for detailed investigation. Furthermore, the incredible improvements in the processing and data storage capabilities in the modern-day smartphones may allow for faster, real-time and onboard execution of complex predictive algorithms and/or artificial intelligence (AI) technologies using the high-volume of raw data measured by the smartphone sensors. Thus, smartphones may play an incredible role in enabling a low-cost solution for early diagnosis through continuous monitoring, initial screening of diseases such as melanoma, and diabetic retinopathy and remote monitoring of the progression of some diseases.

Owing to the high market penetration and ever-increasing computational capabilities of smartphones, there have been growing interests among the researchers and the manufacturers in building smartphone-based devices for healthcare and wellness purposes. However, there remain some key challenges that need to be addressed prior to achieving a global acceptance of smartphones as medical devices.

First, most of the works reported in the literature are based-on nonrandomized, non-blinded studies on a limited number of subjects using a proof-of-concept device. Further, the limited size and possible bias in the samples implies that the universal efficacy of the devices is still a critical concern. Therefore, rigorous clinical trials are required to evaluate the safety and efficacy of the proposed smartphone-based 'medical' devices.

Second, although major regulatory bodies have their own guidelines for a medical app to be considered as a 'medical device', the boundaries between the fitness and wellness apps and the medical apps remain ambiguous, particularly in a situation when the self-monitoring thorough a fitness app is integrated within the patient care and treatment scheme. These blurred boundaries need to be resolved to safeguard the users from possible harmful consequences.

Third, unlike the US Food and Drug Administration (FDA), the intermediate- and high-risk devices in the EU require an authorized private and for-profit third-party organization called the 'Notified Body' (NB) to assess and certify the device's compliance with the corresponding directive. Although this process offers more flexibility to the manufacturers and reduces unnecessary delay in the approval process, it is, however, subject to the risk of compromised safety owing to varying standards, pricing and work ethics of different NBs.

Fourth, approving a medical device based on a predicate may cause safety concerns and was therefore criticized by some experts. It was argued that some predicates were in the market even before any regulatory policies were implemented. Some predicate devices were never tested on humans and some were even recalled voluntarily from the market due to their poor performance, thus questioning the credibility of the predicate itself. In addition, this process of device approval encourages the 
manufacturers to evade the expensive and time-consuming but critical clinical trials before bringing the product in the market.

Fifth, among the abundant number of healthcare and wellness apps published to-date, the user is often left perplexed in finding and using the most appropriate and safe one, specific to his/her needs. A centralized database or a dedicated app store of approved medical apps can be of immense benefit for both product developers and consumers. The centralized system, similar to other app stores, can serve as a common platform for both the users and the developers. It can also review and recommend the apps based on the quality, reliability, medical effectiveness, safety, privacy and value-for-money.

Sixth, in order to ensure widespread acceptance of the smartphone-based health monitoring devices/apps among the users, these devices/apps need to be affordable, easy-to-use, and compatible with the most mobile operating systems as well as smartphones from different manufacturers. Therefore, more research and development efforts are needed to improve the systems' ease-of-use and pervasiveness.

Seventh, one of the major concerns for smartphone-based healthcare systems is associated with the privacy and security of any sensitive medical information. However, to date, most publications either did not address these critical issues or did so in a cursory manner. Therefore, more efforts are needed to develop and implement robust algorithms to ensure data privacy and information security.

Author Contributions: S.M. and M.J.D. collaborated on the research for various aspects of the paper. S.M. and M.J.D. prepared the preliminary draft of the manuscript. M.J.D. directed the research and did the final revisions. All authors carefully reviewed the final manuscript.

Funding: This research work was partially funded by grants from the Natural Sciences and Engineering Council (NSERC) of Canada, the Canada Research Chair (CRC) program and a Catalyst grant from McMaster Institute for Research on Aging (MIRA) \& Labarge Centre for Mobility in Aging.

Conflicts of Interest: The authors declare no conflict of interest.

\section{References}

1. Thomas, V.S.; Darvesh, S.; Macknight, C.; Rockwood, K. Estimating the Prevalence of Dementia in Elderly People: A Comparison of the Canadian Study of Health and Aging and National Population Health Survey Approaches. Int. Psychogeriatr. 2001, 13, 169-175. [CrossRef]

2. Kalache, A.; Gatti, A. Active Ageing: A Policy Framework. Adv. Gerontol. Uspekhi Gerontol. Akad. Nauk. Gerontol. Obs. 2002, 11, 7-18.

3. World Health Organization. Are You Ready? What You Need to Know About Ageing. 27 March 2012. Available online: http://www.who.int/world-health-day/2012/toolkit/background/en/ (accessed on 3 January 2019).

4. Kulik, C.T.; Ryan, S.; Harper, S.; George, G. Aging populations and management. Acad. Manag. J. 2014, 57, 929-935. [CrossRef]

5. World Health Organization. Disability and Health. Available online: https://www.who.int/en/news-room/ fact-sheets/detail/disability-and-health (accessed on 3 January 2019).

6. Centers for Disease Control and Prevention. About Chronic Diseases. 19 November 2018. Available online: https://www.cdc.gov/chronicdisease/about/index.htm (accessed on 3 January 2019).

7. Majumder, S.; Aghayi, E.; Noferesti, M.; Memarzadeh-Tehran, H.; Mondal, T.; Pang, Z.; Deen, M.J. Smart Homes for Elderly Healthcare-Recent Advances and Research Challenges. Sensors 2017, 17, 2496. [CrossRef] [PubMed]

8. “National Center for Health Statistics," Centers for Disease Control and Prevention. 3 May 2017. Available online: https://www.cdc.gov/nchs/fastats/deaths.htm (accessed on 3 January 2019).

9. Mathers, C.D.; Loncar, D. Projections of Global Mortality and Burden of Disease from 2002 to 2030. PLoS Med. 2006, 3, e442. [CrossRef]

10. World Health Organization. Priority Eye Diseases. 18 April 2018. Available online: https://www.who.int/ blindness/causes/priority/en/index5.html (accessed on 3 January 2019).

11. World Health Organization. Global Data on Visual Impairments 2010. Available online: https://www.who. int/blindness/GLOBALDATAFINALforweb.pdf (accessed on 3 January 2019). 
12. World Health Organization. Asthma. Available online: http://www.who.int/mediacentre/factsheets/fs307/en/ (accessed on 3 January 2019).

13. 2017 Budget in Brief: Strengthening Health Care. ontario.ca. Available online: https://www.ontario.ca/page/ 2017-budget-brief-strengthening-health-care (accessed on 3 January 2019).

14. CIHI. National Health Expenditure Trends, 1975 to 2018. 20 December 2018. Available online: https: //www.cihi.ca/en/health-spending/2018/national-health-expenditure-trends (accessed on 12 March 2019).

15. Venkat, R. Global Outlook of the Healthcare Industry. In Advances in Information and Communication; Frost \& Sullivan: San Antonio, TX, USA, 2015.

16. Population Ageing Projections. Helping Older People Live Full and Secure Lives. Available online: http://www.helpage.org/global-agewatch/populationageing-data/population-ageing-projections/ (accessed on 3 January 2019).

17. The Globe and Mail. Canada Ranks Fifth in Well-Being of Elderly: Study. 11 May 2018. Available online: https://www.theglobeandmail.com/life/health-and-fitness/health/canada-ranks-fifth-in-well-beingof-elders-study/article14621721/ (accessed on 3 January 2019).

18. Canadian Institute for Health Information. National Health Expenditure Trends, 1975 to 2014. Available online: https://www.cihi.ca/en/nhex_2014_report_en.pdf (accessed on 3 January 2019).

19. Working-Age Shift. The Economist. 26 January 2013. Available online: https://www.economist.com/financeand-economics/2013/01/26/working-age-shift (accessed on 3 January 2019).

20. Anderson, G.; Knickman, J.R. Changing the Chronic Care System To Meet People's Needs. Heal. Aff. 2001, 20, 146-160. [CrossRef]

21. Advantages \& Disadvantages of Nursing Homes. AmeriGlide Stair lifts and Vertical Platform lifts. Available online: http://www.ameriglide.com/advantages-disadvantages-nursing-homes.htm (accessed on 3 January 2019).

22. Majumder, S.; Mondal, T.; Deen, M.J. Wearable Sensors for Remote Health Monitoring. Sensors 2017, 17, 130. [CrossRef] [PubMed]

23. Deen, M.J. Information and communications technologies for elderly ubiquitous healthcare in a smart home. Pers. Ubiquitous Comput. 2015, 19, 573-599. [CrossRef]

24. Agoulmine, N.; Deen, M.J.; Lee, J.S.; Meyyappan, M. U-Health Smart Home: Innovative solutions for the management of the elderly and chronic diseases. IEEE Nanotechnol. Mag. 2011, 5, 6-11. [CrossRef]

25. National Center for Chronic Disease Prevention and Health Promotion / CDC. Centers for Disease Control and Prevention. 19 December 2018. Available online: https://www.cdc.gov/chronicdisease/ (accessed on 3 January 2019).

26. Takei, K.; Honda, W.; Harada, S.; Arie, T.; Akita, S. Toward flexible and wearable human-interactive health-monitoring devices. Adv. Healthc. Mater. 2015, 4, 487-500. [CrossRef] [PubMed]

27. Pantelopoulos, A.; Bourbakis, N. A Survey on Wearable Sensor-Based Systems for Health Monitoring and Prognosis. IEEE Trans. Syst. Man Cybern. Part C Appl. Rev. 2010, 40, 1-12. [CrossRef]

28. Kooistra, J. Newzoo's 2018 Global Mobile Market Report: Insights into the World's 3 Billion Smartphone Users. Newzoo. 11 September 2018. Available online: https://newzoo.com/insights/articles/newzoos-2018-globalmobile-market-report-insights-into-the-worlds-3-billion-smartphone-users/ (accessed on 3 January 2019).

29. Tweedie, S. The World's First Smartphone, Simon, Was Created 15 Years Before the iPhone. Business Insider. 14 June 2015. Available online: https://www.businessinsider.com/worlds-first-smartphone-simon-launchedbefore-iphone-2015-6 (accessed on 4 January 2019).

30. The Evolution of the Mobile Phone, from the Motorola DynaTAC to the Samsung Galaxy S9. The Telegraph. 23 February 2018. Available online: https://www.telegraph.co.uk/technology/0/evolution-mobile-phonepictures/ (accessed on 4 January 2019).

31. Woyke, E. The Smartphone: Anatomy of an Industry. The New Press: New York, NY, USA, 2015.

32. Sager, I. Before IPhone and Android Came Simon, the First Smartphone. Bloomberg.com. 29 June 2012. Available online: https://www.bloomberg.com/news/articles/2012-06-29/before-iphone-and-android-camesimon-the-first-smartphone (accessed on 4 January 2019).

33. Vaishnav, S.; Stevenson, R.; Marchant, B.; Lagi, K.; Ranjadayalan, K.; Timmis, A.D. Relation between heart rate variability early after acute myocardial infarction and long-term mortality. Am. J. Cardiol. 1994, 73, 653-657. [CrossRef]

34. Nemati, E.; Deen, M.; Mondal, T. A wireless wearable ECG sensor for long-term applications. IEEE Commun. Mag. 2012, 50, 36-43. [CrossRef] 
35. Rolfe, P. In Vivo Near-Infrared Spectroscopy. Annu. Rev. Biomed. Eng. 2000, 2, 715-754. [CrossRef]

36. Siddiqui, S.A.; Zhang, Y.; Feng, Z.; Kos, A. A Pulse Rate Estimation Algorithm Using PPG and Smartphone Camera. J. Med Syst. 2016, 40, 126. [CrossRef]

37. Bánhalmi, A.; Borbás, J.; Fidrich, M.; Bilicki, V.; Gingl, Z.; Rudas, L. Analysis of a Pulse Rate Variability Measurement Using a Smartphone Camera. J. Healthc. Eng. 2018, 2018, 4038034. [CrossRef]

38. Nam, Y.; Kong, Y.; Reyes, B.; Reljin, N.; Chon, K.H. Monitoring of Heart and Breathing Rates Using Dual Cameras on a Smartphone. PLoS One 2016, 11, 0151013. [CrossRef]

39. Koenig, N.; Seeck, A.; Eckstein, J.; Mainka, A.; Huebner, T.; Voss, A.; Weber, S. Validation of a New Heart Rate Measurement Algorithm for Fingertip Recording of Video Signals with Smartphones. Telemed. e-Health 2016, 22, 631-636. [CrossRef]

40. Matsumura, K.; Rolfe, P.; Lee, J.; Yamakoshi, T. iPhone 4s Photoplethysmography: Which Light Color Yields the Most Accurate Heart Rate and Normalized Pulse Volume Using the iPhysioMeter Application in the Presence of Motion Artifact? PLoS ONE 2014, 9. [CrossRef]

41. Lavanya, M.P. Real Time Motion Detection Using Background Subtraction Method and Frame Difference. Int. J. Sci. Res. 2014, 3, 1857-1861.

42. Singla, N. Motion Detection Based on Frame Difference Method. Int. J. Inf. Comput. Technol. 2014, 4, 1559-1565.

43. Warren, S.; Krishnan, R.; Natarajan, B. Two-Stage Approach for Detection and Reduction of Motion Artifacts in Photoplethysmographic Data. IEEE Trans. Biomed. Eng. 2010, 57, 1867-1876.

44. Lamonaca, F.; Kurylyak, Y.; Grimaldi, D.; Spagnuolo, V. Reliable pulse rate evaluation by smartphone. In Proceedings of the 2012 IEEE International Symposium on Medical Measurements and Applications, Budapest, Hungary, 18-19 May 2012.

45. Kwon, S.; Kim, H.; Park, K.S. Validation of heart rate extraction using video imaging on a built-in camera system of a smartphone. In Proceedings of the 2012 Annual International Conference of the IEEE Engineering in Medicine and Biology Society, San Diego, CA, USA, 28 August-1 September 2012.

46. Poh, M.-Z.; McDuff, D.J.; Picard, R.W. Non-contact, automated cardiac pulse measurements using video imaging and blind source separation. Opt. Express 2010, 18, 10762. [CrossRef]

47. Verkruysse, W.; Svaasand, L.O.; Nelson, J.S. Remote plethysmographic imaging using ambient light. Opt. Express 2008, 16, 21434. [CrossRef]

48. Papin, C.; Greenwald, S.; Hu, S.; Sun, Y.; Azorin-Peris, V.; Kalawsky, R. Use of ambient light in remote photoplethysmographic systems: Comparison between a high-performance camera and a low-cost webcam. J. Biomed. Opt. 2012, 17, 37005.

49. Sanyal, S.; Nundy, K.K. Algorithms for Monitoring Heart Rate and Respiratory Rate from the Video of a User's Face. IEEE J. Transl. Eng. Heal. Med. 2018, 6, 1-11. [CrossRef]

50. Guede-Fernandez, F.; Ferrer-Mileo, V.; Ramos-Castro, J.; Fernandez-Chimeno, M.; Garcia-Gonzalez, M. Real time heart rate variability assessment from Android smartphone camera photoplethysmography: Postural and device influences. In Proceedings of the 2015 37th Annual International Conference of the IEEE Engineering in Medicine and Biology Society (EMBC), Milan, Italy, 25-29 August 2015; pp. 7332-7335.

51. Lagido, R.; Lobo, J.; Leite, S.; Sousa, C.; Ferreira, L.; Silva-Cardoso, J. Using the smartphone camera to monitor heart rate and rhythm in heart failure patients. In Proceedings of the IEEE-EMBS International Conference on Biomedical and Health Informatics (BHI), Valencia, Spain, 1-4 June 2014; pp. 556-559.

52. Bolkhovsky, J.B.; Scully, C.G.; Chon, K.H. Statistical analysis of heart rate and heart rate variability monitoring through the use of smart phone cameras. In Proceedings of the 2012 Annual International Conference of the IEEE Engineering in Medicine and Biology Society, San Diego, CA, USA, 28 August-1 September 2012; pp. 1610-1613.

53. Gregoski, M.J.; Mueller, M.; Vertegel, A.; Shaporev, A.; Jackson, B.B.; Frenzel, R.M.; Sprehn, S.M.; Treiber, F.A. Development and Validation of a Smartphone Heart Rate Acquisition Application for Health Promotion and Wellness Telehealth Applications. Int. J. Telemed. Appl. 2012, 2012, 1-7. [CrossRef] [PubMed]

54. Vidal, J. Air Pollution Rising at an 'Alarming Rate' in World's Cities. The Guardian. 12 May 2016. Available online: https://www.theguardian.com/environment/2016/may/12/air-pollution-rising-at-an-alarming-ratein-worlds-cities (accessed on 21 March 2019).

55. World Health Organization. Cancer. Available online: https://www.who.int/news-room/fact-sheets/detail/ cancer (accessed on 21 March 2019). 
56. Stafford, M.; Lin, F.; Xu, W. Flappy Breath: A Smartphone-Based Breath Exergame. In Proceedings of the 2016 IEEE First International Conference on Connected Health: Applications, Systems and Engineering Technologies (CHASE), Washington, DC, USA, 27-29 June 2016; pp. 332-333.

57. Larson, E.C.; Lee, T.; Liu, S.; Rosenfeld, M.; Patel, S.N. Accurate and privacy preserving cough sensing using a low-cost microphone. In Proceedings of the 13th International Conference on Ubiquitous Computing, Beijing, China, 17-21 September 2011; p. 375.

58. Chen, N.-C.; Wang, K.-C.; Chu, H.-H. Listen-to-nose: A low-cost system to record nasal symptoms in daily life. In Proceedings of the 2012 ACM Conference on Ubiquitous Computing, Pittsburgh, PA, USA, 5-8 September 2012; pp. 590-591.

59. Larson, E.C.; Goel, M.; Boriello, G.; Heltshe, S.; Rosenfeld, M.; Patel, S.N. SpiroSmart: Using a microphone to measure lung function on a mobile phone. In Proceedings of the 2012 ACM Conference Ubiquitous Comput.-UbiComp '12, Pittsburgh, PA, USA, 5-8 September 2012; pp. 280-289.

60. Larson, E.C.; Goel, M.; Redfield, M.; Boriello, G.; Rosenfeld, M.; Patel, S.N. Tracking lung function on any phone. In Proceedings of the 3rd ACM Symposium on Computing for Development, Bangalore, India, 11-12 January 2013; p. 29.

61. Goel, M.; Saba, E.; Stiber, M.; Whitemire, E.; Fromm, J.; Larson, E.C.; Borriello, G.; Patel, S.N. SpiroCall: Measuring Lung Function over a Phone Call. In Proceedings of the 2016 CHI Conference on Human Factors in Computing Systems, San Jose, CA, USA, 7-12 May 2016; pp. 5675-5685.

62. Thap, T.; Chung, H.; Jeong, C.; Hwang, K.-E.; Kim, H.-R.; Yoon, K.-H.; Lee, J.; Chon, K.H. High-Resolution Time-Frequency Spectrum-Based Lung Function Test from a Smartphone Microphone. Sensors 2016, 16, 1305. [CrossRef]

63. Szanto, Z.; Benko, I.; Jakab, L.; Szalai, G.; Vereczkei, A. The use of a smartphone application for fast lung cancer risk assessmentt. Eur. J. Cardio-Thoracic Surg. 2017, 51, 1171-1176. [CrossRef]

64. Szanto, Z.; Szalai, G.; Jakab, L.; Vereczkei, A. P1.03-034 Implementing Smartphone Application in Early Lung Cancer Detection and Screening. J. Thorac. Oncol. 2017, 12, S562-S563. [CrossRef]

65. Early Treatment Diabetic Retinopathy Study Research Group. Grading Diabetic Retinopathy from Stereoscopic Color Fundus Photographs-An Extension of the Modified Airlie House Classification: ETDRS Report Number 10. Ophthalmology 1991, 98, 786-806. [CrossRef]

66. Lawrence, M.G. The accuracy of digital-video retinal imaging to screen for diabetic retinopathy: an analysis of two digital-video retinal imaging systems using standard stereoscopic seven-field photography and dilated clinical examination as reference standards. Trans. Am. Ophthalmol. Soc. 2004, 102, 321-340.

67. Williams, G.A.; Scott, I.U.; Haller, J.A.; Maguire, A.M.; Marcus, D.; McDonald, H.R. Single-field fundus photography for diabetic retinopathy screening: A report by the American Academy of Ophthalmology. Ophthalmology 2004, 111, 1055-1062. [CrossRef]

68. Toy, B.C.; Myung, D.J.; He, L.; Pan, C.K.; Chang, R.T.; Polkinhorne, A.; Merrell, D.; Foster, D.; Blumenkranz, M.S. Smartphone-Based Dilated Fundus Photography and Near Visual Acuity Testing as Inexpensive Screening Tools to Detect Referral Warranted Diabetic Eye Disease. Retina 2016, 36, 1000-1008. [CrossRef]

69. Lord, R.K.; Shah, V.A.; Filippo, A.N.S.; Krishna, R. Novel Uses of Smartphones in Ophthalmology. Ophthalmology 2010, 117, 1274-1274.e3. [CrossRef]

70. Strauss, R.W.; Krieglstein, T.R.; Priglinger, S.G.; Reiß, W.; Ulbig, M.W.; Kampik, A.; Neubauer, A.S. Image quality characteristics of a novel colour scanning digital ophthalmoscope (SDO) compared with fundus photography. Ophthalmic Physiol. Opt. 2007, 27, 611-618. [CrossRef]

71. Bastawrous, A. Smartphone fundoscopy. Ophthalmology 2012, 119, 432-433. [CrossRef] [PubMed]

72. Haddock, L.J.; Kim, D.Y.; Mukai, S. Simple, Inexpensive Technique for High-Quality Smartphone Fundus Photography in Human and Animal Eyes. J. Ophthalmol. 2013, 2013, 1-5. [CrossRef]

73. Myung, D.; Jais, A.; He, L.; Blumenkranz, M.S.; Chang, R.T. 3D Printed Smartphone Indirect Lens Adapter for Rapid, High Quality Retinal Imaging. J. Mob. Technol. Med. 2014, 3, 9-15. [CrossRef]

74. Sharma, A.; Subramaniam, S.D.; Ramachandran, K.I.; Lakshmikanthan, C.; Krishna, S.; Sundaramoorthy, S.K. Smartphone-based fundus camera device (MII Ret Cam) and technique with ability to image peripheral retina. Eur. J. Ophthalmol. 2015, 26, 142-144. [CrossRef]

75. Maamari, R.N.; Keenan, J.D.; Fletcher, D.A.; Margolis, T.P. A mobile phone-based retinal camera for portable wide field imaging. Br. J. Ophthalmol. 2014, 98, 438-441. [CrossRef] [PubMed] 
76. Russo, A.; Morescalchi, F.; Costagliola, C.; Delcassi, L.; Semeraro, F. A Novel Device to Exploit the Smartphone Camera for Fundus Photography. J. Ophthalmol. 2015, 2015, 1-5. [CrossRef] [PubMed]

77. Russo, A.; Morescalchi, F.; Costagliola, C.; Delcassi, L.; Semeraro, F. Comparison of Smartphone Ophthalmoscopy with Slit-Lamp Biomicroscopy for Grading Diabetic Retinopathy. Am. J. Ophthalmol. 2015, 159, 360-364.e1. [CrossRef] [PubMed]

78. Giardini, M.; Livingstone, I.; Bolster, N.; Jordan, S.; Bastawrous, A. Phone-based ophthalmoscopy for Peek, the Portable Eye Examination Kit. Eng. Med. Biol. Soc. (EMBC) 2014, 96, 2014.

79. Bastawrous, A. Increasing access to eye care ... there's an app for that. Peek: Smartphone technology for eye health. Int. J. Epidemiol. 2016, 45, 1040-1043. [CrossRef]

80. Eysenbach, G.; Sawesi, S.; Jones, J.; Sheets, L.; Lodhia, V.; Karanja, S.; Lees, S.; Bastawrous, A. Acceptability, Usability, and Views on Deployment of Peek, a Mobile Phone mHealth Intervention for Eye Care in Kenya: Qualitative Study. JMIR mHealth uHealth 2016, 4, e30.

81. Rono, H.K.; Bastawrous, A.; MacLeod, D.; Wanjala, E.; Di Tanna, G.L.; A Weiss, H.; Burton, M.J. Smartphone-based screening for visual impairment in Kenyan school children: A cluster randomised controlled trial. Lancet Glob. Health 2018, 6, e924-e932. [CrossRef]

82. Pasolini, A. Smartphone-Based Kit Makes Eye Tests Cheap and Portable. Newatlas.com. 2013. Available online: https://newatlas.com/peek-eye-testing-smartphone/28764/ (accessed on 9 May 2019).

83. American Cancer Society. Key Statistics for Melanoma Skin Cancer. Available online: https://www.cancer. org/cancer/melanoma-skin-cancer/about/key-statistics.html (accessed on 6 January 2019).

84. Employment and Benefits|American Academy of Dermatology. New Study Shows Significant Economic Burden of Skin Disease in the United States. 1 March 2017. Available online: https://www.aad.org/media/ news-releases/burden-of-skin-disease (accessed on 6 January 2019).

85. Hubiche, T.; Valério, L.; Boralevi, F.; Mahe, E.; Skandalis, C.B.; Phan, A.; del Giudice, P. for the Research Group of the French Society of Pediatric Dermatology (Groupe de Recherche de la Société Française de Dermatologie Pédiatrique) Visualization of patients' skin lesions on their smartphones: A newstep during dermatology visits. JAMA Dermatol. 2016, 152, 95-97. [CrossRef]

86. Börve, A.; Gyllencreutz, J.; Terstappen, K.; Backman, E.; Aldenbratt, A.; Danielsson, M.; Gillstedt, M.; Sandberg, C.; Paoli, J. Smartphone Teledermoscopy Referrals: A Novel Process for Improved Triage of Skin Cancer Patients. Acta Derm. Venereol. 2015, 95, 186-190. [CrossRef]

87. Friedman, R.J.; Rigel, D.S.; Kopf, A.W. Early Detection of Malignant Melanoma: The Role of Physician Examination and Self-Examination of the Skin. CA Cancer. J. Clin. 1985, 35, 130-151. [CrossRef]

88. Wadhawan, T.; Situ, N.; Lancaster, K.; Yuan, X.; Zouridakis, G. SkinScan@): A Portable Library for Melanoma Detection on Handheld Devices. In Proceedings of the 2011 IEEE International Symposium on Biomedical Imaging: From Nano to Macro, Chicago, IL, USA, 30 March-2 April 2011; pp. 133-136.

89. Vo-Dinh, T.; Cullum, B.; Kasili, P. Development of a multi-spectral imaging system for medical applications. J. Phys. D Appl. Phys. 2003, 36, 1663-1668. [CrossRef]

90. Kim, S.; Cho, D.; Kim, J.; Kim, M.; Youn, S.; Jang, J.E.; Je, M.; Lee, D.H.; Lee, B.; Farkas, D.L.; Hwang, J.Y. Smartphone-based multispectral imaging: system development and potential for mobile skin diagnosis. Biomed. Opt. Express 2016, 7, 5294-5307. [CrossRef] [PubMed]

91. Li, Q.; He, X.; Wang, Y.; Liu, H.; Xu, D.; Guo, F. Review of spectral imaging technology in biomedical engineering: Achievements and challenges. J. Biomed. Opt. 2013, 18, 100901. [CrossRef]

92. Kapsokalyvas, D.; Cicchi, R.; Bruscino, N.; Alfieri, D.; Prignano, F.; Massi, D.; Lotti, T.; Pavone, F.S. In-vivo imaging of psoriatic lesions with polarization multispectral dermoscopy and multiphoton microscopy. Biomed. Opt. Express 2014, 5, 2405-2419. [CrossRef] [PubMed]

93. Elbaum, M.; Kopf, A.W.; Rabinovitz, H.S.; Langley, R.G.; Kamino, H.; Mihm, M.C.; Sober, A.J.; Peck, G.L.; Bogdan, A.; Gutkowicz-Krusin, D.; et al. Automatic differentiation of melanoma from melanocytic nevi with multispectral digital dermoscopy: A feasibility study. J. Am. Acad. Dermatol. 2001, 44, 207-218. [CrossRef] [PubMed]

94. Fujii, H.; Yanagisawa, T.; Mitsui, M.; Murakami, Y.; Yamaguchi, M.; Ohyama, N.; Abe, T.; Yokoi, I.; Matsuoka, Y.; Kubota, Y. Extraction of acne lesion in acne patients from multispectral images. In Proceedings of the 2008 30th Annual International Conference of the IEEE Engineering in Medicine and Biology Society, Vancouver, BC, Canada, 20-25 August 2008; pp. 4078-4081. 
95. Kuzmina, I.; Lacis, M.; Spigulis, J.; Berzina, A.; Valeine, L. Study of smartphone suitability for mapping of skin chromophores. J. Biomed. Opt. 2015, 20, 90503. [CrossRef] [PubMed]

96. Groner, W.; Winkelman, J.W.; Harris, A.G.; Ince, C.; Bouma, G.J.; Messmer, K.; Nadeau, R.G. Orthogonal polarization spectral imaging: A new method for study of the microcirculation. Nat. Med. 1999, 5, 1209-1212. [CrossRef] [PubMed]

97. Freeman, E.E.; Semeere, A.; Osman, H.; Peterson, G.; Rajadhyaksha, M.; González, S.; Martin, J.N.; Anderson, R.R.; Tearney, G.J.; Kang, D. Smartphone confocal microscopy for imaging cellular structures in human skin in vivo. Biomed. Opt. Express 2018, 9, 1906-1915. [CrossRef]

98. Kim, S.; Crose, M.; Eldridge, W.J.; Cox, B.; Brown, W.J.; Wax, A. Design and implementation of a low-cost, portable OCT system. Biomed. Opt. Express 2018, 9, 1232-1243. [CrossRef] [PubMed]

99. Karargyris, A.; Karargyris, O.; Pantelopoulos, A. DERMA/Care: An Advanced image-Processing Mobile Application for Monitoring Skin Cancer. In Proceedings of the 2012 IEEE 24th International Conference on Tools with Artificial Intelligence (ICTAI 2012), Athens, Greece, 7-9 November 2012; pp. 1-7.

100. Bourouis, A.; Zerdazi, A.; Feham, M.; Bouchachia, A. M-health: Skin disease analysis system using smartphone's camera. Procedia Comput. Sci. 2013, 19, 1116-1120. [CrossRef]

101. Abuzaghleh, O.; Barkana, B.D.; Faezipour, M. Noninvasive Real-Time Automated Skin Lesion Analysis System for Melanoma Early Detection and Prevention. IEEE J. Transl. Eng. Heal. Med. 2015, 3, 1-12. [CrossRef] [PubMed]

102. Cornet, V.P.; Holden, R.J. Systematic review of smartphone-based passive sensing for health and wellbeing. J. Biomed. Inform. 2018, 77, 120-132. [CrossRef]

103. Lu, H.; Frauendorfer, D.; Rabbi, M.; Mast, M.S.; Chittaranjan, G.T.; Campbell, A.T.; Gatica-Perez, D.; Choudhury, T. StressSense: Detecting stress in unconstrained acoustic environments using smartphones. In Proceedings of the 2012 ACM Conference on Ubiquitous Computing-UbiComp '12, Pittsburgh, PA, USA, 5-8 September 2012; p. 351.

104. Estevão, M.S.; Duarte, F.J.; Fernandes, E.; Gil Santos, A.; Marques, M.M.B. Unexpected reactivity of trifluoromethylated olefins with indole: A mechanistic investigation. Tetrahedron Lett. 2012, 53, 2132-2136. [CrossRef]

105. Huang, Y.; Xiong, H.; Leach, K.; Zhang, Y.; Chow, P.; Fua, K.; Teachman, B.A.; Barnes, L.E. Assessing social anxiety using gps trajectories and point-of-interest data. In Proceedings of the 2016 ACM International Joint Conference on Pervasive and Ubiquitous Computing, Heidelberg, Germany, 12-16 September 2016; pp. 898-903.

106. Eysenbach, G.; Saeb, S.; Mohr, D.; Reis, D.; Asselbergs, J.; Ruwaard, J.; Ejdys, M.; Schrader, N.; Sijbrandij, M.; Riper, H. Mobile Phone-Based Unobtrusive Ecological Momentary Assessment of Day-to-Day Mood: An Explorative Study. J. Med Internet Res. 2016, 18, e72.

107. Ma, Y.; Xu, B.; Bai, Y.; Sun, G.; Zhu, R. Infer Daily Mood using Mobile Phone Sensing. Ad Hoc Sens. Wirel. Netw. 2014, 20, 133-152.

108. Ben-Zeev, D.; Scherer, E.A.; Wang, R.; Xie, H.; Campbell, A.T. Next-Generation Psychiatric Assessment: Using Smartphone Sensors to Monitor Behavior and Mental Health. Psychiatr. Rehabil. J. 2015, 38, 218-226. [CrossRef] [PubMed]

109. Eysenbach, G.; Proudfoot, J.; Dear, B.; Burns, M.N.; Begale, M.; Duffecy, J.; Gergle, D.; Karr, C.J.; Giangrande, E.; Mohr, D.C. Harnessing Context Sensing to Develop a Mobile Intervention for Depression. J. Med. Internet Res. 2011, 13, e55.

110. Canzian, L.; Musolesi, M. Trajectories of depression. In Proceedings of the 2015 ACM International Joint Conference on Pervasive and Ubiquitous Computing_UbiComp '15, New York, NY, USA, 07-11 September 2015; pp. 1163-1304.

111. Saeb, S.; Lattie, E.G.; Schueller, S.M.; Kording, K.P.; Mohr, D.C.; Jorm, A. The relationship between mobile phone location sensor data and depressive symptom severity. PeerJ 2016, 4, 2137. [CrossRef]

112. Eysenbach, G.; Ruwaard, J.; Bardram, J.; Saeb, S.; Zhang, M.; Karr, C.J.; Schueller, S.M.; E Corden, M.; Körding, K.P.; Mohr, D.C. Mobile Phone Sensor Correlates of Depressive Symptom Severity in Daily-Life Behavior: An Exploratory Study. J. Med. Internet Res. 2015, 17, e175.

113. Wahle, F.; Kowatsch, T.; Fleisch, E.; Rufer, M.; Weidt, S. Mobile Sensing and Support for People with Depression: A Pilot Trial in the Wild. JMIR mHealth uHealth 2016, 4, e111. [CrossRef] [PubMed] 
114. Wang, R.; Chen, F.; Chen, Z.; Li, T.; Harari, G.; Tignor, S.; Zhou, X.; Ben-Zeev, D.; Campbell, A.T. StudentLife: Assessing mental health, academic performance and behavioral trends of college students using smartphones. In Proceedings of the 2014 ACM International Joint Conference on Pervasive and Ubiquitous Computing, Seattle, WA, USA, 13-17 September 2014; pp. 3-14.

115. Osmani, V.; Maxhuni, A.; Grünerbl, A.; Lukowicz, P.; Haring, C.; Mayora, O. Monitoring activity of patients with bipolar disorder using smart phones. In Proceedings of the International Conference on Advances in Mobile Computing \& Multimedia, Vienna, Austria, 2-4 December 2013; pp. 85-92.

116. Gruenerbl, A.; Osmani, V.; Bahle, G.; Carrasco-Jimenez, J.C.; Oehler, S.; Mayora, O.; Haring, C.; Lukowicz, P. Using smart phone mobility traces for the diagnosis of depressive and manic episodes in bipolar patients. In Proceedings of the 5th Augmented Human International Conference, Kobe, Japan, 7-8 March 2014.

117. Grüunerbl, A.; Muaremi, A.; Osmani, V.; Bahle, G.; Ohler, S.; Troster, G.; Mayora, O.; Haring, C.; Lukowicz, P. Smartphone-based recognition of states and state changes in bipolar disorder patients. IEEE J. Biomed. Heal. Informatics 2015, 19, 140-148. [CrossRef]

118. Abdullah, S.; Matthews, M.; Frank, E.; Doherty, G.; Gay, G.; Choudhury, T. Automatic detection of social rhythms in bipolar disorder. J. Am. Med Informatics Assoc. 2016, 23, 538-543. [CrossRef]

119. Eysenbach, G.; Faurholt-Jepsen, M.; Mayora, O.; Buntrock, C.; Beiwinkel, T.; Kindermann, S.; Maier, A.; Kerl, C.; Moock, J.; Barbian, G.; et al. Using Smartphones to Monitor Bipolar Disorder Symptoms: A Pilot Study. JMIR Heal. 2016, 3, e2.

120. Ben-Zeev, D.; Wang, R.; Abdullah, S.; Brianv, R.; Scherer, E.A.; Mistler, L.A.; Hauser, M.; Kane, J.M.; Campbell, A.; Choudhury, T. Mobile Behavioral Sensing for Outpatients and Inpatients with Schizophrenia. Psychiatr. Serv. 2016, 67, 558-591. [CrossRef]

121. DiFrancesco, S.; Fraccaro, P.; Van Der Veer, S.N.; Alshoumr, B.; Ainsworth, J.; Bellazzi, R.; Peek, N. Out-of-Home Activity Recognition from GPS Data in Schizophrenic Patients. In Proceedings of the 2016 IEEE 29th International Symposium on Computer-Based Medical Systems (CBMS), Dublin, Ireland, 20-24 June 2016; pp. 324-328.

122. Wang, R.; Aung, M.S.H.; Abdullah, S.; Brian, R.; Campbell, A.T.; Choudhury, T.; Hauser, M.; Kane, J.; Scherer, E.A.; Tseng, V.W.S.; Ben-Zeev, D. CrossCheck: Toward passive sensing and detection of mental health changes in people with schizophrenia. In Proceedings of the 2016 ACM International Joint Conference on Pervasive and Ubiquitous Computing-UbiComp '16, Heidelberg, Germany, 12-16 September 2016.

123. About the Study. Resources for Parents|Autism \& Beyond. Available online: https://autismandbeyond. researchkit.duke.edu/study (accessed on 6 January 2019).

124. Coutinho, E.S.F.; Bloch, K.V.; Coeli, C.M. One-year mortality among elderly people after hospitalization due to fall-related fractures: comparison with a control group of matched elderly. Cad. Saúde Pública 2012, 28, 801-805. [CrossRef] [PubMed]

125. Morris, S.; Fawcett, G.; Brisebois, L.; Hughes, J. A Demographic, Employment and Income Profile of Canadians with Disabilities Aged 15 Years and Over, 2017. Statistics Canada: Canada's National Statistical Agency. 28 November 2018. Available online: https://www150.statcan.gc.ca/n1/pub/89-654-x/89-654-x2018002-eng.htm (accessed on 5 February 2019).

126. Edjoc, R.; Gal, J. Sleep Apnea in Canada, 2016 and 2017. Statistics Canada: Canada's National Statistical Agency. 24 October 2018. Available online: https://www150.statcan.gc.ca/n1/pub/82-625-x/2018001/article/ 54979-eng.htm (accessed on 5 February 2019).

127. Nandakumar, R.; Gollakota, S.; Watson, N. Contactless Sleep Apnea Detection on Smartphones. GetMobile: Mob. Comput. Commun. 2015, 19, 22-24. [CrossRef]

128. Sin, D.D.; Fitzgerald, F.; Parker, J.D.; Newton, G.; Floras, J.S.; Bradley, T.D. Risk Factors for Central and Obstructive Sleep Apnea in 450 Men And Women with Congestive Heart Failure. Am. J. Respir. Crit. Care Med. 1999, 160, 1101-1106. [CrossRef] [PubMed]

129. Ni, B.; Wang, G.; Moulin, P. RGBD-HuDaAct: A color-depth video database for human daily activity recognition. In Proceedings of the 2011 IEEE International Conference on Computer Vision Workshops (ICCV Workshops), Barcelona, Spain, 6-13 November 2011; pp. 1147-1153.

130. Derawi, M.; Bours, P. Gait and activity recognition using commercial phones. Comput. Secur. 2013, 39, 137-144. [CrossRef] 
131. Ronao, C.A.; Cho, S.-B. Human activity recognition using smartphone sensors with two-stage continuous hidden Markov models. In Proceedings of the 2014 10th International Conference on Natural Computation (ICNC), Xiamen, China, 19-21 August 2014; pp. 681-686.

132. Seera, M.; Loo, C.K.; Lim, C.P. A hybrid FMM-CART model for human activity recognition. In Proceedings of the 2014 IEEE International Conference on Systems, Man and Cybernetics-SMC, San Diego, CA, USA, 5-8 October 2014; pp. 182-187.

133. Eastwood, M.; Jayne, C. Evaluation of hyperbox neural network learning for classification. Neurocomputing 2014, 133, 249-257. [CrossRef]

134. Catal, C.; Tufekci, S.; Pirmit, E.; Kocabag, G. On the use of ensemble of classifiers for accelerometer-based activity recognition. Appl. Soft Comput. 2015, 37, 1018-1022. [CrossRef]

135. De, D.; Bharti, P.; Das, S.; Chellappan, S. Multi-modal Wearable Sensing for Fine-grained Activity Recognition in Healthcare. IEEE Comput. Soc. 2015, 19, 1.

136. Wang, A.; Chen, G.; Yang, J.; Zhao, S.; Chang, C.-Y. A Comparative Study on Human Activity Recognition Using Inertial Sensors in a Smartphone. IEEE Sensors J. 2016, 16, 4566-4578. [CrossRef]

137. Chen, Z.; Zhu, Q.; Soh, Y.C.; Zhang, L. Robust Human Activity Recognition Using Smartphone Sensors via CT-PCA and Online SVM. IEEE Trans. Ind. Informatics 2017, 13, 3070-3080. [CrossRef]

138. Anguita, D.; Ghio, A.; Oneto, L.; Parra, X.; Reyes-Ortiz, J.L. Human Activity Recognition on Smartphones Using a Multiclass Hardware-Friendly Support Vector Machine. Adv. Nonlinear Speech Process. 2012, 7657, 216-223.

139. Kwon, Y.; Kang, K.; Bae, C. Unsupervised learning for human activity recognition using smartphone sensors. Expert Syst. Appl. 2014, 41, 6067-6074. [CrossRef]

140. Ronao, C.A.; Cho, S.-B. Human activity recognition with smartphone sensors using deep learning neural networks. Expert Syst. Appl. 2016, 59, 235-244. [CrossRef]

141. Ronao, C.A.; Cho, S.-B. Deep Convolutional Neural Networks for Human Activity Recognition with Smartphone Sensors. Adv. Nonlinear Speech Process. 2015, 9492, 46-53.

142. Tao, D.; Wen, Y.; Hong, R. Multicolumn Bidirectional Long Short-Term Memory for Mobile Devices-Based Human Activity Recognition. IEEE Internet Things J. 2016, 3, 1124-1134. [CrossRef]

143. Ordóñez, F.J.; Roggen, D. Deep Convolutional and LSTM Recurrent Neural Networks for Multimodal Wearable Activity Recognition. Sensors 2016, 16, 115. [CrossRef] [PubMed]

144. He, Y.; Li, Y.; Bao, S.-O. Fall detection by built-in tri-accelerometer of smartphone. In Proceedings of the 2012 IEEE-EMBS International Conference on Biomedical and Health Informatics (BHI), Hong Kong, China, 5-7 January 2012; pp. 184-187.

145. Thammasat, E.; Chaicharn, J. A simply fall-detection algorithm using accelerometers on a smartphone. In Proceedings of the 2012 5th Biomedical Engineering International Conference (BMEiCON), Ubon Ratchathani, Thailand, 5-7 December 2012; pp. 1-4.

146. Lee, H.S.; Choi, Y.S.Y.S.; Seo, Y.Y.; Shim, E.E.; Hosub, L.; Sunjae, L.; Sang, C.Y. A new posture monitoring system for preventing physical illness of smartphone users. In Proceedings of the 2013 IEEE 10th Consumer Communications and Networking Conference (CCNC), Las Vegas, NV, USA, 11-14 January 2013; pp. 821-825.

147. Fleury, A.; Mourcou, Q.; Franco, C.; Diot, B.; Demongeot, J.; Vuillerme, N. Evaluation of a Smartphone-based audio-biofeedback system for improving balance in older adults-A pilot study. In Proceedings of the 2013 35th Annual International Conference of the IEEE Engineering in Medicine and Biology Society (EMBC), Osaka, Japan, 3-7 July 2013; pp. 1198-1201.

148. Chen, Z.; Jiang, C.; Xie, L. A Novel Ensemble ELM for Human Activity Recognition Using Smartphone Sensors. IEEE Trans. Ind. Informatics 2018, 1. [CrossRef]

149. Vaughn, A.; Biocco, P.; Liu, Y.; Anwar, M. Activity Detection and Analysis Using Smartphone Sensors. In Proceedings of the 2018 IEEE International Conference on Information Reuse and Integration (IRI), Salt Lake City, UT, USA, 6-9 July 2018.

150. Hassan, M.M.; Uddin, M.Z.; Mohamed, A.; Almogren, A. A robust human activity recognition system using smartphone sensors and deep learning. Futur. Gener. Comput. Syst. 2018, 81, 307-313. [CrossRef]

151. Li, S.; Li, C.; Li, W.; Hou, Y.; Cook, C. Smartphone-sensors Based Activity Recognition Using IndRNN. In Proceedings of the 2018 ACM International Joint Conference and 2018 International Symposium on Pervasive and Ubiquitous Computing and Wearable Computers-UbiComp '18, Singapore, Singapore, 08-12 October 2018; pp. 1541-1547. 
152. Li, H.; Trocan, M. Deep learning of smartphone sensor data for personal health assistance. Microelectron. J. 2018. [CrossRef]

153. Bort-Roig, J.; Puig-Ribera, A.; Contreras, R.S.; Chirveches-Pérez, E.; Martori, J.C.; Gilson, N.D.; McKenna, J. Monitoring sedentary patterns in office employees: validity of an m-health tool (Walk@Work-App) for occupational health. Gac. Sanit. 2018, 32, 563-566. [CrossRef]

154. Wan, N.; Lin, G. Classifying Human Activity Patterns from Smartphone Collected GPS data: a Fuzzy Classification and Aggregation Approach. Trans. GIS 2016, 20, 869-886. [CrossRef]

155. Shoaib, M.; Scholten, H.; Havinga, P. Towards Physical Activity Recognition Using Smartphone Sensors. In Proceedings of the 2013 IEEE 10th International Conference on Ubiquitous Intelligence \& Computing and 2013 IEEE 10th International Conference on Autonomic \& Trusted Computing (UIC/ATC), Vietri sul Mere, Italy, 18-21 December 2013; pp. 80-87.

156. Eysenbach, G.; Dunton, G.; Hekler, E.; Gay, V.; Wu, W.; Dasgupta, S.; Ramirez, E.E.; Peterson, C.; Norman, G.J. Classification Accuracies of Physical Activities Using Smartphone Motion Sensors. J. Med. Internet Res. 2012, 14, e130.

157. Lee, Y.; Yeh, H.; Kim, K.-H.; Choi, O. A Real-time Fall Detection System Based on the Acceleration Sensor of Smartphone. Int. J. Autom. 2017, 10, 315-326. [CrossRef]

158. Hakim, A.; Huq, M.S.; Shanta, S.; Ibrahim, B. Smartphone Based Data Mining for Fall Detection: Analysis and Design. Procedia Comput. Sci. 2017, 105, 46-51. [CrossRef]

159. Hsu, Y.W.; Chen, K.H.; Yang, J.J.; Jaw, F.S. Smartphone-based fall detection algorithm using feature extraction. In Proceedings of the 2016 9th International Congress on Image and Signal Processing, BioMedical Engineering and Informatics, CISP-BMEI 2016, Datong, China, 15-17 October 2016; pp. 1535-1540.

160. Shen, V.R.; Lai, H.-Y.; Lai, A.-F. The implementation of a smartphone-based fall detection system using a high-level fuzzy Petri net. Appl. Soft Comput. 2015, 26, 390-400. [CrossRef]

161. Ashfak Habib, M.; Mohktar, M.S.; Bahyah Kamaruzzaman, S.; Seang Lim, K.; Maw Pin, T.; Ibrahim, F. Smartphone-based solutions for fall detection and prevention: Challenges and open issues. Sensors (Switzerland) 2014, 14, 7181-7208.

162. Luque, R.; Casilari, E.; Morón, M.-J.; Redondo, G. Comparison and Characterization of Android-Based Fall Detection Systems. Sensors 2014, 14, 18543-18574. [CrossRef]

163. Støve, M.P.; Palsson, T.S.; Hirata, R.P. Smartphone-based accelerometry is a valid tool for measuring dynamic changes in knee extension range of motion. Knee 2018, 25, 66-72. [CrossRef] [PubMed]

164. Jenny, J.Y.; Bureggah, A.; Diesinger, Y. Measurement of the knee flexion angle with smartphone applications: Which technology is better? Knee Surg. Sport. Traumatol. Arthrosc. 2016, 24, 2874-2877. [CrossRef] [PubMed]

165. Min, J.-K.; Doryab, A.; Wiese, J.; Amini, S.; Zimmerman, J.; Hong, J.I. Toss 'N' Turn: Smartphone as Sleep and Sleep Quality Detector. In Proceedings of the 32nd Annual ACM Conference on Human Factors in Computing Systems-CHI '14, Toronto, ON, Canada, 26 April-1 May 2014; pp. 477-486.

166. Chen, Z.; Lin, M.; Chen, F.; Lane, N.; Cardone, G.; Wang, R.; Li, T.; Chen, Y.; Choudhury, T.; Cambell, A. Unobtrusive Sleep Monitoring using Smartphones. In Proceedings of the ICTs for Improving Patients Rehabilitation Research Techniques, Venice, Italy, 5-8 May 2013; pp. 145-152.

167. Natale, V.; Drejak, M.; Erbacci, A.; Tonetti, L.; Fabbri, M.; Martoni, M. Monitoring sleep with a smartphone accelerometer. Sleep Boil. Rhythm. 2012, 10, 287-292. [CrossRef]

168. Prevention of Blindness and Deafness World Health Organization. 26 July 2018. Available online: https: //www.who.int/pbd/deafness/estimates/en/ (accessed on 25 April 2019).

169. Bernstein, J.G.W.; Grant, K.W. Auditory and auditory-visual intelligibility of speech in fluctuating maskers for normal-hearing and hearing-impaired listeners. J. Acoust. Soc. 2009, 125, 3358. [CrossRef] [PubMed]

170. Darwin, C.J. Listening to speech in the presence of other sounds. Philos. Trans. R. Soc. B Biol. Sci. 2008, 363, 1011-1021. [CrossRef] [PubMed]

171. Arlinger, S. Negative consequences of uncorrected hearing loss-A review. Int. J. Audiol. 2003, 42, 17-20. [CrossRef]

172. Pichora-Fuller, M.K.; Dupuis, K.; Reed, M.; Lemke, U. Helping Older People with Cognitive Decline Communicate: Hearing Aids as Part of a Broader Rehabilitation Approach. Semin. Hear. 2013, 34, 308-330.

173. American Academy of Audiology. Childhood Hearing Screening Guidelines. 2011. Available online: https://www.cdc.gov/ncbddd/hearingloss/documents/aaa_childhood-hearing-guidelines_2011.pdf (accessed on 25 April 2019). 
174. American Speech-Language-Hearing Association. Guidelines for Audiologic Screening. 1 January 1997. Available online: https://www.asha.org/policy/GL1997-00199.htm (accessed on 25 April 2019).

175. Maclennan-Smith, F.; Swanepoel, D.W.; Hall, J.W. Validity of diagnostic pure-tone audiometry without a sound-treated environment in older adults. Int. J. Audiol. 2013, 52, 66-73. [CrossRef] [PubMed]

176. Abu-Ghanem, S.; Handzel, O.; Ness, L.; Ben-Artzi-Blima, M.; Fait-Ghelbendorf, K.; Himmelfarb, M. Smartphone-based audiometric test for screening hearing loss in the elderly. Eur. Arch. Oto Rhino Laryngol. 2016, 273, 333-339. [CrossRef]

177. Hussein, S.Y.; Swanepoel, D.W.; De Jager, L.B.; Myburgh, H.C.; Hugo, J.; Eikelboom, R.H. Smartphone hearing screening in mHealth assisted community-based primary care. J. Telemed. Telecare 2016, 22, 405-412. [CrossRef]

178. Louw, C.; Swanepoel, D.W.; Eikelboom, R.H.; Myburgh, H.C. Smartphone-Based Hearing Screening at Primary Health Care Clinics. Ear Hear. 2017, 38, 1. [CrossRef] [PubMed]

179. Chen, F.; Wang, S.; Li, J.; Tan, H.; Jia, W.; Wang, Z. Smartphone-Based Hearing Self-Assessment System Using Hearing Aids with Fast Audiometry Method. IEEE Trans. Biomed. Circuits Syst. 2019, 13, 170-179. [CrossRef] [PubMed]

180. Eysenbach, G.; Paglialonga, A.; Handzel, O.; Mahomed-Asmail, F.; Moodie, S.; Bright, T.; Pallawela, D. Validated Smartphone-Based Apps for Ear and Hearing Assessments: A Review. JMIR Rehabilitation Assist. Technol. 2016, 3, e13.

181. Amlani, A.M.; Taylor, B.; Levy, C.; Robbins, R. Utility of smartphone-based hearing aid applications as a substitute to traditional hearing aids. Hear. Rev. 2013, 20, 16-18.

182. Lin, Y.C.; Lai, Y.H.; Chang, H.W.; Tsao, Y.; Chang, Y.P.; Chang, R.Y. SmartHear: A Smartphone-Based Remote Microphone Hearing Assistive System Using Wireless Technologies. IEEE Syst. J. 2018, 12, 20-29. [CrossRef]

183. Boulos, M.N.K.; Brewer, A.C.; Karimkhani, C.; Buller, D.B.; Dellavalle, R.P. Mobile medical and health apps: state of the art, concerns, regulatory control and certification. Online J. Public Health Inform. 2014, 5, 229.

184. Van Norman, G.A. Drugs and Devices: Comparison of European and U.S. Approval Processes. JACC Basic Transl. Sci. 2016, 1, 399-412. [CrossRef]

185. Buijink, A.W.G.; Visser, B.J.; Marshall, L. Medical apps for smartphones: Lack of evidence undermines quality and safety. Evid. Based Med. 2013, 18, 90-92. [CrossRef]

186. Cummings, E.; Borycki, E.M.; Roehrer, E. Issues and considerations for healthcare consumers using mobile applications. Stud. Heal. Technol. Inform. 2013, 183, 227-231.

187. O'Neill, S.; Brady, R.R.W. Colorectal smartphone apps: Opportunities and risks. Color. Dis. $2012,14$. [CrossRef]

188. Demidowich, A.P.; Bloomgarden, Z.; Lu, K.; Tamler, R. An evaluation of diabetes self-management applications for Android smartphones. J. Telemed. Telecare 2012, 18, 235-238. [CrossRef]

189. Ferrero, N.A.; Morrell, D.S.; Burkhart, C.N. Skin scan: A demonstration of the need for FDA regulation of medical apps on iPhone. J. Am. Acad. Dermatol. 2013, 68, 515-516. [CrossRef]

190. Wolf, J.A.; Ferris, L.K. Diagnostic Inaccuracy of Smartphone Applications for Melanoma Detection-Reply. JAMA Dermatol. 2013, 149, 885. [CrossRef] [PubMed]

191. Visvanathan, A.; Hamilton, A.; Brady, R. Smartphone apps in microbiology-is better regulation required? Clin. Microbiol. Infect. 2012, 18, E218-E220. [CrossRef]

192. Robson, Y.; Blackford, S.; Roberts, D. Caution in melanoma risk analysis with smartphone application technology. Br. J. Dermatol. 2012, 167, 703-704. [CrossRef]

193. Huckvale, K.; Car, M.; Morrison, C.; Car, J. Apps for asthma self-management: a systematic assessment of content and tools. BMC Med. 2012, 10, 144. [CrossRef]

194. McKinstry, B. Currently available smartphone apps for asthma have worrying deficiencies. Evidence-Based Med. 2013, 18, 45. [CrossRef]

195. O'neill, S.; Brady, R.R. Clinical involvement and transparency in medical apps; not all apps are equal. Colorectal Dis. 2013, 15, 122. [CrossRef] [PubMed]

196. Sucala, M.; Cuijpers, P.; Muench, F.; Cardoș, R.; Soflau, R.; Dobrean, A.; Achimas-Cadariu, P.; David, D.; Achimas-Cadariu, P. Anxiety: There is an app for that. A systematic review of anxiety apps. Depress. Anxiety 2017, 34, 518-525. [CrossRef] [PubMed] 
197. Strickland, E. The FDA Takes on Mobile Health Apps. IEEE Spectrum: Technology, Engineering, and Science News. 12 September 2012. Available online: https://spectrum.iee.org/biomedical/devices/the-fda-takes-onmobile-health-apps (accessed on 6 January 2019).

198. U.S. Department of Health and Human Services Food and Drug Administration. Mobile Medical Applications: Guidance for Industry and Food and Drug Administration Staff. 2015; Available online: https://www.fda. gov/media/80958/download (accessed on 6 January 2019).

199. Premarket Notification 510(k). U S Food and Drug Administration Home Page. Available online: https://www.fda.gov/MedicalDevices/DeviceRegulationandGuidance/HowtoMarketYourDevice/ PremarketSubmissions/PremarketNotification510k/default.htm (accessed on 6 January 2019).

200. Institute of Medicine (US); Committee on the Public Health Effectiveness of the FDA 510 (k) Clearance Process. Medical Devices and the Public's Health: The FDA 510(k) Clearance Process at 35 Years; National Academies Press: Washington, DC, USA, 2011.

201. Waxman, H.A. H.R.3095-101st Congress (1989-1990): Safe Medical Devices Act of 1990. Congress.gov, 28 November 1990. Available online: https://www.congress.gov/bill/101st-congress/house-bill/3095 (accessed on 6 January 2019).

202. Cain, M. One company's experience: blazing the trail with the first FDA-approved medical imaging app. Biomed. Instrum. Technol. 2012, 46, 87-90. [CrossRef] [PubMed]

203. Dolan, B. FDA Clears First Diagnostic Radiology App, Mobile MIM. MobiHealthNews. 4 February 2011. Available online: https:/www.mobihealthnews.com/10173/fda-clears-first-diagnostic-radiology-app-mobilemim (accessed on 6 January 2019).

204. AliveCor, Inc. KardiaMobile. Available online: https://store.alivecor.com/products/kardiamobile (accessed on 6 January 2019).

205. IExaminer. iEXAMINER. Available online: http://www.welchallyn.ca/en/microsites/iexaminer.html (accessed on 6 January 2019).

206. Welldoc Inc. Product. Available online: https://www.welldoc.com/product/ (accessed on 6 January 2019).

207. PureWeb. Healthcare Solutions|PureWeb|ResolutionMD. Available online: https://www.pureweb.com/ healthcare (accessed on 6 January 2019).

208. The European Parliament and the Council of the European Union. Medical Device Directive 93/42/EEC. Off. J. Eur. Union 1993, 169, 1-60. Available online: https://eur-lex.europa.eu/LexUriServ/LexUriServ.do?uri= CONSLEG:1993L0042:20071011:en:PDF (accessed on 6 January 2019).

209. The European Parliament and the Council of the European Union. Medical Device Directive 2007/47/EC. Off. J. Eur. Union 2007, 1-35. Available online: https://eur-lex.europa.eu/LexUriServ/LexUriServ.do?uri=OJ:L: 2007:247:0021:0055:en:PDF (accessed on 6 January 2019).

210. CE Marking. Together Against Trafficking in Human Beings. 30 August 2017. Available online: http: //ec.europa.eu/growth/single-market/ce-marking/ (accessed on 6 January 2019).

211. ONCOassist. Adjuvant Calculator-Oncology Apps-ONCOassist healthcare professional. Available online: https://oncoassist.com/ (accessed on 6 January 2019).

212. European Parliament and Council of the European Union. Regulation (EU) 2017/746 of the European Parliament and of the Council of 5 April 2017 on medical devices. Off. J. Eur. Union 2017, 60, 1-175. Available online: https://eur-lex.europa.eu/legal-content/EN/TXT/PDF/?uri=CELEX:32017R0745 (accessed on 6 January 2019).

213. Edwards, C. EU Medical Device Regulation Changes: What do They Mean? Verdict Medical Devices. 16 October 2018. Available online: https:/www.medicaldevice-network.com/features/eu-medical-deviceregulation-changes/ (accessed on 6 January 2019).

214. Making a Success of Brexit. GOV.UK. Available online: https://www.gov.uk/government/news/medicinesand-healthcare-products-regulatory-agency-statement-on-the-outcome-of-the-eu-referendum (accessed on 6 January 2019).

215. How Medicines, Medical Devices and Clinical Trials Would Be Regulated If There's No Brexit deal. GOV.UK. Available online: https://www.gov.uk/government/publications/how-medicines-medical-devices-andclinical-trials-would-be-regulated-if-theres-no-brexit-deal/how-medicines-medical-devices-and-clinicaltrials-would-be-regulated-if-theres-no-brexit-deal (accessed on 6 January 2019).

216. Medicines \& Healthcare products Regulatory Agency. Medical Device Stand-Alone Software Including Apps. GOV.UK. 2014. Available online: https://assets.publishing.service.gov.uk/government/uploads/ system/.uploads/attachment_data/file/548313/Software_flow_chart_Master.pdf (accessed on 6 January 2019). 
217. Lightley, D. When Is A Mobile App Classed as a Medical Device | MHRA Compliant Apps. Genetic Digital. 9 December 2013. Available online: https:/www.geneticdigital.co.uk/2013/03/when-should-an-app-beclassed-as-a-device/ (accessed on 6 January 2019).

218. Heather, B. Explainer: When Is An App Not An App (But A Medical Device)? Digital Health. 7 March 2017. Available online: https://www.digitalhealth.net/2016/09/explainer-when-is-an-app-not-an-app-but-amedical-device/ (accessed on 6 January 2019).

219. Medical Device Technology Forum on the Use of Software as a Medical Device-12 May 2010. Ofcom|Statutory Duties and Regulatory Principles. 11 January 2012. Available online: https://webarchive.nationalarchives.gov.uk/.20150113200213/http://www.mhra.gov.uk/Howweregulate/ NewTechnologiesForums/DevicesNewTechnologyForum/Forums/CON084987 (accessed on 6 January 2019).

220. Approval of Medical Devices. Planning D-Day (April 2003)—Library of Congress Information Bulletin. 1 September 2014. Available online: http://www.loc.gov/law/help/medical-devices/ (accessed on 6 January 2019).

221. Kramer, D.B.; Xu, S.; Kesselheim, A.S. Regulation of Medical Devices in the United States and European Union. New Engl. J. Med. 2012, 366, 848-855. [CrossRef]

222. Sorenson, C.; Drummond, M. Improving Medical Device Regulation: The United States and Europe in Perspective. Milbank Q. 2014, 92, 114-150. [CrossRef]

223. Cohen, D. How a fake hip showed up failings in European device regulation. BMJ 2012, 345, e7090. [CrossRef]

224. Cohen, D.; Billingsley, M. Europeans are left to their own devices. BMJ 2011, 342, d2748. [CrossRef]

225. Curfman, G.D.; Redberg, R.F. Medical Devices-Balancing Regulation and Innovation. New Engl. J. Med. 2011, 365, 975-977. [CrossRef]

226. Emergo. EUROPE-Overview of medical device industry and healthcare statistics. 23 October 2018. Available online: https://www.emergobyul.com/resources/market-europe (accessed on 27 April 2019).

227. Legislative Services Branch, “Consolidated federal laws of Canada, Medical Devices Regulations. Medical Devices Regulations. Available online: https://laws-lois.justice.gc.ca/eng/regulations/sor-98-282/fulltext.html (accessed on 27 April 2019).

228. Emergo. Health Canada Medical Device License (MDL) and MDEL Registration. 12 November 2018. Available online: https://www.emergobyul.com/services/canada/canada-device-license (accessed on 27 April 2019).

229. Australian Government Department of Health; Therapeutic Goods Administration (TGA). Consultation: Designation of Australian conformity assessment bodies for medical devices-Implementation. 14 June 2017. Available online: https://www.tga.gov.au/consultation/consultation-designation-australian-conformityassessment-bodies-medical-devices-implementation (accessed on 27 April 2019).

230. Australian Government Department of Health; Therapeutic Goods Administration (TGA). Use of market authorisation evidence from comparable overseas regulators/assessment bodies for medical devices (including IVDs). 28 November 2018. Available online: https:/www.tga.gov.au/publication/use-market-authorisationevidence-comparable-overseas-regulators-assessment-bodies-medical-devices-including-ivds (accessed on 27 April 2019).

231. Australian Government Department of Health; Therapeutic Goods Administration (TGA). Medical Device Single Audit Program (MDSAP). 6 December 2016. Available online: https://www.tga.gov.au/medical-devicesingle-audit-program-mdsap (accessed on 27 April 2019).

232. Notice: Medical Device Single Audit Program (MDSAP) Transition Plan-Frequently Asked Questions (FAQ). Canada.ca. 22 April 2016. Available online: https://www.canada.ca/en/health-canada/services/ drugs-health-products/medical-devices/activities/international/notice-transition-plan-medical-deviceaudit-program.html (accessed on 27 April 2019).

(C) 2019 by the authors. Licensee MDPI, Basel, Switzerland. This article is an open access article distributed under the terms and conditions of the Creative Commons Attribution (CC BY) license (http://creativecommons.org/licenses/by/4.0/). 